\title{
Backwash Optimization for Drinking Water Treatment Biological Filters
}

\author{
A thesis submitted to \\ the Faculty of Graduate and Postdoctoral Affairs \\ in Partial Fulfillment of the requirements for the degree
}

Master of Applied Science in Environmental Engineering

by

Sarra Ikhlef

Department of Civil and Environmental Engineering

Carleton University

Ottawa-Carleton Institute of Civil and Environmental Engineering

January 2016

(C)2016 Sarra Ikhlef 


\begin{abstract}
A lab scale study has been conducted in order to examine the impacts of backwashing on biofiltration performance. Collapse pulsing resulted in significantly higher DOC removals (21\%) compared to a water only backwash (13\%) under nutrient limited conditions. Three backwash procedures were investigated under nutrient supplemented conditions and were compared to a control backwash. Employing a lower bed expansion of $20 \%$ compared to the $30 \%$ control bed expansion lead to similar \%DOC removals (30\%). However, employing a higher bed expansion (40\%) than the control backwash lead to significantly lower \%DOC removals (24\%). A backwash strategy that reduced the backwash water volume usage by about $20 \%$ resulted in similar \% DOC reductions observed with the control backwash. The investigated backwash procedures were also terminated by the extended terminal subfluidization wash (ETSW). ETSW demonstrated no impact on $\%$ DOC removals and successfully eliminated the filter ripening sequence. The backwash procedures investigated in this study showed no consistent impact on biofilters' biomass concentrations as measured by the phospholipids and the adenosine tri-phosphate (ATP) methods. Moreover, none of these two analyses showed a direct correlation with DOC removal. Meanwhile, dissolved oxygen (DO) uptake showed a direct correlation with DOC removals.
\end{abstract}




\section{ACKNOWLEDGMENTS}

First of all I would like to express my gratitude to my supervisor, Dr.Onita Basu, for giving me the opportunity to work on this project and for your guidance and constant support. I feel fortunate to have had the opportunity to work with you and learn from you.

I would like to thank Dr.Marie Tudoret for her constant help and advice in the laboratory. I also want to thank everyone who has helped me throughout my research; Dejan Chortanoski, Bruna Senna, Miaoyi Yan, Massie Aruiyengho, Adrian Soble, Quang Bac, and everyone in Basu Research Group.

Finally, I would like to thank my family, for their unconditional love, their constant encouragement, and all their sacrifices. Without the encouragement and support of my parents and my brother I wouldn't be where I am today. 


\section{TABLE OF CONTENTS}

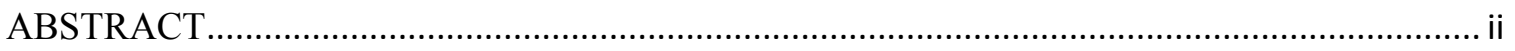

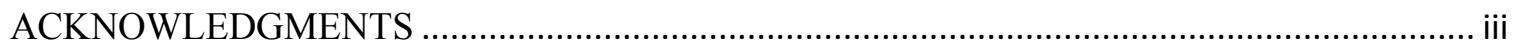

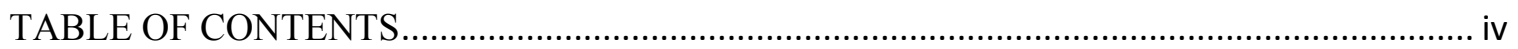

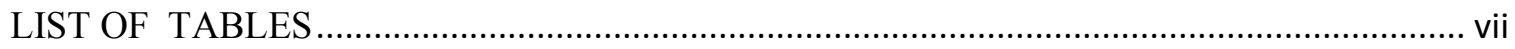

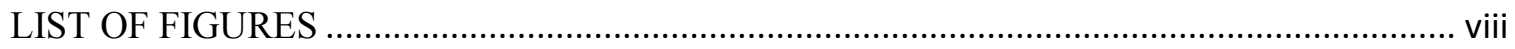

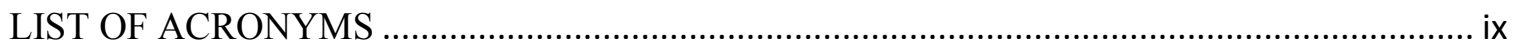

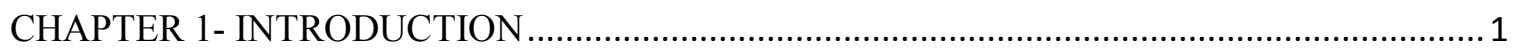

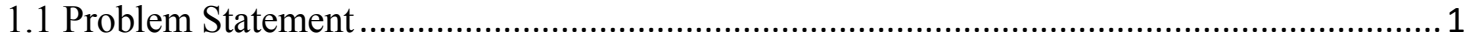

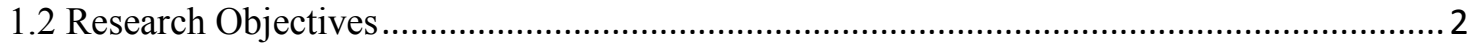

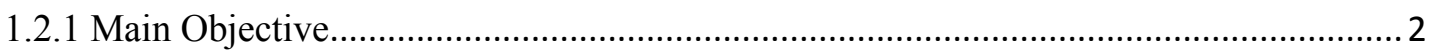

1.2.2 Specific Objectives ....................................................................................... 3

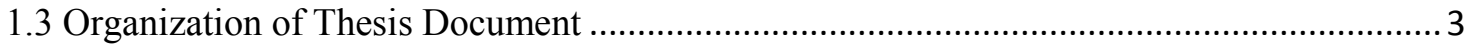

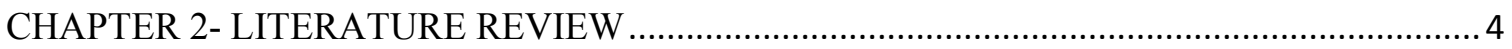

2. 1 Filtration in Drinking Water Treatment ...................................................................... 4

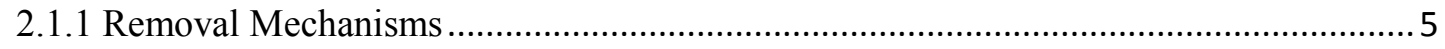

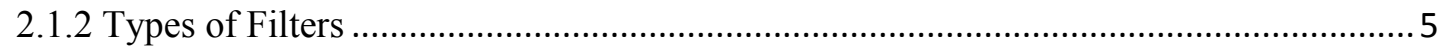

2.2 Biologically Active Filters in Drinking Water Treatment .............................................. 7

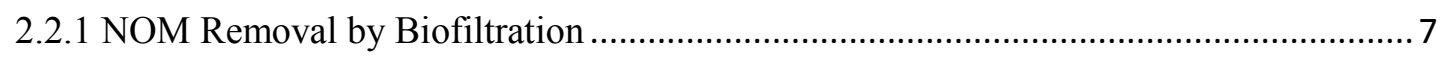

2.2.2 Operational Parameters of Biologically Active Filters ................................................ 8

2.3 Backwashing of Drinking Water Biofilters .................................................................... 11

2.3.1 Backwash Theory and Backwashing Strategies........................................................ 15

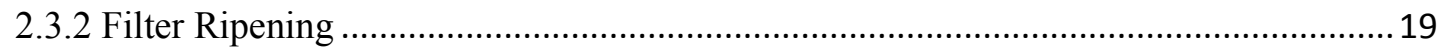

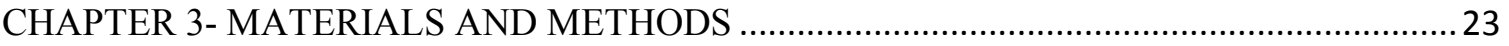

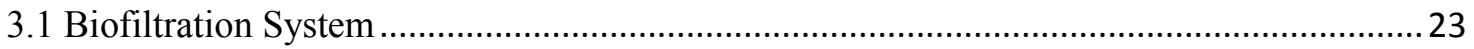

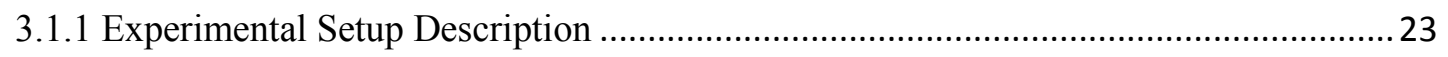

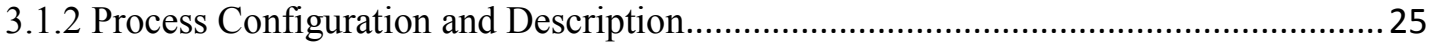

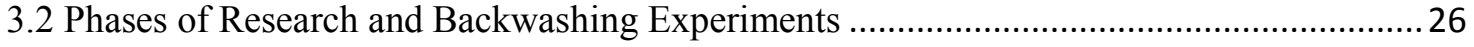

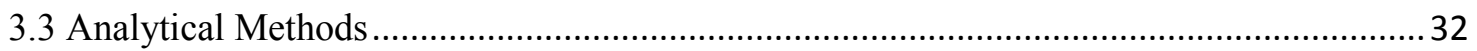

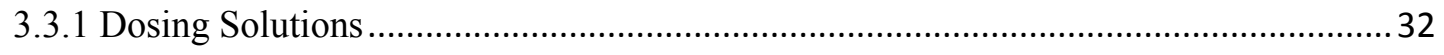




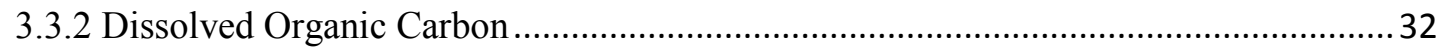

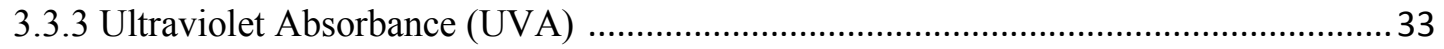

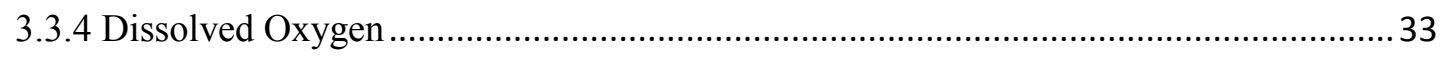

3.3.5 Phospholipids Method for Biomass Quantification ..................................................... 33

3.3.6 Adenosine Tri-Phosphate (ATP) for Biomass Quantification ...................................... 35

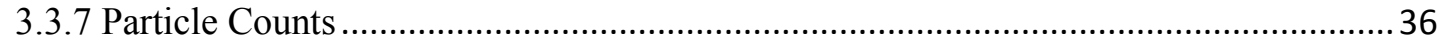

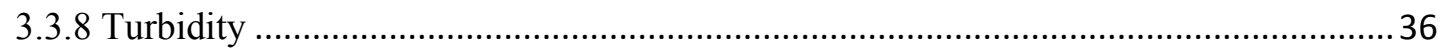

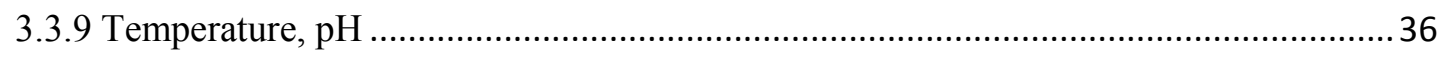

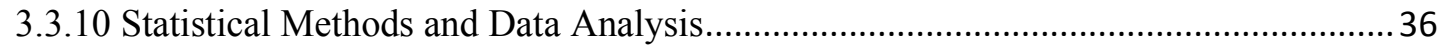

CHAPTER 4- BACKWASH OPTIMIZATION FOR DRINKING WATER TREATMENT

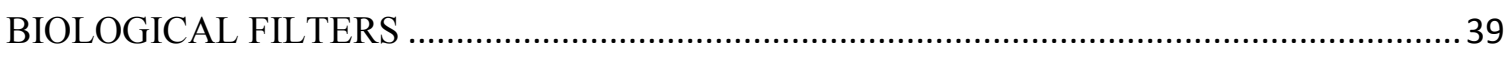

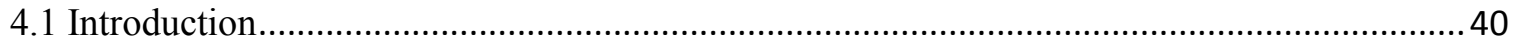

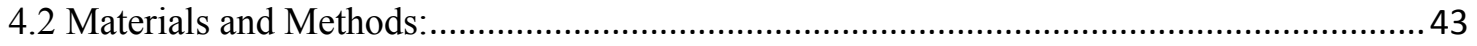

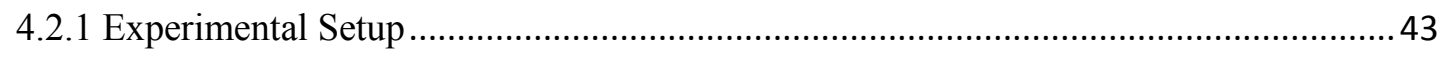

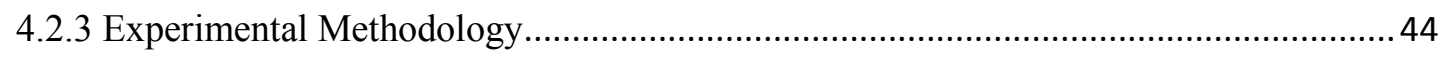

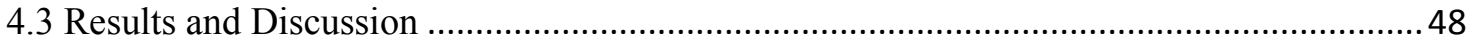

4.3.1 Impact of Backwashing Procedures on DOC Removals............................................ 48

4.3.2 Indirect Measurements of DOC Uptake: Biomass and Dissolved Oxygen ...................52

4.3.3 Impact of Backwashing Procedures on Particles Removal ..........................................58

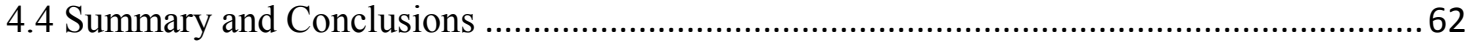

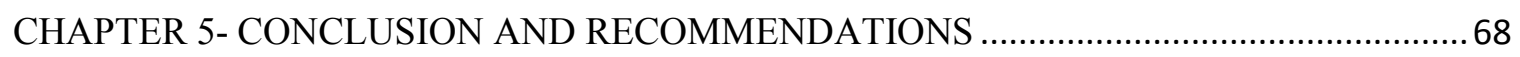

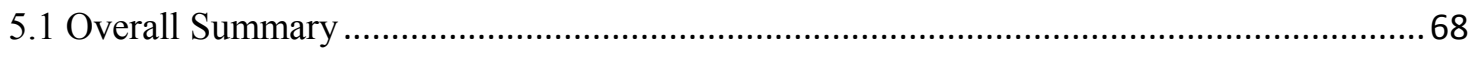

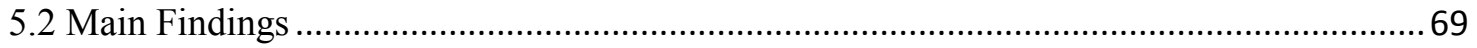

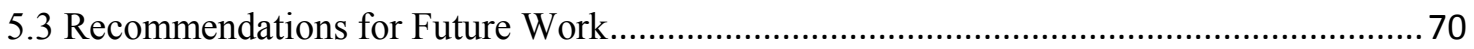

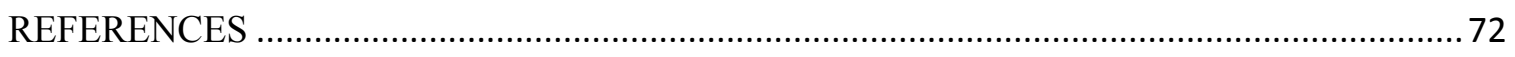

Appendix A- DOSING SOLUTIONS CALCULATIONS ........................................................ 78

Appendix B- EXTENDED TERMINAL SUBFLUIDIZATION WASH CALCULATION ......... 81

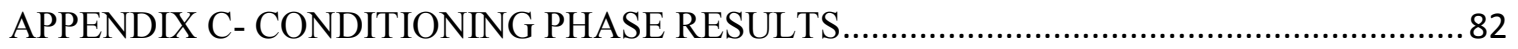

APPENDIX D- POTASSIUM SUPPLEMENTATION PHASE RESULTS ................................ 84

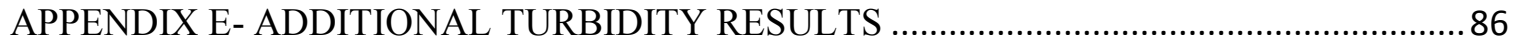

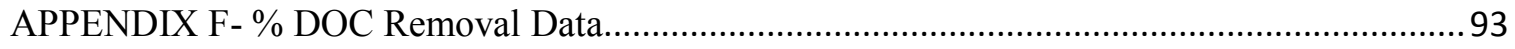

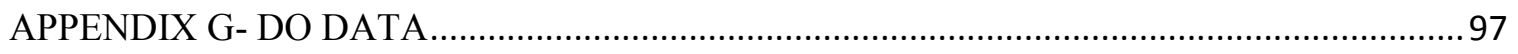




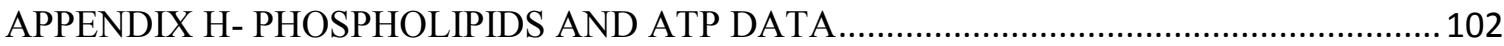

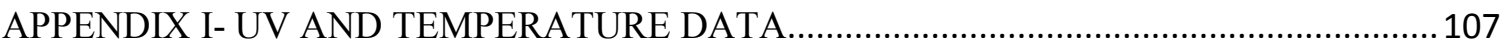




\section{LIST OF TABLES}

Table 2.1- Effect of Backwashing on Drinking Water Treatment Biofilters ............................... 12

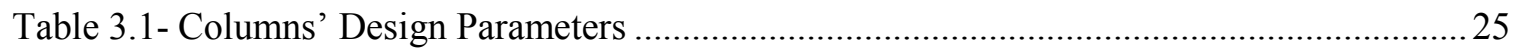

Table 3.2- Study Phases along with Associated Backwash Experiments ...................................28

Table 3.3- Chemicals used for Dosing Solutions Preparation .................................................... 32

Table 4.1- Summary of Experimental Phases and Backwash Procedures .................................. 46

Table 4.2- Comparison of Effluent Particle Counts for Phase 2 Backwash Strategies.................. 61 


\section{LIST OF FIGURES}

Figure 2.1- Filter Ripening Sequence (Amburgey and Amirtharajah, 2005)............................. 20

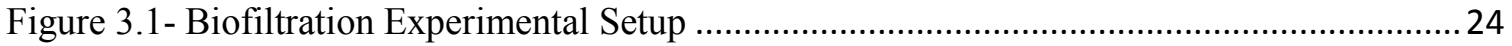

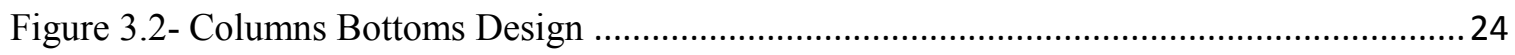

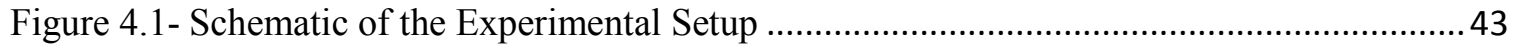

Figure 4.2- Impact of Collapse Pulsing on \% DOC Removals under Nutrient Limited Conditions

Figure 4.3- Impact of Different Bed Expansions on \% DOC Removals ...................................... 51

Figure 4.4- Impact of ETSW Addition on \% DOC Removals.................................................. 52

Figure 4.5- Relationship between Biomass and DOC Removal: ..............................................55

Figure 4.6- Relationship between DOC Removal and DO Uptake ...........................................57

Figure 4.7- Relationship between DOC Removal and DO Uptake ........................................58

Figure 4.8- Impact of Backwash Procedures on Effluent Turbidity: A- Phase 2 Trial 1, B- Phase 2

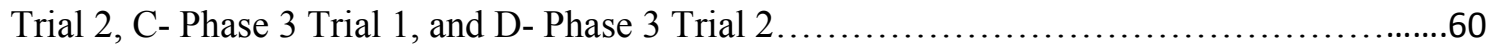




\section{LIST OF ACRONYMS}

\begin{tabular}{|c|c|}
\hline $20 \% \mathrm{ST}$ & $20 \%$ Same Time \\
\hline $20 \% \mathrm{SV}$ & $20 \%$ Same Volume \\
\hline $30 \% \mathrm{~W}$ & $30 \%$ Water \\
\hline $40 \% \mathrm{SV}$ & $40 \%$ Same Volume \\
\hline $\mathrm{ABW}$ & After Backwash \\
\hline AOC & Assimilable Organic Carbon \\
\hline ATP & Adenosine Tri-phosphate \\
\hline BAF & Biologically Active Filters \\
\hline BBW & Before Backwash \\
\hline $\mathrm{BDOC}$ & Biodegradable Dissolved Organic Carbon \\
\hline BOM & Biodegradable Organic Matter \\
\hline BTWP & Britannia Water Treatment Plant \\
\hline $\mathrm{C}: \mathrm{N}: \mathrm{P}$ & Carbon: Nitrogen :Phosphorus \\
\hline DBPs & Disinfection By Products \\
\hline DO & Dissolved Oxygen \\
\hline $\mathrm{DOC}$ & Dissolved Organic Carbon \\
\hline EBCT & Empty Bed Contact Time \\
\hline ETSW & Extended Terminal Subfluidization Wash \\
\hline FTW & Filter to Waste \\
\hline GAC & Granular Activated Carbon \\
\hline HAAs & Halo Acetic Acids \\
\hline $\mathrm{NOM}$ & Natural Organic Matter \\
\hline NPOC & Non Purgeable Organic Carbon \\
\hline NTU & Nephelometric Turbidity Units \\
\hline SSF & Slow Sand Filtration \\
\hline THMs & Trihalomethanes \\
\hline
\end{tabular}




\begin{tabular}{|c|c|}
\hline TOC & Total Organic Carbon \\
\hline UC & Uniformity Coefficient \\
\hline UVA & Ultraviolet Absorbance \\
\hline
\end{tabular}




\section{CHAPTER 1- INTRODUCTION}

\subsection{Problem Statement}

According to Canadian Drinking Water Quality Guidelines; "surface water or any groundwater that is under direct influence of surface water has to be filtered" (Health Canada, 2014). Therefore, in Canada, filtration plays a critical role in the making of potable water and it needs to be employed in conjunction with disinfection in order to ensure that the water is free of pathogens and safe to drink. Biological filters are a special type of filters that have the ability to effectively eliminate water contaminants through the accumulation of naturally occurring bacteria on the media in the form of a biofilm. These microorganisms utilize biodegradable organic matter (BOM) as an energy supply and a carbon source through the mediation of oxidation reduction reactions (Urfer et al., 1997). Benefits of biological filtration include; decrease in the formation potential of disinfection by products (DBPs), elimination of taste and odor compounds, reduction in chlorine demand, and decrease in bacterial re-growth potential within the distribution system resulting in a water that is biologically stable (Chaudhary et al., 2007).

A biofilter that results in high quality effluent water needs to maintain a healthy biomass concentration; therefore, backwashing is performed on a periodic basis to prevent excessive biomass accumulation and headloss buildup and to regenerate the filter's removal capacity. Backwashing is one of the most important parameters that define both the short and long term performances of biofilters. An effective backwash has to take into account the difference in the detachment of both biological and nonbiological particles that were accumulated during the filtration cycle (Ahmad and Amirtharajah, 1998). An effective backwash will also successfully balance the removal of excess biomass while keeping enough attached biomass for subsequent filter runs (Ahmad et al., 1998). Traditionally, conventional filters were backwashed using water only. However, a backwash that uses a combination of water and air flow termed "collapse pulsing" was found to be more effective for cleaning the media due to the increased media collisions and abrasions that are created when air and water are used together (Amirtharajah, 1993). Because maintaining a healthy 
biomass is key in biological filtration success, most of the backwashing research was directed towards understanding the impact that collapse pulsing has on biofiters' biomass and biological activity, this has shown different levels of success (Emelko et al., 2006; Liu et al., 2001; Ahmad and Amirtharajah, 1998; Servais et al., 1991). Therefore, more research is needed to examine the impacts of collapse pulsing backwash on biofiltration performance under different conditions. Moreover, an optimized backwash not only will result in excellent effluent water quality but should also take into account overall process productivity by minimizing filters' time out of service and overall water usage. It is also unclear whether the amount of biomass attached to the filter media is directly related to microbial activity and biological filtration performance. Therefore, more investigations are needed to estimate the relationship between biofilters' biomass and biological activity as related to BOM removal.

Biofilters also face the same challenges that conventional filters face. Filter ripening sequence, which is a period of increased effluent turbidity that is observed after backwash, is a common problem in drinking water treatment industry (Amburgey and Amirtharajah, 2005). Amirtharajah (1988) stated that about $90 \%$ of particles' breakthrough in a well operated filter occurs during the ripening period. Moreover, the main concern about this stage is the potential breakthrough of pathogenic microorganisms such as Cryptosporidium and Giardia (Colton et al., 1996). As a result, backwashing should minimize the risks that are associated with this period by decreasing its duration and intensity. The extended terminal subfluidization wash (ETSW) which is a flushing step added to the end of the normal backwash procedure was proven to be successful in achieving that goal for both conventional and biological filters (Amburgey, 2004). However, the impact of implementing ETSW on biological filtration performance as related to BOM removal needs to be investigated.

\subsection{Research Objectives}

\subsubsection{Main Objective}

The overall objective of this study was to optimize biological filters' backwashing through evaluating and comparing the implications of different backwash procedures on biolfilter's recovery, performance, and overall effluent quality (Particle removal/Organics removal). 


\subsubsection{Specific Objectives}

1. Assess the effect of backwash techniques developed for conventional filters (Collapse pulsing) on biofilters to ensure that DOC removal is not affected.

2. Evaluate the impact of different backwashing procedures that employ the same amount of water volume but different bed expansions on biological filters overall performance (Turbidity/DOC) as well as on biofilters' biomass.

3. Evaluate the impact of a backwash procedure that employs a different amount of water volume and bed expansion compared to the control backwash but follows the same time duration on biofilter's overall performance (Turbidity/DOC) as well as on biofilter's biomass.

4. Assess how different backwashing procedures relate to ripening period duration and intensity.

5. Evaluate the response of a fixed backwash regime to varying raw water quality parameters.

6. Evaluate the effectiveness of adding the extended terminal subfluidization wash (ETSW) to different backwashing procedures on biofilters' ripening period and overall effluent quality, as well as its impact on biofilter's biomass.

7. Assess whether microbial concentrations as measured by Phospholipids and Adenosine tri-phosphate methods are directly related to DOC removal.

8. Assess whether dissolved oxygen uptake is directly related to microbial activity in terms of DOC removal.

\subsection{Organization of Thesis Document}

The thesis document contains five chapters. The literature review that is presented in chapter 2 provides background information for this research. Chapter 3 provides a description of the experimental setup that was used for this study along with a detailed description of the experimental methodology and the analytical methods. The results are presented in chapter 4 in the form of a journal article. Finally, chapter 5 concludes the main findings from this study and provides recommendation for future work. 


\section{CHAPTER 2- LITERATURE REVIEW}

This chapter provides a general insight into the application of filtration in drinking water treatment. A review of biologically active filters (BAFs), their importance, and the main factors affecting their performance is presented. This is followed by a review of backwashing in drinking water treatment biofilters and current backwashing strategies. Finally, this chapter is concluded by discussing the main implications and challenges that are associated with backwashing.

\section{1 Filtration in Drinking Water Treatment}

Water treatment using granular media filters for the removal of contaminants is a process that has been known and applied over decades in drinking water treatment plants. Filtration is simply the removal of impurities from water as it flows through a porous medium such as sand, granular activated carbon (GAC) or anthracite in order to improve water quality. These contaminants can be either algae, sediment, clay, pathogenic microorganisms, organic, inorganic particles or a combination of all of them (Howe et al., 2012). According to Canadian Drinking Water Quality Guidelines, "surface water or any groundwater that is under direct influence of surface water has to be filtered"(Health Canada, 2014). Therefore, in Canada filtration plays a critical role in the making of potable water and it needs to be employed in conjunction with disinfection in order to ensure that the water is free of pathogens and safe to drink.

The importance of filtration lies behind the fact that chemical disinfection alone is insufficient for the removal of microorganisms of public health concerns such as Giardia lamblia and Cryptosporidium parvum. Filters have the ability to act as barriers to such pathogens (Emelko, 2003). Moreover, research has shown that filtration and particularly biofiltration is very successful in eliminating natural organic matter (NOM) from drinking water (Huck et al., 1991; Melin and Odegaard, 2000; Liu et al., 2001; Basu and Huck, 2004; Gibertet al., 2012). NOM contributes to color, taste, and odor in the water. It also promotes biological growth within the distribution system resulting in a water that is biologically unstable. Furthermore, NOM is known to act as precursor to disinfection by 
products which have been proven to result in adverse health effects (Matilainen et.al, 2010).

\subsubsection{Removal Mechanisms}

The removal of contaminants and particles within the water suspension can occur through many mechanisms, it can be either physical, chemical, or biological. Chemical removal can take place through adsorption, whereas biological removal is governed by the biodegradation of pollutants through a biofilm that develops on the media grains. In the case of physical removal, when the particle size is larger than the pores size, the removal takes place through straining. However, straining occurs mostly for particles that are larger than 75 microns (Howe et al., 2012). If the particle is smaller than the void space between the media grains then straining is not possible and removal occurs through other means. In that situation, the particle needs to be transported into the media grain and then removed, there are several transportation mechanisms in which this can happen, and they include:

- Interception, which takes place when the particle is moving uniformly within the streamline and is captured when it collides with the media grain.

- Sedimentation, this happens mainly due to the gravitational force which causes the particle to deviate from the streamline and settle on the filter media.

- Diffusion, which refers to the random movement of small particles by Brownian motion (less than 1 micron in diameter).

- Hydrodynamic action, which occurs when particles move towards the media grains as a result of the velocity gradient in the vicinity of the filter media (Binnie and Kimber, 2009; Howe et al., 2012).

\subsubsection{Types of Filters}

There are two main types of gravity filters in drinking water treatment, slow sand filters and rapid sand filters and it is very important to note the differences between them.

\subsubsection{Slow Sand Filters}

As its name implies, "slow" sand filtration (SSF) occurs at a loading rate much slower than rapid sand filtration; in fact ssf is about 50 to 100 times slower than rapid sand filtration (Howe et al., 2012). SSF is the oldest and cheapest method for treating water. The filters 
employ physical filtration, biological removal and adsorption. Moreover, they are very efficient in removing particulate suspended matter and bacterial contamination. Fine sand is used as the medium where a biological mat called the "Schmutzdecke" develops on its surface, therefore most of the biological activity takes place at the top of the media. These types of filters are mostly used in small communities, rural areas, or developing countries where there is a lack of skilled operators as they do not require high maintenance. Depending on the quality of the raw water they may run for several weeks to several months without the need of cleaning. Once the filter is clogged and cleaning is required, the top sand layer is scraped off either manually or mechanically, the filter is restarted afterwards and the effluent is discharged into waste until testing shows that it meets the required water quality (Huisman and Wood, 1974).

Although they have several advantages, slow sand filters do have few limitations that need to be taken into account and these include; decreased biological activity at lower temperatures, high sensitivity to sudden increases in raw water turbidity which might require more frequent cleaning, and most importantly, slow sand filters can only be implemented when there is enough land as they require larger areas compared to other types of filters (Huisman and Wood, 1974).

\subsubsection{Rapid Gravity Filters}

Rapid gravity filters are the most common types of filters, and unlike slow sand filters, they are usually part of a process train unless the water that is being treated is of exceptional quality (Binnie and Kimber, 2009). The media grains are coarser and these filters can operate at much higher flowrates compared to slow sand filters and thus cover less surface area. This high filtration velocity indicates that the filtration run time would be shorter and that the media bed would clog at a faster rate. As a result, cleaning or "backwashing" is required more frequently which is achieved by simply reversing the water flow and expanding the filter bed for a fixed time duration. Over the years, several modifications have been made to the backwashing strategy (Slavik et al., 2013) and these will be discussed in details in section 2.3. For this reason, rapid sand filters require high maintenance and thus cannot be employed in areas where there is a limitation of skilled workers (Howe et al., 2012). Rapid gravity filters employ the same physical and chemical 
process for contaminants removal as a slow sand filters. However, when a biofilm develops on the media and biological activities start playing a major role in degrading certain pollutants they become biologically active filters (BAFs) (Zhu and Bates, 2013).

\subsection{Biologically Active Filters in Drinking Water Treatment}

Since their discovery, BAFs have been applied for decades in drinking water treatment to remove a variety of contaminants that might include natural organic matter, nitrates, perchlorate, sulfate, iron, manganese and trace organic compounds (Chaudhary et al., 2007). BAFs are considered to be mostly effective in removing the fraction of pollutants that promote bacterial regrowth within the distribution system and thus they result in a water that is biologically stable.

Since they are rapid gravity filters in nature, BAFs are generally implemented in conjunction with other treatment processes and they are almost always followed by disinfection. As a result, their performance is highly affected by the design of the water treatment plant, operational and water quality parameters (Moll and Summers, 1999).

\subsubsection{NOM Removal by Biofiltration}

Natural organic matter in water refers to a wide range of compounds that are derived from the decaying and leaching processes of organic materials coming from animals, plants, and microorganisms. Up until today, characterizing NOM remains challenging as it constitutes of a complex mixture of humic substances, polysaccharides, proteins and amino acids. Moreover, the abundance of each of these compounds within NOM is affected by seasonal variations (Prevost et al., 2005). NOM has the potential of promoting microbial growth within the distribution system. Furthermore, it is the main contributor to taste and odor problems and to the formation of disinfection by products which are known to be harmful and carcinogenic (Siddiqui et al., 1997). The Canadian Water Quality Guidelines set a maximum acceptable concentration of $0.1 \mathrm{mg} / \mathrm{L}$ and $0.08 \mathrm{mg} / \mathrm{L}$ for Trihalomethanes (THMs) and Haloacetic acids (HAAs) respectively (Health Canada, 2014).As a result, the drinking water treatment industry places great importance on the removal of NOM. Several treatment steps contribute to NOM removal within the drinking water treatment plant, coagulation and flocculation are known to be effective at NOM removal. Research has 
shown that the coagulation flocculation process contributes mostly to the removal of the hydrophobic fraction of the organic matter which is composed mainly of humic substances (Matilainen et al., 2010).

Biofilters have also been proven to be successful in eliminating the biodegradable fraction of NOM (Urfer et al., 1997). Biodegradable organic matter (BOM) is mainly the fraction of NOM that can be consumed by microorganisms as an energy supply and carbon source (Prevost et al., 2005). Removal of BOM by biofilters has been investigated by many researchers. For example, the optimization of ozone dose has always been a topic of research as generally the biofiltration step is preceded by an ozonation step, the use of ozone increases the biodegradable fraction of the organic matter and results in the formation of lower molecular weight organic compounds that could be consumed more easily by the bacteria (Urfer et al., 1997). Over the years, many studies have been conducted to investigate the effect of ozonation in reducing the formation potential of DBPs. For example, Siddiqui et al. (1997) looked at an optimal ozone dose that reduced the DOC by $40-50 \%$ and resulted in a $40-60 \%$ decrease in THMs formation potential. Melin et al. (2002) observed a significant biological activity in biofilters treating ozonated water even at cold temperatures. However, optimizing biofiltration performance for ideal NOM removal is not simple as there are many parameters that impact the way it performs which will be discussed in the next section.

\subsubsection{Operational Parameters of Biologically Active Filters}

As previously mentioned, biologically active filters have the same physical structure as rapid gravity filters except that there is a significant presence of biological activity in BAFs (Zhu and Bates, 2013). Therefore, most of the operational parameters that are discussed here are also considered when optimizing the performance of conventional rapid gravity filters.

\subsubsection{Filter Media}

Selecting the right filter media is of great importance for good operation of the biofilter. The macroporous structure of GAC and its irregular shape makes it a more suitable surface for the attachment of microorganisms than other types of media (Chaudhary et al., 2007). 
By analyzing for phospholipids as an indicator for the amount of biomass present, Wang et al. (1995) found that GAC media can support higher concentrations of biomass than anthracite does. Urfer et al. (1997) recommended that future evaluations where biological analysis and removal of BOM are being assessed start only when enough filtration time has been run to ensure that the adsorptive capacity of GAC is completely exhausted and that all the removal is actually attributed to biological activity rather than chemical

adsorption. In their study, Emelko and colleagues (2006) used spent GAC that has been in service for several years and found that similar total organic carbon (TOC) removals were achieved with both anthracite and GAC at high temperatures $\left(21-24^{\circ} \mathrm{C}\right)$ whereas the removals were higher with $\mathrm{GAC}$ at lower temperatures $\left(1-3^{\circ} \mathrm{C}\right)$.

\subsubsection{Empty Bed Contact Time (EBCT)}

EBCT is a key design parameter for filters used in water treatment, in biofilters it is very important to select a suitable contact time for ideal BOM removals (Urfer et al., 1997). Both the hydraulic loading and the bed depth could be altered to increase or decrease the EBCT as long as they are within the design ranges for rapid filtration. Research has shown that increasing this parameter increases the removal but up to an optimum value (Chaudhary et. al, 2007). A considerable amount of studies were conducted in order to evaluate the impact of contact time on the performance of biofilters. For example, an investigation that was carried by Hozalski et al. (1995) demonstrated that the removal of total organic carbonis independent of EBCT in the range of 4-20 min. On the other hand, Servais et al. (1992) observed a linear increase in BDOC removal with increasing EBCT between 10 and 30 minutes. Following ozonation, (Wang and Summers, 1996) reported that some ozonation by products such as aldehydes, glyoxal and methyl glyoxal were successfully removed to below the detection limits after 2 minutes of EBCT and no further removal was observed with increasing EBCTs. What is really important to note here, is that generally, optimum contact time selection depends on the objective of the biofiltration and on the water quality parameters as longer EBCTs are required to remove chlorination by products precursors than the EBCTs required to remove ozonation by products (Urfer et al., 1997). 


\subsubsection{Temperature}

Generally, better biofiltration performance is observed at higher temperatures than at colder ones, this is attributed to faster mass transfer and microbial kinetics during warm conditions (Urfer et al., 1997). Emelko et al. (2006) observed significantly higher BOM removals expressed in terms of oxalate during warm temperatures $\left(21-24^{\circ} \mathrm{C}\right)$ than at colder temperatures $\left(1-3^{\circ} \mathrm{C}\right)$ for the same type of media. For example, GAC media had a median TOC removal of $92 \%$ at warm temperatures whereas the median removal was about $50 \%$ under cold temperatures. This is consistent with Moll et al. (1999) findings that demonstrated average DOC removals of $15 \%$ at $5^{\circ} \mathrm{C}$ compared to average removals of $24 \%$ for tests conducted at $20^{\circ} \mathrm{C}$ and $35^{\circ} \mathrm{C}$. Likewise, Andersson et al. (2001) conducted a study to examine ammonia removal in biologically activated carbon filters. The authors reported ammonia removals of $40 \%$ to $90 \%$ at temperatures higher than $10^{\circ} \mathrm{C}$ and removals that were below $30 \%$ for temperatures below $4^{\circ} \mathrm{C}$.

\subsubsection{Biomass}

Perhaps the most important parameter governing biofiltration performance would be the biomass that is attached to the media as most -if not all- of the biodegradable organic matter removal is attributed to microbial activities. Many factors could affect biomass accumulation and attachment on the media including backwashing procedures, type of media used, filtration rate, and the type and concentration of nutrients and organics in the raw water (Chaudhary et. al, 2007). In order to quantify biomass concentrations within the biolfilters, numerous techniques have been adapted such as heterotrophic plate counts (HPC) (Kaur et al., 2003; Ahmad et al., 1998), phospholipids analysis (Emelko et al., 2006; Moll et al., 1999; Liu et al., 2002), and Adenosine Tri-Phosphate (ATP) analysis (Gibert et al., 2013; Velten et al., 2011). Dissolved oxygen uptake rate is another method that is adapted by several researcher to track biofilm activity in biological wastewater treatment processes (Shariati et al., 2013; Meric et al., 2003; Orupold et al., 1999; Yoong et al., 1999).

\subsubsection{Backwashing}

Backwashing is performed in order to clean the biofilters and restore their removal capacity. It is triggered by either headloss, time, breakthrough, or a combination of them. This parameter is crucial as it doesn't only result in the start of a new filtration cycle but it 
also determines the entire performance of the biolfilter both on the short and long terms. Therefore, it is extremely critical to select a suitable backwashing regime to ensure optimum and stable performance of biofilters (Chaudhary et. al, 2007). Backwashing is discussed in detail in the next section (Section 2.3).

\subsection{Backwashing of Drinking Water Biofilters}

As stated earlier, it is highly essential to carry out biolfilter backwashes on a regular basis to ensure their proper performance. However, determining which backwashing technique is suitable for a certain type of biofilters is not always an easy task due to the fact that they capture all sorts of pollutants including biological and nonbiological particles, therefore the difference in the detachment of these particles need to be taken into account when designing a cleaning strategy (Urfer et al., 1997; Chaudhary et al., 2007).

Furthermore, the biomass that is attached to the media is an important aspect that should be considered as it contributes to most of the BOM removal. Successful performance of biofilters is determined by maintaining an active biofilm that has the ability to degrade the organic matter efficiently. As a result, an effective backwash procedure would control biomass growth within the biolfilter by balancing the removal of excess biofilm that might cause clogging and substrate diffusion limitations while keeping enough for subsequent filter runs (Ahmad et al., 1998). When it comes to filtration (both conventional and biological), most treatment plants design their backwash based on historical assumptions and what has been applied in practice (Xue, 2011). But in fact, backwashing is one of the parameters that cannot be generalized, meaning that each treatment plant has to optimize its own procedure based on its own raw water quality characteristics, as a result what has been proven to be optimal for a certain treatment facility might not be the best option for another. Over the past few years, several investigations have been performed to study the effect of backwashing on biofiltration performance, a number of them is summarized in table 2 . 
Table 2.1- Effect of Backwashing on Drinking Water Treatment Biofilters

\begin{tabular}{|c|c|c|c|}
\hline $\begin{array}{c}\text { Source/ } \\
\text { Reference }\end{array}$ & Backwash Strategy & $\begin{array}{c}\text { Duration } \\
\text { (Min) }\end{array}$ & Main Findings \\
\hline $\begin{array}{l}\text { Kim et al. } \\
\text { (2013) }\end{array}$ & $\begin{array}{l}\text { 1. Air scouring } \\
\text { 2. Collapse pulsing: } \\
\text { Air flowrate }=1 \mathrm{~m} / \mathrm{min} \\
\text { Water flowrate }=0.28 \mathrm{~m} / \mathrm{min} \\
\text { 3. Water only wash at } 0.4 \mathrm{~m} / \mathrm{min}\end{array}$ & $\begin{array}{c}\mathrm{NA} \\
1\end{array}$ & $\begin{array}{l}\text { A large fraction of biomass was lost due to } \\
\text { backwashing }\left(\approx 10^{15} \text { bacteria } / \mathrm{m}^{3} \text { BAC), however }\right. \\
\text { the backwash had no impact on the bacteria } \\
\text { community composition and organization } \\
\text { (diversity, richness, and evenness) }\end{array}$ \\
\hline $\begin{array}{c}\text { Emelko et al. } \\
(2006)\end{array}$ & $\begin{array}{l}\text { Investigation } 1: \\
\text { 1. Air scour }=3 \mathrm{scfm} / \mathrm{sqft} \\
\text { 2. Low rate water wash }=10.7 \mathrm{~m} / \mathrm{hr} \\
\text { 3. High rate water wash }=42.7 \mathrm{~m} / \mathrm{hr} \\
\text { Investigation2: } \\
\text { 1. Low rate water wash }=10.7 \mathrm{~m} / \mathrm{hr} \\
\text { 2. High rate water wash }=42.7 \mathrm{~m} / \mathrm{hr} \\
\text { Investigation3: } \\
\text { 1. Low rate water wash }=7.3 \mathrm{~m} / \mathrm{hr} \\
\text { 2. Collapse pulsing } \\
\text { Air flowrate }=3 \mathrm{scfm} / \mathrm{sqft} \\
\text { Water flowrate }=7.3 \mathrm{~m} / \mathrm{hr}\end{array}$ & $23-24$ & $\begin{array}{l}\text { The backwash protocol had a significant effect on } \\
\text { the top of media biomass concentrations in } \\
\text { certain cases (When air scouring was absent, } \\
\text { higher biomass concentrations were observed } \\
\text { under warm water conditions } 21-24^{\circ} \mathrm{C} \text { ). However, } \\
\text { BOM removals were not affected by any of the } \\
\text { backwashing procedures. Similarly, effluent } \\
\text { turbidities and particles removal were not } \\
\text { influenced by the presence or absence of air } \\
\text { scouring. Shorter filter run times were obtained } \\
\text { when collapse pulsing was employed. }\end{array}$ \\
\hline
\end{tabular}




\begin{tabular}{|c|c|c|c|}
\hline $\begin{array}{l}\text { Kaur et al. } \\
\text { (2003) }\end{array}$ & $\begin{array}{l}\text { Investigation } 1 \text { : Water only wash to } \\
\text { achieve } 20 \% \text { and } 40 \% \text { bed } \\
\text { expansions. } \\
\text { Investigations } 2 \text { : } \\
\text { 1. Collapse pulsing } \\
\text { 2. Water only wash at } 20 \% \text { bed } \\
\text { expansion }\end{array}$ & 15 & $\begin{array}{l}\text { In general, collapse pulsing seemed to be a more } \\
\text { efficient method for cleaning biofilters compared } \\
\text { to water only backwash ( } 20 \% \text { and } 40 \% \text { bed } \\
\text { expansions) as it resulted in more biomass } \\
\text { detachment (measured in terms of HPC) from the } \\
\text { media bed. } \\
\text { Both the } 20 \% \text { and } 40 \% \text { bed expansions were } \\
\text { considered to be inappropriate processes for } \\
\text { removing excess biomass from the media grains. }\end{array}$ \\
\hline $\begin{array}{c}\text { Ahmad et al. } \\
\text { (1998) }\end{array}$ & $\begin{array}{l}\text { Investigation } 1: \\
\text { 1. Collapse pulsing } \\
\text { Air flowrate }=0.9 \mathrm{~m} / \mathrm{hr} \\
\text { Water flowrate }=12.5 \mathrm{~m} / \mathrm{hr} \text { (using } \\
\text { chlorinated and nonchlorinated } \\
\text { water) } \\
2 . \text { Water wash only at } 25 \% \text { bed } \\
\text { expansion } \\
\text { Investigation } 2: \\
\text { Water only backwash to achieve } \\
15 \%, 25 \% \text {, and } 50 \% \text { bed expansions. }\end{array}$ & NA & $\begin{array}{l}\text { Collapse pulsing resulted in higher initial } \\
\text { turbidity peak compared to water only } \\
\text { backwashes. } \\
\text { In the absence of chlorine, both the collapse } \\
\text { pulsing and the water only backwash produced } \\
\text { similar effluent AOC and NPOC. } \\
\text { The use of chlorine in backwash water inhibits } \\
\text { microbial growth initially which seems to recover } \\
\text { by the end of the filter run. This is reflected on } \\
\text { both effluent AOC and NPOC which were lower } \\
\text { in the filter that received nonchlorinated } \\
\text { backwash. } \\
\text { Among the water only backwashes the } 50 \% \text { bed } \\
\text { expansion resulted in the lowest effluent AOC } \\
\text { and NPOC values corresponding to } 10 \mu \mathrm{g} / \mathrm{L} \text { and } \\
1.74 \text { mg/L respectively. However, due to } \\
\text { variations in influent AOC values no conclusion } \\
\text { could be drawn regarding the water only } \\
\text { backwashes. }\end{array}$ \\
\hline
\end{tabular}




\begin{tabular}{|c|c|c|c|}
\hline $\begin{array}{l}\text { Hozalski and } \\
\text { Bouwer (1998) }\end{array}$ & $\begin{array}{l}\text { Water only backwash to achieve } \\
15 \%-50 \% \text { bed expansions. } \\
\text { Water flowrates }=23-53 \mathrm{~m} / \mathrm{hr}\end{array}$ & 10 & $\begin{array}{l}\text { A } 20-40 \% \text { bacterial detachment was observed } \\
\text { during backwash which was not significantly } \\
\text { affected by the different bed expansions and the } \\
\text { backwashing. The authors concluded that TOC } \\
\text { removal is not impacted by water only } \\
\text { backwashing. }\end{array}$ \\
\hline $\begin{array}{l}\text { Miltner et al. } \\
\text { (1995) }\end{array}$ & $\begin{array}{l}\text { Water only backwash to achieve } 50 \\
\text { \% bed expansion } \\
\text { Investigation } 1 \text { : Utilizing chlorinated } \\
\text { water }(1 \mathrm{mg} / \mathrm{L} \text { free chlorine }) \\
\text { Investigation2: Utilizing non } \\
\text { chlorinated water }\end{array}$ & 10 & $\begin{array}{l}\text { Backwashing using chlorinated water resulted in } \\
\text { an average biomass loss of about } 22 \% \text {, However } \\
\text { biomass always recovered to its pre-backwash } \\
\text { concentration at about } 40 \text { hours after restart. } \\
\text { Backwashing using nonchlorinated water had no } \\
\text { apparent impact on biomass concentration. } \\
\text { Average formaldehyde removal was } 67 \% 1 \text { hour } \\
\text { after backwashing using chlorinated water and } \\
\text { then increased to an average of } 85 \% \text { at about } 50 \\
\text { hours after restart, similar trends were observed } \\
\text { for acetaldehyde, methyl glyoxal, and AOC- } \\
\text { NOX. } \\
\text { Backwashing using nonchlorinated water had no } \\
\text { negative impact on natural organic matter } \\
\text { removal. }\end{array}$ \\
\hline $\begin{array}{l}\text { Servais et al. } \\
\quad(1991)\end{array}$ & $\begin{array}{l}\text { 1. Collapse pulsing: } \\
\text { Air flowrate }=30 \mathrm{~m} / \mathrm{hr} \\
\text { Water flowrate }=10 \mathrm{~m} / \mathrm{hr} \\
\text { 2. Water only wash at } 25 \mathrm{~m} / \mathrm{hr}\end{array}$ & 20 & $\begin{array}{l}\text { Backwash did not result in a vertical stratification } \\
\text { of the filter media and resulted in only } 4-8 \% \text { of } \\
\text { biomass detachment. Biological filtration } \\
\text { performance is not impacted by collapse pulsing } \\
\text { conditions. }\end{array}$ \\
\hline
\end{tabular}


It is important to note that the intensity and frequency of backwash should be selected with caution. By conducting bench scale experiments, Choi et al. (2007) evaluated the impact of strong and weak daily backwashes on biofilters performance used for perchlorate removal, the weak cleaning regimes had a slight negative effect on the removals whereas the strong cleaning regimes resulted in a complete deterioration of perchlorate biodegradation.

Usually a filter cycle can last for several days, the end of this stage can be triggered either by filter breakthrough which basically means that the filter is no longer efficient in collecting particles and that increased turbidity is observed in the effluent. Excessive headloss can also bring the filtration phase to an end, this happens when headloss reaches the available head which is typically between 2 to 3 meters for rapid gravity filters. If the filter has not reached headloss or breakthrough, then plant operators schedule a set period of time for the filtration stage in which backwash needs to take place once that period is over (Howe et al., 2012).

\subsubsection{Backwash Theory and Backwashing Strategies}

\subsubsection{Water Only Backwash}

Generally, by the end of filter run, the inlet is closed and the water direction is reversed upwards to fluidize the media for a certain length of time in order to flush out all the impurities that were collected during the filtration stage (Binnie and Kimber, 2009). The backwash water velocity needs to be high enough to flush out all the captured impurities but not too high that it would result in media loss (Howe et al., 2012). Some engineering manuals recommend a $30-50 \%$ bed expansion, others state that a 15 to $20 \%$ bed expansion would be sufficient with the right backwash duration (Satterfield, 2005). After determining the required expansion, the following equations could be used to determine the required backwash water flowrate (Howe et al., 2012), starting by Reynolds number equation:

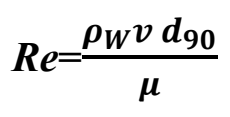

Equation 2.1

Where: $\rho_{\mathrm{W}}=$ water density $(\mathrm{kg} / \mathrm{m} 3)$ 


$$
\begin{aligned}
& \mathrm{v}=\text { backwash velocity }(\mathrm{m} / \mathrm{hr}) \\
& \mu=\text { water viscosity }(\mathrm{kg} / \mathrm{m} . \mathrm{s}) \\
& \mathrm{d}_{90}=\text { the media grain diameter at which } 90 \% \text { of the media by weight is smaller }
\end{aligned}
$$

(m)

Equation 2.2 can be used to determine $d_{90}$ using the effective size $\left(d_{10}\right)$ and the uniformity coefficient (UC):

$$
\begin{aligned}
& d_{90}=d_{10}\left[10^{1.67 \log (U C)}\right] \\
& U C=\frac{d_{60}}{d_{10}}
\end{aligned}
$$

Where: $d_{60}, d_{10}=$ the 60 th and 10th percentile media grain diameters respectively $(\mathrm{mm})$ Equation 2.4 is used to determine Reynolds number:

$$
R e=\frac{-k_{V}\left(1-\varepsilon_{E}\right)}{2 k_{l}}+\frac{1}{2 k_{l}} \sqrt{k_{v}^{2}\left(1-\varepsilon_{E}\right)^{2}+4 k_{l} \beta}
$$

Where: $\mathrm{k}_{\mathrm{V}}, \mathrm{k}_{\mathrm{l}}=$ Ergun coefficients for viscous and inertial losses (unitless)

$$
\begin{aligned}
& \varepsilon_{E}=\text { expanded bed porosity (dimensionless) } \\
& \beta=\text { backwash calculation factor (dimensionless) }
\end{aligned}
$$

The backwash calculation factor can be calculated by equation 2.5 :

$$
\boldsymbol{\beta}=\frac{g \rho_{W}\left(\rho_{P}-\rho_{W}\right) d_{90}^{3} \varepsilon_{E}^{3}}{\mu^{2}}
$$

Where: $\rho_{\mathrm{P}}$ : density of the media particles $(\mathrm{kg} / \mathrm{m} 3)$ 
Finally the relationship between the expansion and the bed porosity is described by equation 2.6:

$\frac{L_{E}}{L_{F}}=\frac{\left(1-\varepsilon_{F}\right)}{\left(1-\varepsilon_{E}\right)}$

Equation 2.6

Where: $\mathrm{L}_{\mathrm{E}}, \mathrm{L}_{\mathrm{F}}$ : depth of expanded and fixed bed respectively $(\mathrm{m})$

Another important parameter to consider during backwash is the minimum fluidization velocity $\left(\mathrm{V}_{\mathrm{mf}}\right)$, which is the water flowrate rate at which the media bed starts fluidizing (Xue, 2011).

To determine $\mathrm{V}_{\mathrm{mft}}$ the following equations are used (Taylor and Francis, 2006):

$R_{m f}=\frac{d_{90} V_{m f} \rho_{W}}{\mu}$

Equation 2.7

Where: $\mathrm{V}_{\mathrm{mf}}=$ minimum fluidization velocity $(\mathrm{m} / \mathrm{hr})$

$\mathrm{R}_{\mathrm{mf}}=$ Reynolds number at minimum fluidizationvelocity

$R_{m f}=\left[33.7^{2}+0.0408 G a\right]^{0.5}-33.7$

Equation 2.8

Where: Ga represents Galileo number and it can be calculated using equation 2.9:

$G a=\frac{d_{90}^{3} \rho_{W}\left(\rho_{P}-\rho_{w}\right) g}{\mu^{2}}$

Equation 2.9

It is very important to note that the backwash velocity would be different for summer and winter as it depends on the viscosity of water. In order to keep the same expansion, a lower flowrate should be employed during colder temperatures than the one used during warm temperatures, keeping the same flowrate in winter might result in media loss (Howe et al., 2012).

In rapid gravity filters the backwash can sometimes be coupled with a surface wash, which is simply jets of water that are directed on the filter surface to help break the crust that was formed during the filtration cycle. Even when the media finally starts fluidizing the surface wash can still be employed to provide additional vigorous agitations which are believed to result in more efficient cleaning (Howe et al., 2012; Binnie and Kimber, 2009). 


\subsubsection{Air Assisted Backwash}

Research has shown that the use of water alone is not a very effective method for cleaning filters due to the limited collisions and abrasions between media particles during fluidization. Thus the most effective backwash that a filter could receive would be by the simultaneous use of air scouring and subfluidization water flowrates (Amirtharajah et al., 1990). As a result, modern water treatment plants employ both air and water for backwashing. A typical sequence would be pumping air for 2 to 3 minutes through the bed to break the surface crust that has formed during the filtration cycle. After that, water at a very low rate is pumped simultaneously with air for about 5 minutes in order to carry out dirt that is coming out from the media. Finally the air flow is stopped and the water flow is increased to achieve the required bed expansion (Binnie and Kimber, 2009).

Amirtharajah et al. (1990) defined collapse pulsing conditions as the agitations that are observed when the filter bed is backwashed with concurrent air and water flow. This phenomenon results in a more adequate cleaning due to the high degree of abrasions and collisions between the media grains. Air scouring is a technique that was initially developed for nonbiological filters which are mainly employed for particle removal. As a result, the main concern about employing collapse pulsing for biofilters was that this vigorous cleaning regime would result in a great biomass loss and would therefore impair BOM removal (Urfer et al., 1997). However, a lab scale study that was conducted by Ahmad and Amirtharajah (1998) indicated that a greater force is needed to detach biological particles from the media grains than the one needed to detach nonbiological particles. As a result, a cleaning technique that is successful for the removal of particles could be implemented on biofilters without the fear of compromising BOM degradation. Various studies investigated the effect of implementing air scouring and collapse pulsing on filter biomass and biofilters performance in general. Servais et al. (1991) reported only a 4-8\% loss in biomass. Interestingly, Emelko et al. (2006) found that utilizing air when backwashing had a significant effect on top of filter biomass under warm water conditions $\left(21-24^{\circ} \mathrm{C}\right)$. However, this did not seem to have any impact on BOM and particle removals. This is consistent with Ahmad et al. (1998) findings which indicated that filters backwashed under collapse pulsing conditions produced similar effluent assimilable 
organic carbon (AOC) to the filters that haven't received any air scouring. Furthermore, their results indicated that collapse pulsing was actually a more efficient method of cleaning as effluent microbial counts -expressed as HPC- were higher for the filter that received a water only wash. Therefore, essentially, adding air to the backwash regime is considered to be a more efficient strategy for controlling biofilm thickness and growth. Liu et al. (2001) evaluated the impact of air scouring conditions under warm and cold temperatures, $5^{\circ} \mathrm{C}$ and $20^{\circ} \mathrm{C}$ respectively, as well as the presence of chlorine or chloramines in the water when collapse pulsing is employed, the only negative effect that air had on BOM removal was observed under cold conditions and when chloramine was present, other than that this backwash strategy did not seem to compromise biological activities.

\subsubsection{Chlorinated Water Backwash}

Some plants use chlorinated water for their backwash, therefore understanding the implications of chlorine presence in the water is of great importance. Mitlner et al. (1995) observed an immediate loss of biomass after employing a chlorinated water backwash. Nevertheless, the amount of biomass present always seemed to recover to its prebackwash concentration later in the filter run. Their observations were also consistent with BOM removals which dropped right away after backwash and then returned to steady state removal later in the filter cycle. Similarly, Ahmad et al. (1998), found that a higher initial headloss is associated with biological filters backwashed with nonchlorinated water compared to the ones backwashed with chlorinated water, this higher headloss was attributed to microbial growth which indicates that chlorine use inhibits biomass growth within the filter media. The authors also emphasized on the fact that the effects of chlorine inhibition were only considerable during the initial stages of filter restart. In their study on the impact of different factors on biofilters performance, Liu and colleagues (2001) recommended that plants should avoid the use of chlorine in backwash water unless when it is necessary to control excessive biomass growth and development within the filter.

\subsubsection{Filter Ripening}

Filter ripening is a well-known problem to the water treatment community, it is a period of poor effluent quality and increased turbidity seen immediately after a filter has been backwashed and put back into operation (Amirtharajah, 1984). The intensity and duration 
of this phase could be affected by several parameters, including raw water quality characteristics, efficiency of the coagulation, and the adapted backwash regime (Amburgey and Amirtharajah, 2005).

As shown in figure 2.1, the filter ripening sequence is distinguished by five different stages; the lag phase is associated with the clean backwash water that exists the filter first when it is put back into service. Following that is the intramedia remnants stage which is observed due to the particles that have been detached from the media during backwash and that have remained in the pore water. The third phase is also linked to backwash remnants that ended up in the filter box above the media, after that comes the fourth phase which represents the second peak and it is related to the particles in the influent water mixing with the backwash remnants. Finally, the fifth stage represents the improvement in the filtration efficiency as newly attached particles act as collectors of other particles (Amburgey and Amirtharajah, 2005).

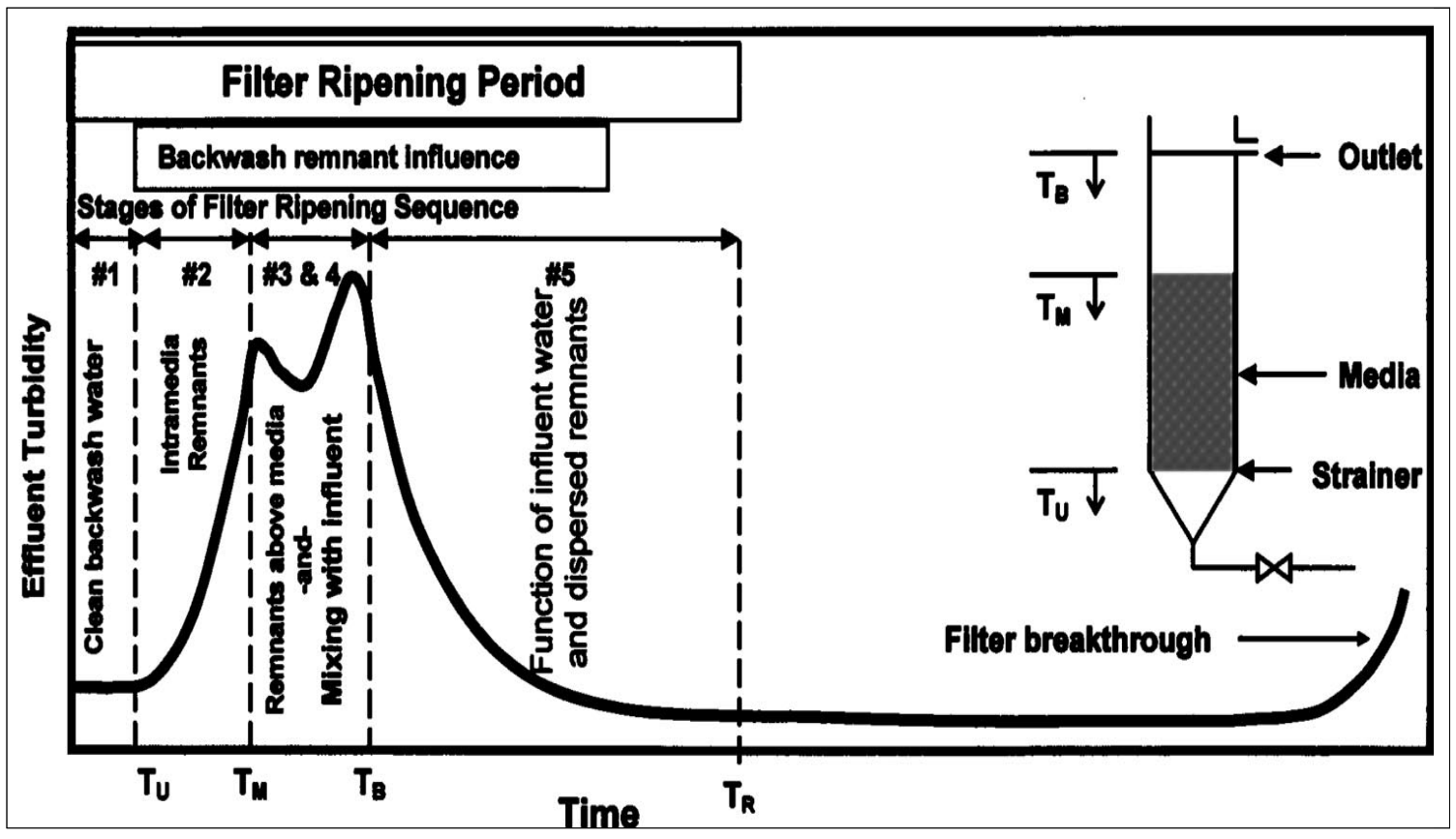

Figure 2.1- Filter Ripening Sequence (Amburgey and Amirtharajah, 2005) 
The major concern about this period of poor filtrate quality is associated with the potential passage of pathogenic microorganisms (Slavik et al., 2013). Colton et al. (1996) reported that $42 \%-48 \%$ of the particles exiting filters during ripening period are of the Cryptosporidium oocysts size range. Canadian Drinking Water Quality Guidelines set a maximum filter effluent turbidity of 0.3 NTU in at least $95 \%$ of the measurements per filter cycle or per month and state that effluent turbidity should never exceed 1 NTU (Health Canada, 2014). Therefore, the filter can only be put into operation after backwash when the effluent turbidity falls below 0.3 NTU in order to avoid the risks that are associated with the ripening period. This results in a waste of treated water.

For the reasons mentioned above, several efforts have been done trying to reduce the duration and the intensity of this stage. One approach is the addition of filter aid polymers or coagulants which increases the size of particles, enhances their attachment to the filter media, and eventually ends up reducing backwash turbidity (Harris, 1970; Francois and Van Haute, 1985; Zhu et al., 1996). Nevertheless, this is not always a feasible technique as the dose of the chemical added needs to be optimized based on the changes in raw water quality characteristics. Furthermore, the formed flocs may clog the filter and result in excessive headloss development (Amburgey, 2004). Colton et al. (1996) suggested optimizing the collapse pulsing duration to not be too short that it would result in poor cleaning and not too long that it would detach all the particles that might act as additional collectors. Furthermore, the authors proposed the slow start mode which is based on restricting the flowrate through the filter until the filtrate becomes of acceptable quality. This was a useful strategy as it reduced the particles passage (2-5 $\mu \mathrm{m}$ in size) by more than half. However, for this to be successful extensive flow control is required. Amburgey (2004) investigated the impacts of the extended terminal subfluidization wash technique (ETSW) on filter ripening period. ETSW is an additional flushing step to the normal backwash procedure that is employed for the purpose of eliminating the backwash remnants and preventing them from ending up in the effluent and causing turbidity spikes. In order for it to be successful, the subfluidization wash has to allow for a sufficient time duration to pass one theoretical filter volume of water through the bed. The critical part about it is that the water flowrate has be high enough to flush out remnant particles but not too high that it would results in the detachment of new particles that are needed to 
contribute to the filtration efficiency once the filter is restarted. Salvik et al. (2013), reported that the benefits of the additional flushing step is delaying turbidity breakthrough and thus resulting in longer filter run times. Furthermore, Amburgey (2004) reported that when ETSW was tested on biofilters it lead to the same results that were observed on conventional filters. Although proven to be successful, not enough research has been conducted to assess the implication of ETSW under varying conditions. The impact of employing ETSW on biological filters performance in terms of DOC removal hasn't been investigated before. Moreover, although previous research has proved that backwashing is a parameter that may affect both the short and long term performances of biological filters, however, the exact impacts of this factor are still poorly understood. It is still unclear whether collapse pulsing results in major biomass loss and deteriorates biodegradable organic matter removal. In addition to that, backwash strategies should be optimized while taking into account the detachment of both biological and nonbiological particles that were accumulated during the filtration cycle. More information is needed to understand how a backwash procedure could be optimized without compromising biological activity and the biofilter particles 'accumulation capacity. It is also important to note that there is a lack of appropriate methods for estimating biological activity within the biofilters. The experiments conducted in this research are directed towards developing a better understanding of biological filtration performance by addressing these questions and by contributing to the overall knowledge that was developed throughout the years about biologically active filters. 


\section{CHAPTER 3- MATERIALS AND METHODS}

This chapter provides a description of the experiments that were conducted for the backwash optimization research on biofilters. A thorough description of the experimental setup and process configuration is provided first, followed by a description of the different phases of the experiments along with the backwashing procedures adapted. In addition to that, a description of the water quality parameters analyzed and microbial analysis are provided.

\subsection{Biofiltration System}

\subsubsection{Experimental Setup Description}

The experiments were conducted on a system consisting of four bench scale dual media filters operating in parallel and containing $520 \mathrm{~mm}$ of GAC on top of $180 \mathrm{~mm}$ of sand as the filter media along with $15 \mathrm{~mm}$ of synthetic underdrain that acted as a media support. The columns were identical, each one of them was made of plexi-glass and had an inside diameter of $50 \mathrm{~mm}$. As seen in the experimental set up shown in figure 3.1, each column had 5 sampling ports spaced equally at different media depths in addition to one overflow port with an attached tubing that allowed for dirty backwash water collection. The flow rate through each column was $100 \mathrm{~mL} / \mathrm{min}$ to allow for an empty bed contact time of 15 minutes, however, flow control challenges lead to $20 \%$ variations in the incoming flowrate.

Figure 3.2 shows the design of the columns bottoms which was selected in order to allow for effluent collection as well as the introduction of backwash water and air scour. Each bottom had a $1 / 4$ inch union cross attached to it which was also connected to a $1 / 4$ inch tee fitting at the other end. 1/4 inch ball valves were attached to each port. The effluent ball valve was open 7 days a week except when the biofilter was put out of operation in order to backwash it, then the effluent would be closed and the top left and right ball valves would be open allowing for backwash water and air introduction. 


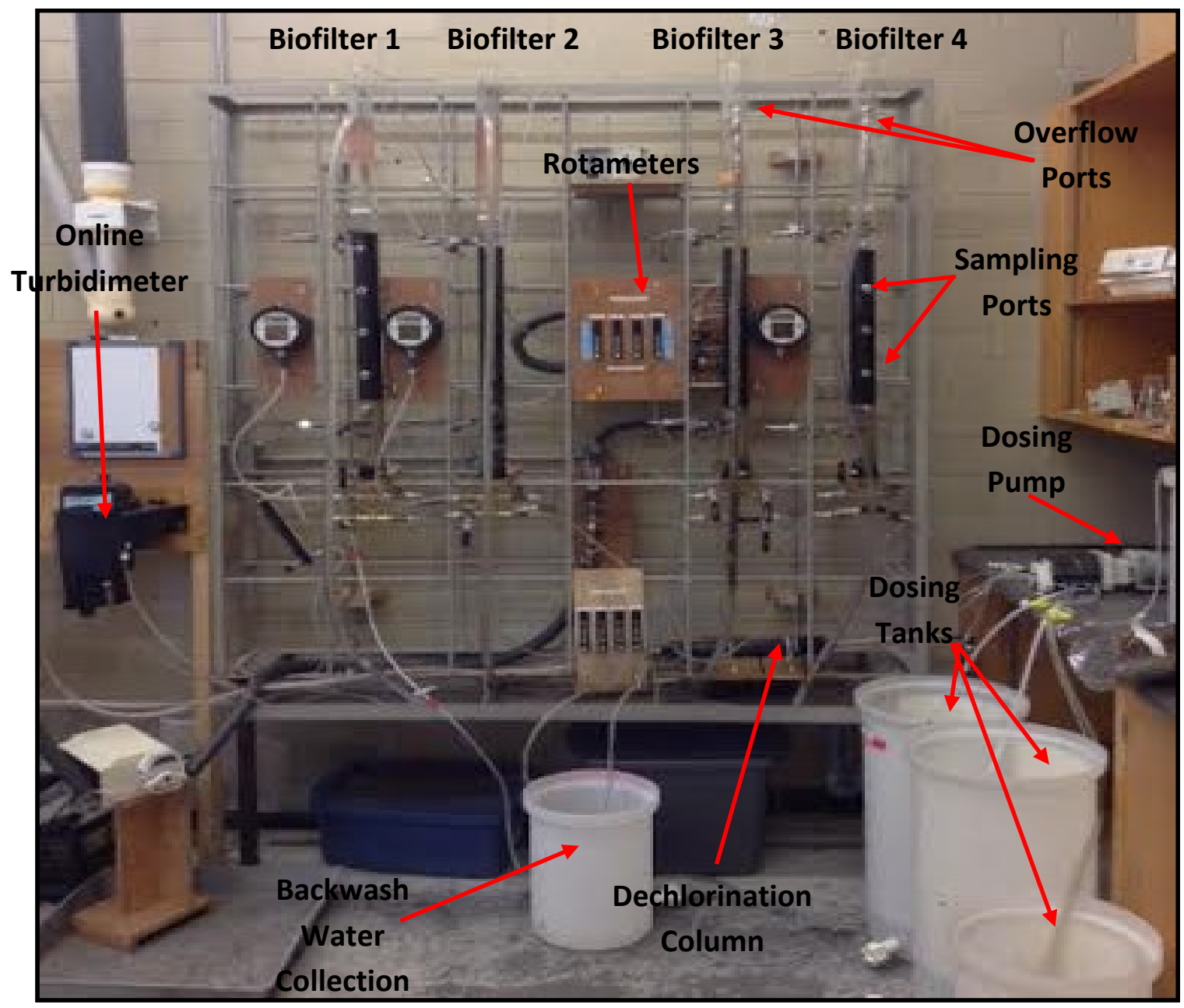

Figure 3.1- Biofiltration Experimental Setup

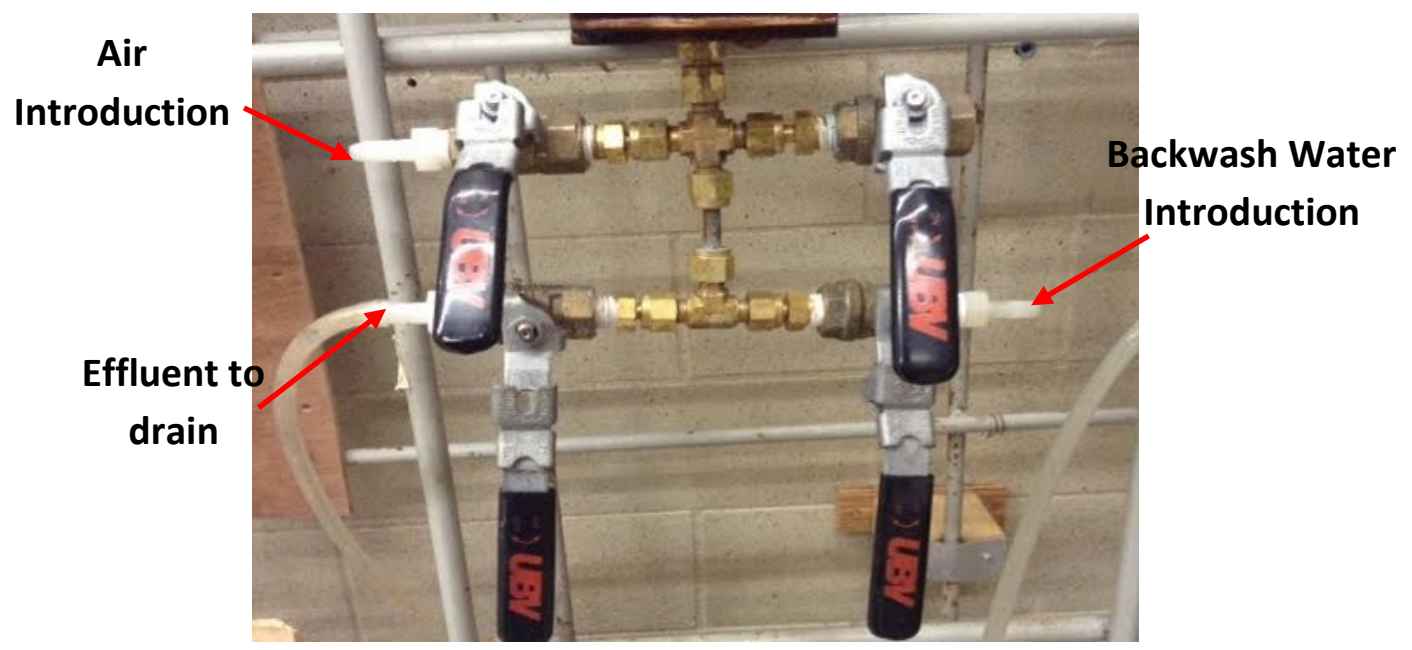

Figure 3.2- Columns Bottoms Design 
Table 3.1 shows the different parameters that are associated with the biofilters.

Table 3.1- Columns’ Design Parameters

\begin{tabular}{|c|c|}
\hline Design Parameter & Value/Description \\
\hline Flow Rate (ml/min) & 100 \\
\hline EBCT (min) & 15 \\
\hline Column Height (mm) & 1250 \\
\hline Column Diameter (mm) & 50 \\
\hline GAC Bed Depth (mm) & 520 \\
\hline Sand Bed Depth (mm) & 180 \\
\hline GAC Effective Size (mm) & 0.7 \\
\hline Sand Effective Size (mm) & 0.5 \\
\hline Number of Sampling Ports (\#/column) & $5(+1$ overflow port) \\
\hline
\end{tabular}

\subsubsection{Process Configuration and Description}

To feed the columns, two 50 L Nalgene heavy cylindrical containers were used, one of them contained a mixture of carbon solutions (glyoxal, acetic acid, and formic acid), and the other contained a mixture of nitrogen, phosphorous, and micronutrients (magnesium and sodium). The carbon and nutrients solutions were dosed using a Masterflex peristaltic pump (model 7519-15, Master flex tubing (LS-14) and cartridges) into a line where they mixed with dechlorinated tap water. The tap water flow was controlled using a $1 / 2$ inch McMaster Carr brass check valve followed by a McMaster Carr flow meter. To ensure that the dosing solutions were mixed adequately an inline static mixer was used (McMaster Carr). After this, the flow went through a manifold (McMaster Carr) in order to split it equally into four different rotameters (Cole Palmer) employed to control the influent 
flowrate into the biofilters. The effluent flow from the columns was also controlled using the same type of flow meters. In order to measure the effluent turbidity prior to and after backwash an inline low range turbidimeter (HACH, Filter Track 660) was used, the device was either attached to biofilter 1, 2 or 3 depending on the experiment being carried out.

During the conditioning phase -4 months- the carbon, nitrogen, and phosphorous concentrations in the influent water were maintained at a C:N:P ratio of $546: 24: 1$ on a weight to weight basis. The synthetic water was prepared to mimic the nutrient limited conditions of the raw water at the Britannia Water Treatment Plant (BWTP) located in Ottawa, Ontario. Throughout that period, all 4 biofilters were inoculated five times with backwash water from BWTP in order to promote bacterial attachment and growth on the media.

According to LeChevalier et al. (1991), a ratio of 100:10:1 on a mol basis is considered to be adequate for bacterial growth corresponding to 39:4.1:1 on a weight basis. Therefore, the 546:24:1 C:N:P ratio was phosphorous limited and was not adequate for ideal bacterial activity. As a result, starting from phase 2, the conditions were changed to a ratio of 25:5:1 (w/w) (Tchobanoglous et al., 2003) for biofilter 1 (B1), biofilter 2 (B2), and biofilter 3 (B3). A 26 L Nalgene cylindrical tank was used to provide the columns with the additional phosphorus and nitrogen concentrations required to accomplish the 25:5:1 ratio. The new solution was also dosed into the columns using the Masterflex peristaltic pump and the two tubings were placed to drain directly into the columns. The carbon, nitrogen, and phosphorous concentrations remained constant throughout the entire duration of the backwash study. The influent water had an average turbidity of 0.3 and an average $\mathrm{pH}$ of 7.

\subsection{Phases of Research and Backwashing Experiments}

A summary of the different phases and the backwash protocols associated with them is provided in table 3.2. The experiments consisted of 5 phases in total in addition to a preliminary conditioning stage. B1 and B2 were used for this study. B4 and B3 were in use by another graduate student. B3 was added into this study at phases 3 and 4 . The conditioning phase lasted around 4 months and its purpose was to develop an active biofilm that has the ability to effectively degrade the DOC that the columns were constantly dosed 
with. During that period the biofilters received the same backwashing regime to ensure that similar conditions developed in them before conducting a backwash comparison study. Water collected from the biofilters' effluent was used for the backwash. The filtration cycle lasted for 7 days, and prior to each backwash the water level in the columns was drained to $5 \mathrm{~cm}$ above the media. During the conditioning phase the backwash regime consisted of a $30 \mathrm{~m} / \mathrm{hr}$ nonchlorinated water flush that lasted for 10 minutes to achieve a $30 \%$ bed expansion. In order to examine whether B1 and B2 developed the same behavior during this phase, UV and particle counts samples were collected at different time intervals after backwash and both biological filters showed the same performance. Results associated with this phase can be found in Appendix C.

The backwash experiments started once a constant performance was observed in the columns, the changes in the backwashing technique were made on B1. B2 served as the control and had a control backwash strategy (30\%Control) that remained constant throughout the entire duration of the study which was selected based on the ranges that are applied in practice and recommended by the Ontario Ministry of Environment (MOE, 2008). 30\%Control consisted of $6 \mathrm{~min}$ of air and water flow combination to achieve collapse pulsing conditions, followed by a high water wash to achieve a $30 \%$ bed expansion, followed by a 2 min lower water wash to achieve $10 \%$ bed expansion. Phase 1 compared the implementation of a water only backwash $(30 \% \mathrm{~W})$ versus a collapse pulsing backwash (30\%Control) under nutrient limited conditions. After that, phase 2 was initiated. The purpose of phase 2a was to examine the impact of changing the second step of the control backwash that consists of the $30 \%$ bed expansion to a lower bed expansion (20\%) while utilizing the same amount of water volume, $20 \% \mathrm{SV}$ served for this purpose. Phase $2 \mathrm{~b}$ investigated the addition of the ETSW to $20 \% \mathrm{SV}$. Calculations associated with ETSW can be found in Appendix B. Phase 3 was initiated to study the impact of implementing a higher bed expansion (40\%) than the one used in the 30\%Control while utilizing a constant water volume, $40 \% \mathrm{SV}$ served for this purpose. $\mathrm{B} 3$ was added to the experiments starting from phase 3 . 
Table 3.2- Study Phases along with Associated Backwash Experiments

\begin{tabular}{|c|c|c|c|c|c|c|c|}
\hline $\begin{array}{c}\text { Phase/ } \\
\text { Backwash }\end{array}$ & \multicolumn{3}{|c|}{$\begin{array}{c}\text { Backwash Protocol } \\
\text { Biolfilter }\end{array}$} & \multicolumn{3}{|c|}{$\begin{array}{c}\text { Duration } \\
\text { (min) }\end{array}$} & \multirow[t]{2}{*}{$\begin{array}{l}\text { Monitored } \\
\text { Parameters }\end{array}$} \\
\hline & Biofilter 1 & Biofilter 2 (Control) & Biofilter 3 & B1 & B2 & B3 & \\
\hline $\begin{array}{c}\text { Conditioning } \\
\text { Phase } \\
30 \% \mathrm{~W}\end{array}$ & $\begin{array}{l}\text { Water only Backwash } \\
\text { at } 30 \% \text { bed expansion: } \\
\mathrm{V}_{\text {water }}=30 \mathrm{~m} / \mathrm{hr} \\
(10 \mathrm{~min})\end{array}$ & $\begin{array}{l}\text { Water only Backwash at } \\
30 \% \text { bed expansion: } \\
\mathrm{V}_{\text {water }}=30 \mathrm{~m} / \mathrm{hr}\end{array}$ & $\begin{array}{l}\text { Water only } \\
\text { Backwash at } 30 \% \\
\text { bed expansion: } \\
\mathrm{V}_{\text {water }}=30 \mathrm{~m} / \mathrm{hr}\end{array}$ & 10 & 10 & 10 & $\begin{array}{l}\text { DOC }+ \text { UV } 3 / \text { week } \\
\text { UV }+ \text { PCs every } 5 \text { min for } \\
50 \text { min after backwash } \\
\text { (ABW) } \\
\text { Turbidity } 3 / \text { week }\end{array}$ \\
\hline $\begin{array}{c}\text { Phase } 1 \\
30 \% \mathrm{~W} \text { Versus } \\
30 \% \text { Control }\end{array}$ & $\begin{array}{l}\text { Water only Backwash } \\
\text { at } 30 \% \text { bed expansion: } \\
\mathrm{V}_{\text {water }}=30 \mathrm{~m} / \mathrm{hr} \\
(10 \mathrm{~min})\end{array}$ & $\begin{array}{l}\text { 1. Collapse Pulsing }(6 \\
\mathrm{min}) \\
\mathrm{V}_{\text {air }}=70 \mathrm{~m} / \mathrm{hr} \\
\mathrm{V}_{\text {water }}=8 \mathrm{~m} / \mathrm{hr} \\
\text { 2. High Rate Water Flush: } \\
(2 \mathrm{~min}) \\
\mathrm{V}_{\text {water }}=30 \mathrm{~m} / \mathrm{hr}(30 \%) \\
\text { 3. Low Rate Water Flush: } \\
(2 \mathrm{~min}) \\
\mathrm{V}_{\text {water }}=12 \mathrm{~m} / \mathrm{hr}(10 \%)\end{array}$ & NA & 10 & 10 & - & $\begin{array}{l}\text { DOC + UV 3/week } \\
\text { Turbidity 3/week }\end{array}$ \\
\hline $\begin{array}{c}\text { Phase } 2 \mathrm{a} \\
20 \% \mathrm{SV} \\
\text { Versus } \\
30 \% \text { Control }\end{array}$ & $\begin{array}{l}\text { 1.Collapse Pulsing (6 } \\
\text { min) } \\
\mathrm{V}_{\text {air }}=70 \mathrm{~m} / \mathrm{hr} \\
\mathrm{V}_{\text {water }}=8 \mathrm{~m} / \mathrm{hr} \\
\text { 2. High Rate Water } \\
\text { Flush: }(3 \mathrm{~min}, 20 \mathrm{sec})\end{array}$ & Control Backwash & NA & 12 & 10 & - & $\begin{array}{l}\text { DOC+ UV 3/week } \\
\text { DOC + UV+ PCs at } \\
\text { different time intervals } \\
\text { ABW }\end{array}$ \\
\hline
\end{tabular}




\begin{tabular}{|c|c|c|c|c|c|c|c|}
\hline & $\begin{array}{l}\mathrm{V}_{\text {water }}=18 \mathrm{~m} / \mathrm{hr}(20 \%) \\
\text { 3. Low Rate Water } \\
\text { Flush: }(2 \mathrm{~min}) \\
\mathrm{V}_{\text {water }}=12 \mathrm{~m} / \mathrm{hr}(10 \%)\end{array}$ & & & & & & $\begin{array}{l}\text { Phopsholipids before } \\
\text { backwash (BBW) and } \\
\text { ABW } \\
\text { Turbidity continuously } \\
\text { ABW }\end{array}$ \\
\hline $\begin{array}{c}\text { Phase } 2 \mathrm{~b} \\
20 \% \text { SV+ETSW } \\
\text { Versus } \\
30 \% \text { Control }\end{array}$ & $\begin{array}{l}\text { 1. Collapse Pulsing (6 } \\
\text { min) } \\
\mathrm{V}_{\text {air }}=70 \mathrm{~m} / \mathrm{hr} \\
\mathrm{V}_{\text {water }}=8 \mathrm{~m} / \mathrm{hr} \\
\text { 2. High Rate Water } \\
\text { Flush: }(3 \mathrm{~min}, 20 \mathrm{sec}) \\
\mathrm{V}_{\text {water }}=18 \mathrm{~m} / \mathrm{hr}(20 \%) \\
\text { 3. Low Rate Water } \\
\text { Flush: }(2 \mathrm{~min}) \\
\mathrm{V}_{\text {water }}=12 \mathrm{~m} / \mathrm{hr}(10 \%) \\
\text { 4.ETSW }:(6 \mathrm{~min}) \\
\mathrm{V}_{\text {water }}=9.5 \mathrm{~m} / \mathrm{hr}\end{array}$ & Control Backwash & NA & 18 & 10 & - & $\begin{array}{l}\text { DOC+ UV 3/week } \\
\text { DO BBW and at different } \\
\text { time steps ABW } \\
\text { DOC + UV+ PCs at } \\
\text { different time intervals } \\
\text { ABW } \\
\text { Phopsholipids BBW and } \\
\text { ABW } \\
\text { Turbidity continuously } \\
\text { ABW }\end{array}$ \\
\hline $\begin{array}{c}\text { Phase } 3 \\
40 \% \mathrm{SV}, \\
40 \% \mathrm{SV}+\mathrm{ETSW} \\
\text { Versus } \\
30 \% \text { Control }\end{array}$ & $\begin{array}{l}\text { 1. Collapse Pulsing }(6 \\
\text { min) } \\
\mathrm{V}_{\text {air }}=70 \mathrm{~m} / \mathrm{hr} \\
\mathrm{V}_{\text {water }}=8 \mathrm{~m} / \mathrm{hr} \\
\text { 2. High Rate Water } \\
\text { Flush: }(1 \mathrm{~min}: 37 \mathrm{sec}) \\
\mathrm{V}_{\text {water }}=37 \mathrm{~m} / \mathrm{hr}(40 \%) \\
\text { 3. Low Rate Water } \\
\text { Flush: }(2 \mathrm{~min}) \\
\mathrm{V}_{\text {water }}=12 \mathrm{~m} / \mathrm{hr}(10 \%)\end{array}$ & Control Backwash & $\begin{array}{l}\text { 1-3. Same as B1 } \\
\text { 4. ETSW : }(6 \mathrm{~min}) \\
\mathrm{V}_{\text {water }}=9.5 \mathrm{~m} / \mathrm{hr}\end{array}$ & 9 & 10 & 15 & $\begin{array}{l}\mathrm{DOC}+\mathrm{UV}+\mathrm{DO}+\mathrm{PCs} \\
\mathrm{BBW} \text { and at different time } \\
\text { intervals } \mathrm{ABW} \\
\text { ATP BBW and ABW. } \\
\text { Turbidity continuously } \\
\text { ABW }\end{array}$ \\
\hline
\end{tabular}




\begin{tabular}{|c|c|c|c|c|c|c|c|}
\hline $\begin{array}{c}\text { Phase } 4 \\
\\
20 \% \text { ST, } \\
20 \% \text { ST+ETSW } \\
\text { Versus } \\
30 \% \text { Control }\end{array}$ & $\begin{array}{l}\text { 1. Collapse Pulsing (6 } \\
\text { min) } \\
\mathrm{V}_{\text {air }}=70 \mathrm{~m} / \mathrm{hr} \\
\mathrm{V}_{\text {water }}=8 \mathrm{~m} / \mathrm{hr} \\
\text { 2. High Rate Water } \\
\text { Flush: }(2 \mathrm{~min}) \\
\mathrm{V}_{\text {water }}=18 \mathrm{~m} / \mathrm{hr}(20 \%) \\
\text { 3. Low Rate Water } \\
\text { Flush: }(2 \mathrm{~min}) \\
\mathrm{V}_{\text {water }}=12 \mathrm{~m} / \mathrm{hr}(10 \%)\end{array}$ & Control Backwash & \begin{tabular}{|l} 
1-3. Same as B1 \\
4. ETSW : $(6 \mathrm{~min})$ \\
$\mathrm{V}_{\text {water }}=9.5 \mathrm{~m} / \mathrm{hr}$
\end{tabular} & 10 & 10 & 16 & $\begin{array}{l}\mathrm{DOC}+\mathrm{UV}+\mathrm{DO}+\mathrm{PCs} \\
\text { BBW and at different time } \\
\text { intervals ABW } \\
\text { ATP BBW and ABW. } \\
\text { Turbidity continuously } \\
\text { ABW }\end{array}$ \\
\hline
\end{tabular}


It received the $40 \% \mathrm{SV}$ backwash strategy in addition to the ETSW. Phase 4 examined the impact of implementing $20 \%$ ST on B1 which adapted a $20 \%$ bed expansion but followed the same time duration as $30 \%$ Control therefore utilizing less water volume than $30 \%$ Control. $20 \%$ ST was implemented to examine if potential water savings could be achieved while maintaining adequate biofiltration performance. $20 \% \mathrm{ST}$ was also tested on B3 but terminated with the ETSW. In addition to that, during phase 4, turbidity was added in the feed in the form of kaolin clay at a concentration of $2 \mathrm{mg} / \mathrm{L}$ to increase the influent water turbidity to 4-5 NTU in order to investigate the response of the biofilters and the efficiency of the backwash protocol when higher particle concentrations are present. The clay was added to the nutrients dosing tank which was mixed continuously to ensure that the particles remained in suspension. However, keeping constant operating conditions was challenging during this period due to flow control operational difficulties which resulted in a turbidity range of 4-24 NTU. Nevertheless, it was believed that this mimicked real operating conditions where sudden increases in turbidity may occur during spring runoffs or heavy rain events. As a result, it was important to examine the response of the biofilters' performance and the effectiveness of the backwashing strategies under these extreme conditions.

For phase 5, a change in the water quality conditions was made and the same backwash experiments as phase 2 were conducted in order to investigate the reproducibility of the results under these different conditions. Potassium was being added to the influent water $(0.315 \mathrm{~mol} \mathrm{~K} / \mathrm{mol} \mathrm{P})$. In wastewater treatment, potassium is an important parameter that promotes biological phosphorous uptake (Mulkerrins et al., 2004) and there is no information about the impact of potassium addition on the microbial activity of biofilms used to treat dirking water. Therefore, it was import to investigate the impact of potassium addition on DOC removal. Results associated with this phase can be found in Appendix D. 


\subsection{Analytical Methods}

\subsubsection{Dosing Solutions}

Table 3.3 shows the different chemicals that were used to prepare the dosing solutions. The solutions were prepared using distilled water, stock solutions were made in $1 \mathrm{~L}$ volumetric flasks and allowed to mix overnight on a stir plate with magnetic stirrer. After replacing each solution into its tank and filling the tank to its mark, a stand mixer was used to mix them at $350 \mathrm{rpm}$ for a minimum of 30 minutes. Dosing solutions calculations and associated concentrations can be found in Appendix A.

Table 3.3- Chemicals used for Dosing Solutions Preparation

\begin{tabular}{|c|c|c|}
\hline Purpose & Chemicals Used & Phase \\
\hline Carbon Source & Acetic acid, formic acid, glyoxal & All phases \\
\hline $\begin{array}{c}\text { Phosphorous } \\
\text { Source }\end{array}$ & Potassium dihydrogen phosphate & All phases \\
\hline Nitrogen Source & Aluminum nitrates/ Sodium nitrates & All phases \\
\hline Potassium Source & Potassium sulphate & Phase 5 \\
\hline Micronutrients & Magnesium sulphate & All phases \\
\hline Alkalinity & Sodium carbonate & All phases \\
\hline
\end{tabular}

\subsubsection{Dissolved Organic Carbon}

Water samples were collected in clean amber glass bottles that were stored in $10 \% \mathrm{HCl}$ solution overnight, rinsed with DI water, wrapped in aluminum foil, and baked at $450^{\circ} \mathrm{C}$ for 45 minutes in order to ensure that they were free of any organic contaminants. For the purpose of DOC analysis, samples were filtered through a $0.45 \mu \mathrm{m}$ filter paper and then stored in $50 \mathrm{ml}$ clean and baked glass vials at $4^{\circ} \mathrm{C}$ and analyzed within one week of storage. 
DOC analysis was conducted based on Persulfate Ultraviolet Oxidation Method in Standard Methods 5310C (APHA, 2012).A SHIMADZU TOC-VCPH/ CPN total organic carbon analyzer was used.

\subsubsection{Ultraviolet Absorbance (UVA)}

UV absorbance was conducted on the same samples that were stored for DOC analysis (using a UV visible Spectrophotometer, Spectronic Unicam), this was done before carrying out the DOC test. This parameter was measured in accordance with Standard Methods 5910B (APHA, 2012). A $1 \mathrm{~cm}$ quartz cell was used, the sample scan was performed from $200-400 \mathrm{~nm}$ and the values at $254 \mathrm{~nm}$ were recorded.

\subsubsection{Dissolved Oxygen}

Dissolved oxygen measurements were conducted using a Dissolved Oxygen probe (Thermo Scientific ORION).

\subsubsection{Phospholipids Method for Biomass Quantification}

Phospholipids procedure was performed in order to determine top of media biomass concentration. Media samples were taken from the top sampling port before backwash and within one hour after backwash. The media was collected in $50 \mathrm{ml}$ glass vials that have been soaked for 24 hours in a phosphate free soap solution, rinsed with DI water, soaked after that for another 24 hours in a $10 \% \mathrm{HCl}$ solution and then rinsed again with DI water and dried before collecting the media. This technique is based on the method described by Wang et al. (1995) it involves lipids extraction, followed by a digestion with potassium persulfate and then measurement.

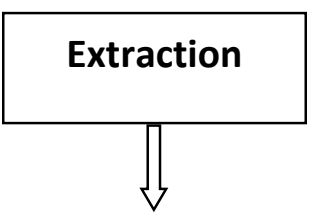


1. Transfer $0.1-1 \mathrm{~g}$ of the media after draining the column to a $50 \mathrm{ml}$ clean glass vial

2. Add $1.8 \mathrm{ml}$ of ultrapure water, followed by $5 \mathrm{ml}$ of methanol and $2.5 \mathrm{ml}$ of chloroform., mix at low speed for 10 minutes on a shaker and let stand overnight for lipids extraction

3. Add $2.5 \mathrm{ml}$ chloroform and $2.5 \mathrm{ml}$ of ultrapure water. Let stand for phase separation for 30 minutes

4. Remove the upper layer to waste with a pasteur pipette

5. Transfer the lower layer to a COD HACH vial with a pasteur pipette and let the media dry

6. Under a steam of nitrogen remove the solvent (chloroform)

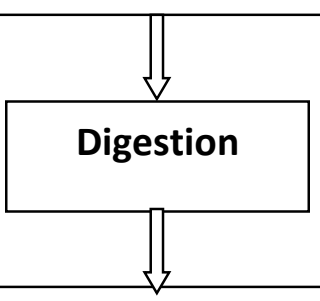

Add $1.1 \mathrm{ml}$ of potassium persulfate, close tightly and let digest overnight on a heating plate $\left(95^{\circ} \mathrm{C}\right)$

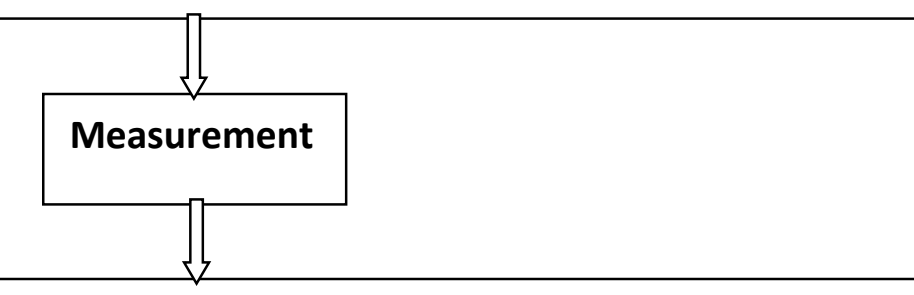

1. Remove the HACH vials from the heating plate and let them cool

2. Add $0.2 \mathrm{ml}$ of ammonium molybdate solution, wait for 10 minutes

3. Add $0.9 \mathrm{ml}$ of malachite green oxalate and wait for 30 minutes

4. Measure the absorbance at $610 \mathrm{~nm}$, use reagent blank

5. Record the measurement and convert it to nmol of lipid phosphate using a calibration curve

6. Weigh the dried media and record the measurement as nmol of lipid phosphate per g of media 


\subsubsection{Adenosine Tri-Phosphate (ATP) for Biomass Quantification}

ATP tests were performed on top and middle of the media before and after backwash based on the method described by Hammes et al. (2010), a Deposit and Surface Analysis test kit was used (LuminUltra Technologies Ltd). The test steps involve calibration, sample preparation, and total ATP analysis.

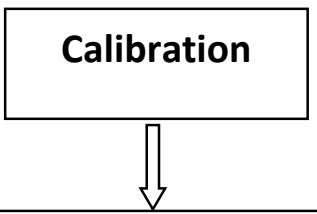

1. Add $100 \mu \mathrm{l}$ of UltraCheck 1 into $12 \times 55 \mathrm{~mm}$ test tube

2. Add $100 \mu 1$ of Luminase to the same tube, and swirl gently five times.

3. Insert the tube into the luminator and record the measurement $\mathrm{ATP}_{1}$

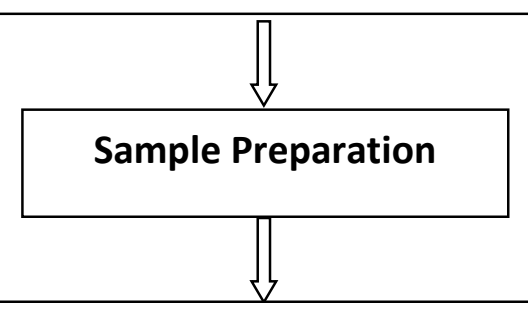

1. Take $1 \mathrm{~g}$ of the media after draining the column. Add the sample to a $6 \mathrm{ml}$ UltraLyse 7 to extract the ATP. Cap and mix the contents of the tube.

2. Transfer $1 \mathrm{ml}$ from the UltraLyse 7 to $9 \mathrm{ml}$ UltraLute dilution tube. Cap and invert three times.

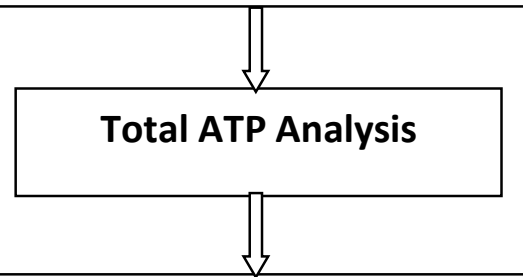

1. Transfer $100 \mu \mathrm{l}$ from the ultraLute dilution tube to a new $12 \times 55 \mathrm{~mm}$ test tube

2. Add $100 \mu 1$ of luminase to the test tube and swirl gently for five times

3. Insert the tube into the luminometer and record the measurement as $\mathrm{ATP}_{t}$

4. Use the following equation to convert relative light units to ATP concentrations:

$t A T P(p g A T P / g)=\frac{R L U_{t A T P}}{R L U_{A T P 1}} \cdot \frac{50000(p g A T P)}{m \text { sample }(g)}$ 


\subsubsection{Particle Counts}

Particle counts measurements were conducted using a BrightWell Technologies INC. Dynamic Particle Analyzer (BP-4100-HEV). A BP-1400-FC-100-U flow cell was used and it had the ability to detect the size and concentration of particles from the $0.75 \mu \mathrm{m}$ lower size range to the $100 \mu \mathrm{m}$ upper size range.

Prior to each analysis, the flow cell had to be rinsed thoroughly with DI water and then flushed with the sample solution which was inverted several times before introducing it to the sampling syringe. At the end of the analyses, the flow cell had to be rinsed with DI water again until no residual particles were shown on the screen. This was followed by introducing the cleaning solution (50\% PCC54 detergent by volume) and then a final thorough DI rinse to flush out the cleaning solution and to ensure that the flow cell was free from any particles or cleaning solution residuals. If the cell was not to be used the following day, in addition to the standard cleaning strategy, the flow cell had to be flushed with analytical grade IPA and then dried using an air duster (MG Chemicals Super Duster).

\subsubsection{Turbidity}

Influent turbidity measurements were performed using a portable HACK turbidimeter. For each column, the effluent turbidity prior to and post backwash was monitored by an inline low range turbidimeter (HACH, Filter Track 660).

\subsubsection{Temperature, $\mathrm{pH}$}

Both $\mathrm{pH}$ and Temperature were carried out using the same probe (Thermo Scientific ORION 087003)

\subsubsection{Statistical Methods and Data Analysis}

To analyze DOC samples minimum, first quartile, median, third quartile, and maximum values were determined and plotted in box and whisker plots.

A student t-test was used in order to carry out statistical analysis. A t-test is a statistical method used to compare the means of two groups by determining the ratio of the sample means to the variance of the samples. Two parameters, T-value and P-value, are used to determine the level of significance between two groups of data. 
For this kind of test a Null Hypothesis $\left(\mathrm{H}_{0}\right)$ and an Alternative Hypothesis $\left(\mathrm{H}_{1}\right)$ need to be determined:

$\mathrm{H}_{\mathrm{o}}=$ There is no significant difference between the two sample groups

$\mathrm{H}_{1}=$ There is a significant difference between the two sample groups

A 5\% ( $\alpha)$ significance level has been chosen in this study. Therefore:

If $\mathrm{P}$ value $<5 \%$ the differences are statistically significant and the Null Hypothesis is rejected

And $t_{s t a t}>t_{\text {critical }}$ the differences are statistically significant and the Null Hypothesis is rejected

If $\mathrm{P}$ value $>5 \%$ the differences are not statistically significant and the Null Hypothesis is accepted

And $t_{\text {Stat }}<t_{\text {critical }}$ the differences are not statistically significant and the Null Hypothesis is accepted

An independent t-test was used to compare the impacts of different backwash procedures on the biofilters:

tStat $=\frac{\bar{x}_{1-} \bar{x}_{2}}{\sqrt{\frac{\left(n_{1}-1\right) s_{1}^{2}+\left(n_{2}-1\right) s_{2}^{2}}{\left(n_{1}-1\right)\left(n_{2}-1\right)} \cdot\left(\frac{1}{n_{1}}+\frac{1}{n_{2}}\right)}}$

Equation 3.1

Where:

$\mathrm{x}_{1}$ and $\mathrm{x}_{2}$ : The means of the first and second group respectively

$\mathrm{s}_{1}$ and $\mathrm{s}_{2}$ : The standard deviations of the first and second group respectively

$\mathrm{n}_{1}$ and $\mathrm{n}_{2}$ : The sample size of the first and second group respectively 
These tests were carried out using Microsoft Excel and $t_{\text {Critical, }} t_{\text {Stat }}$ and the $\mathrm{P}$ value were determined accordingly. 


\title{
CHAPTER 4- BACKWASH OPTIMIZATION FOR DRINKING WATER TREATMENT BIOLOGICAL FILTERS
}

This chapter is written in the form of a journal article and will be submitted to the journal of Water Research. It contains an introduction, a materials and methods section, a combined results and discussion section, and a conclusion. This paper will be published by co-authors Sarra Ikhlef (student) and Dr. Onita Basu (supervisor).

\begin{abstract}
A lab scale biological filtration system was used in this study to examine the implications of different backwash strategies on biological filtration performance. The backwash strategies were evaluated based on dissolved organic carbon (DOC) removals, backwash water volume usage, and filter ripening outcomes. Results showed that under nutrient limited conditions, collapse pulsing improved DOC removal by approximately $10 \%$ compared to a water only backwash condition. Employing a lower bed expansion of $20 \%$ under nutrient supplemented conditions compared to a $30 \%$ Control bed expansion while using the same amount of water volume lead to similar DOC removals of approximately $30 \%$. However, employing a higher bed expansion (40\%) than the control backwash lead to significantly lower \% DOC removals (24\% versus $30 \%$ respectively). A backwash strategy that reduced the backwash water volume usage by about $20 \%$ compared to the control condition resulted in similar \% DOC reductions. The backwash procedures investigated in this study showed no consistent impact on the biofilters' biomass concentrations as measured by the phospholipids and the adenosine tri-phosphate (ATP) methods. Moreover, none of these two analyses showed a direct correlation with DOC removal. On the other hand, dissolved oxygen (DO) uptake showed a direct correlation with DOC removals. Higher DOC removals were obtained at DO uptake levels larger than $8 \mathrm{mg} / \mathrm{L}$ compared to DO uptake levels that were lower than $4 \mathrm{mg} / \mathrm{L}$. The addition of the extended terminal subfluidization wash (ETSW) demonstrated no impact on \% DOC removals and successfully eliminated the filter ripening sequence (FRS).
\end{abstract}

Key Words: biofiltration, backwashing, ETSW, air scour, organics removal, drinking water 


\subsection{Introduction}

The use of biological filtration in the drinking water treatment industry has become increasingly popular over the past couple of decades. Biological filters have the ability to effectively eliminate organic matter from water through the accumulation of naturally occurring bacteria on the media in the form of a biofilm. These microorganisms utilize DOC as an energy supply and a carbon source through the mediation of oxidation reduction reactions (Urfer et al., 1997). Benefits of biological filtration include: a decrease in the formation potential of disinfection by products (DBPs), elimination of taste and odor compounds, reduction in chlorine demand, and decrease in bacterial re-growth potential within the distribution system resulting in a water that is biologically stable (Chaudhary et al., 2007).

In addition to DOC removal, biofilters are also expected to achieve the same level of particle removal that is attained by conventional filters which makes their optimization challenging (Ahmad et al., 1998). A biofilter that results in high quality effluent water needs to maintain a healthy biomass concentration; therefore backwashing is performed on a periodic basis to prevent excessive biomass accumulation and headloss buildup. Furthermore, backwashing has the ability to regenerate the particle accumulation capacity of the biofilter making it one of the most important parameters that define both the short and long term performances of biological filters. An effective backwash will successfully balance the removal of excess biomass while maintaining sufficient attached biomass for continued organic removals in subsequent filter runs (Ahmad et al., 1998). Moreover, an optimized backwash strategy will take into account the difference in detachment of both biological and nonbiological particles that were accumulated during the filtration cycle (Ahmad and Amirtharajah, 1998).

Over the years, studies have looked into optimizing biological filtration through selecting the right type of media (Emelko et al., 2006; Wang et al., 1995; Liu et al., 2001), varying the empty bed contact time (EBCT) (Hozalski et al., 1995; Servais et al., 1991), and examining organics removal under different temperatures (Kim et al., 2014; Eemelko et al., 2006; Liu et al., 2001; Moll et al., 1999). However, backwashing has received less attention. In particular, the influence of backwashing on biofiltration performance in terms 
of organics removal is still poorly understood. Research with respect to backwashing and biofiltration has focused mainly on investigating the impacts of air scouring and collapse pulsing (Emelko et al., 2006; Liu et al., 2001; Ahmad et al., 1998; Servais et al., 1991). When it comes to conventional filters, collapse pulsing is deemed to be a more efficient method for cleaning the media and reducing headloss compared to a water only backwash due to the increased media collisions and abrasions when air and water are used simultaneously (Amirtharajah, 1993). Although some concerns about the impact of biomass loss associated with collapse pulsing have been expressed, research has generally found that collapse pulsing had no significant impact on organics removal (Emelko et al., 2006; Ahmad et al., 1998; Servais et al., 1991). Other investigations have examined the potential detrimental impacts of chlorinated water backwash on biological activity (Liu et al., 2001; Ahmad et al., 1998; Miltner et al., 1995). These studies observed a negative influence of chlorine presence on biolfilter biomass and recommended that chlorinated backwash water should be avoided whenever feasible.

Biomass and biological activity are important parameters governing biofiltration performance. Maintaining a healthy biomass is key in achieving high levels of organics removal. However, more understanding is needed on how specific backwashing procedures impact microbial biomass. It is also unclear whether the amount of biomass attached to the filter media is directly related to microbial activity and biological filtration performance. In order to quantify biomass concentrations within biological filters, numerous techniques have been adapted such as heterotrophic plate counts (HPC) (Kaur et al., 2003; Ahmad et al., 1998), phospholipids analysis (Emelko et al., 2006; Liu et al., 2001; Moll et al., 1999), and ATP analysis (Gibert et al., 2013; Velten et al., 2007; Knezev et al., 2004). Tracking DO uptake in order to determine microbial activity of biolfims has been adapted in wastewater treatments studies (Shariati et al., 2013; Meric et al., 2003; Orupold et al., 1999; Yoong et al., 2000). But DO uptake in drinking water treatment studies seems to have received little attention. Urfer and Huck (2001) looked at biomass respiration potential (BRP) which is a method based on the DO consumption rate and observed a direct correlation between BRP and biodegradable organic matter (BOM) removal potential. 
When it comes to particles removal biofilters face the same challenges that conventional filters face. Filter ripening is a common problem in the drinking water treatment industry. It is a period of poor filtrate quality caused by high particulate passage observed immediately after a filter has been backwashed and put back into operation (Amburgey and Amirtharajah, 2005). Amirtharajah (1985) focused on developing an understanding of the causes behind the ripening period in order to better address it. His findings concluded that remnant particles and newly influent particles are the main causes behind the high effluent turbidity peaks. Amirtharajah (1988) stated that about $90 \%$ of particles' breakthrough in a well operated filter occurs during the ripening period. Moreover, the main concern about this stage is the potential breakthrough of pathogenic microorganisms such as Cryptosporidium and Giardia (Colton et al., 1996). As a result, most backwashing research efforts for conventional filters were directed towards decreasing the intensity and duration of this period. A common practice is the filter to waste procedure, where the treated filter effluent is directed to waste until the effluent quality improves and turbidity meets the desired goals (Soucie and Sheen, 2007). Some researchers suggested the addition of filter aid polymers or coagulants to increase the size of particles and enhance their attachment to the filter media (Francois and Van Haute, 1985; Zhu et al., 1996). This seemed to be successful in reducing the turbidity peaks, however, coagulants addition is not always a feasible technique as the dose of chemicals added needs to be optimized based on the changes in the raw water quality characteristic (Amburgey, 2004). Amburgey (2004) suggested the extended terminal subfluidization wash (ETSW) which is an additional flushing step initiated by the end of the normal backwashing procedure. ETSW employs a subfluidization flow rate that gently removes loose remnants particles without resulting in the detachment of further particles while decreasing or eliminating the filter to waste time period. However, the influence of ETSW on biolfiltration performance in terms of DOC removal hasn't been investigated yet. The main objective of this study is to investigate the impact of various backwashing regimes, including ETSW, on DOC removal in a biofilter. In addition, the relationship between microbial biomass concentrations (as measured by the phospholipids and ATP values), and the DOC removals as well as the correlations between DO and DOC removals to determine the potential of secondary parameters to assist with better understanding biofilter performance. This research is intended to improve 
our understanding of how to determine an optimized backwash strategy that results in shorter ripening times, maximizes DOC and particle removals while efficiently minimizing overall water usage and the biofilter time out of service.

\subsection{Materials and Methods:}

\subsubsection{Experimental Setup}

The experiments were conducted on a laboratory scale system consisting of three dual media filters operating in parallel and containing $520 \mathrm{~mm}$ of GAC on top of $180 \mathrm{~mm}$ of sand along with $15 \mathrm{~mm}$ of synthetic underdrain that acted as a media support. The sand effective size $(\mathrm{ES})=0.5 \mathrm{~mm}$ and the GAC ES $=0.7 \mathrm{~mm}$. The biofilters were made of plexi-glass and had an inside diameter of $50 \mathrm{~mm}$. The experimental setup is shown in figure 4.1. Each column had 5 sampling ports in addition to one overflow port. The flow rate through each column was $100 \mathrm{~mL} / \mathrm{min}$ to allow for an empty bed contact time of 15 minutes, however, flow control operational difficulties resulted in $20 \%$ variations in the incoming flowrate. In order to measure the effluent turbidity prior to and after backwash an inline low range turbidimeter $(\mathrm{HACH}$, Filter Track 660) was used, the device was either

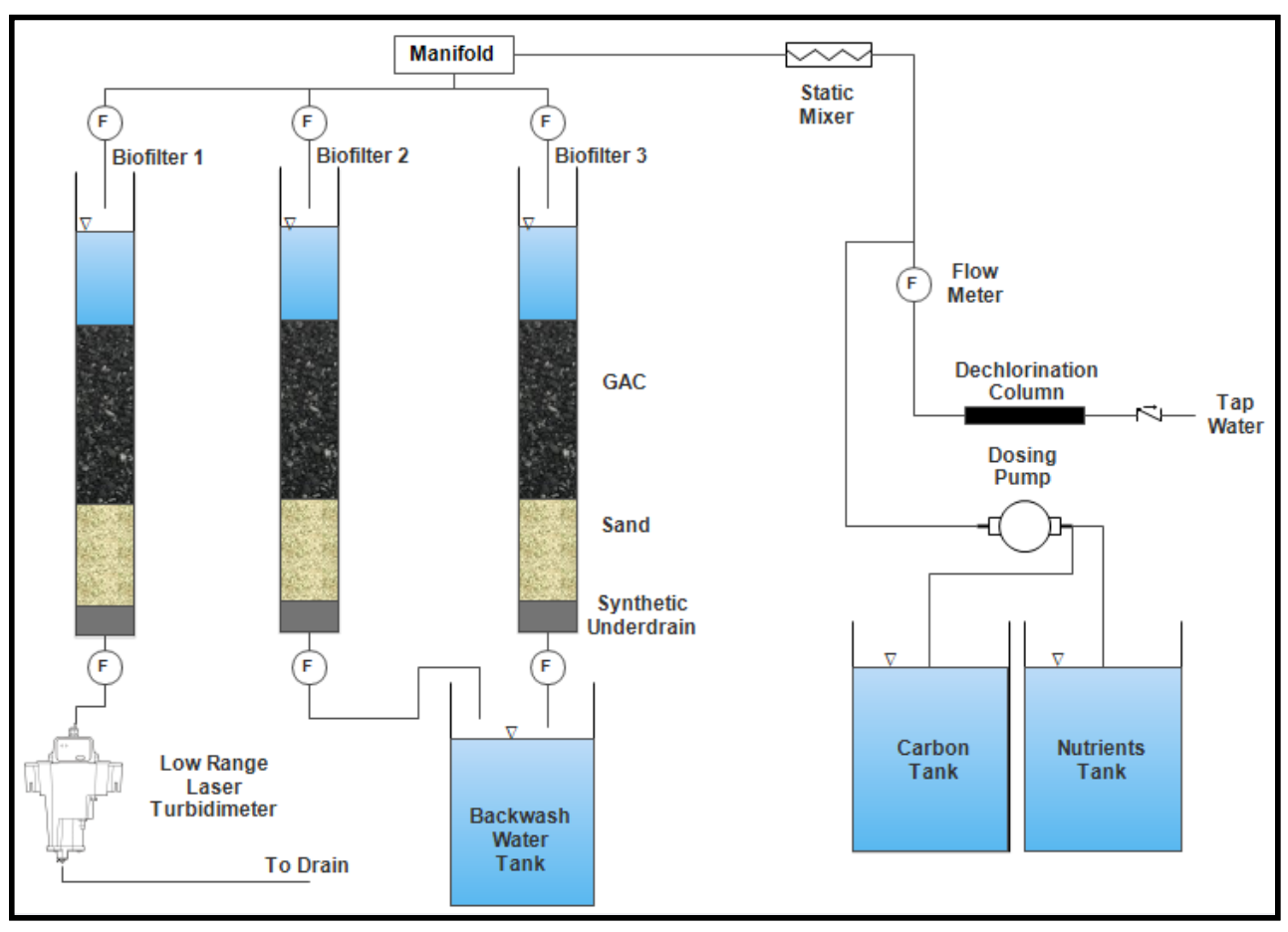

Figure 4.1- Schematic of the Experimental Setup 
attached to biofilter 1 (B1), biofilter 2 (B2), or biofilter 3 (B3) depending on the experiment being carried out.

\subsubsection{Experimental Methodology}

\section{Synthetic Raw Water Preparation}

Biofilter influent was prepared by mixing dechlorinated tap water with dosing solutions containing different concentrations of carbon and micronutrients. The synthetic water was intended to mimic water coming into a biofilter post coagulation/flocculation/sedimentation. Two $50 \mathrm{~L}$ Nalgene heavy cylindrical containers were used (figure 4.1), one of them served as the carbon dosing tank and the other served as the nutrients dosing tank. Glyoxal, acetic acid, and formic acid were selected as the carbon source. They were dosed for a target influent DOC concentration of $7 \mathrm{mg} / \mathrm{L}$. A combination of aluminum nitrates and sodium nitrates served as the nitrogen source. Potassium dihydrogen phosphate served as the phosphorous source. During the first phase of this study, the carbon, nitrogen, and phosphorous concentrations in the influent water were maintained at a C:N:P ratio of 546:24:1 on a weight to weight basis. In order to improve DOC removal, starting from phase 2 the conditions were changed for all biofilters to a ratio of 25:5:1 (w/w) and were maintained constant for the rest of the experiments. This ratio was based on an empirical biomass formula of $\mathrm{C}_{60} \mathrm{H}_{87} \mathrm{O}_{23} \mathrm{~N}_{12} \mathrm{P}$ (Tchobanoglous et al., 2003). Excluding phase 4, influent water had an average turbidity of 0.3 NTU. Average temperatures ranged from $17^{\circ} \mathrm{C}$ to $22^{\circ} \mathrm{C}$ throughout the different experimental phases. Influent water had an average $\mathrm{pH}$ of 7 and an average alkalinity $\left(\mathrm{CaCO}_{3}\right)$ of 24 $\mathrm{mg} / \mathrm{L}$. Influent DO concentrations ranged between 15 to $7 \mathrm{mg} / \mathrm{L}$.

\section{Backwash Experiments}

Table 4.1 shows the backwash strategy associated with each experimental phase. The biofilters were conditioned for four months before initiating the study. During that time all 3 biofilters (B1, B2, and B3) received the same backwash regime to ensure that similar conditions developed in them before conducting a backwash comparison study. Water collected from the biofilters' effluent was used for the backwash. The filtration cycle lasted for 7 days, and prior to each backwash water level in the biofilters was drained to $5 \mathrm{~cm}$ above the media. B2 was operated as the control and had a control backwash strategy 
(30\%Control) that consisted of 6 min of air and water flow combination to achieve collapse pulsing conditions, followed by a high water wash at $30 \%$ bed expansion, followed by a 2 min lower water wash at $10 \%$ bed expansion. The backwash changes were made on B1 and B3. Phase 1 compared the implementation of a water only backwash $(30 \% \mathrm{~W})$ versus a collapse pulsing backwash ( $30 \%$ Control) under nutrient limited conditions. After that, phase 2 was initiated to study the impact of changing the $30 \%$ bed expansion following collapse pulsing to a lower bed expansion (20\%) while utilizing the same amount of water volume, $20 \% \mathrm{SV}$ served for this purpose. Phase 2 also investigated the impact of adding the ETSW to $20 \%$ SV. Phase 3 was initiated to study the impact of implementing a higher bed expansion (40\%) than the one used in the $30 \%$ Control while utilizing a constant water volume, $40 \% \mathrm{SV}$ served for this purpose. B3 received $40 \% \mathrm{SV}$ in addition to the ETSW. Phase 4 examined the impact of implementing $20 \% \mathrm{ST}$ on B1 which adapted a $20 \%$ bed expansion but followed the same time duration as $30 \%$ Control therefore utilizing less water volume than $30 \%$ Control. $20 \%$ ST was also tested on $\mathrm{B} 3$ but terminated with the ETSW. In addition to that, during phase 4, turbidity was added in the feed in the form of kaolin clay at a concentration of $2 \mathrm{mg} / \mathrm{L}$ to increase the influent water turbidity to 4-5 NTU in order to investigate the response of the biofilters and the efficiency of the backwash protocol when higher particle concentrations are present. The clay was added to the nutrients dosing tank which was mixed continuously to ensure that the particles remained in suspension. However, keeping constant operating conditions was challenging during this period due to flow control operational difficulties which resulted in a turbidity range of 424 NTU. Nevertheless, it was believed that this mimicked real operating conditions where sudden increases in turbidity may occur during spring runoffs or heavy rain events. Table 4.1 also shows the backwash water volume utilized for each backwash strategy and the normalized water volume with respect to the control backwash. 
Table 4.1- Summary of Experimental Phases and Backwash Procedures

\begin{tabular}{|c|c|c|c|c|c|}
\hline $\begin{array}{l}\text { Backwash } \\
\text { Procedure }\end{array}$ & Phase(s) & $\begin{array}{c}\text { C:N:P } \\
\text { Ratio/ } \\
\text { Comments }\end{array}$ & Backwashing Steps & $\begin{array}{c}\text { Backwash } \\
\text { Water } \\
\text { Volume } \\
\left(\mathbf{m}^{3}\right) \times \mathbf{1 0}^{-3}\end{array}$ & $\begin{array}{c}\text { Normalized } \\
\text { Backwash } \\
\text { Volume }\end{array}$ \\
\hline 30\%Control & $1 / 2 / 3 / 4$ & $\begin{array}{l}\text { Phase1: } \\
\text { 546:24:1 } \\
\text { Phases } \\
\text { 2/3/4: } \\
\text { 25:5:1 }\end{array}$ & $\begin{array}{l}\text { 1. Collapse Pulsing } \\
(6 \mathrm{~min}) \\
\mathrm{V}_{\text {air }}=70 \mathrm{~m} / \mathrm{hr} \\
\mathrm{V}_{\text {water }}=8 \mathrm{~m} / \mathrm{hr} \\
\text { 2. High Rate Water } \\
\text { Flush: }(2 \mathrm{~min}) \\
\mathrm{V}_{\text {water }}=30 \mathrm{~m} / \mathrm{hr} \\
(30 \%) \\
\text { 3. Low Rate Water } \\
\text { Flush: }(2 \mathrm{~min}) \\
\mathrm{V}_{\text {water }}=12 \mathrm{~m} / \mathrm{hr} \\
(10 \%)\end{array}$ & 4.5 & 1 \\
\hline $30 \% W$ & 1 & $546: 24: 1$ & $\begin{array}{l}\text { Water only } \\
\text { Backwash at } 30 \% \\
\text { bed expansion }(10 \\
\text { min) } \\
V_{\text {water }}=30 \mathrm{~m} / \mathrm{hr}\end{array}$ & 9.8 & 2.2 \\
\hline $20 \% \mathrm{SV}$ & 2 & $25: 5: 1$ & $\begin{array}{l}\text { 1. Collapse Pulsing } \\
(6 \mathrm{~min}) \\
\mathrm{V}_{\text {air }}=70 \mathrm{~m} / \mathrm{hr} \\
\mathrm{V}_{\text {water }}=8 \mathrm{~m} / \mathrm{hr} \\
\text { 2. High Rate Water } \\
\text { Flush: } \\
\quad(3 \mathrm{~min}, 20 \mathrm{sec}) \\
\mathrm{V}_{\text {water }}=18 \mathrm{~m} / \mathrm{hr} \\
(20 \%) \\
\text { 3. Low Rate Water } \\
\text { Flush: }(2 \mathrm{~min}) \\
\mathrm{V}_{\text {water }}=12 \mathrm{~m} / \mathrm{hr} \\
(10 \%)\end{array}$ & $\begin{array}{c}\text { Without } \\
\text { ETSW: } \\
4.5 \\
\text { With ETSW: } \\
6.28\end{array}$ & $\begin{array}{c}\text { Without } \\
\text { ETSW: } \\
1 \\
\\
\text { With } \\
\text { ETSW: } \\
1.4\end{array}$ \\
\hline $40 \% \mathrm{SV}$ & 3 & $25: 5: 1$ & $\begin{array}{l}\text { 1. Collapse Pulsing } \\
(6 \mathrm{~min}) \\
\mathrm{V}_{\text {air }}=70 \mathrm{~m} / \mathrm{hr} \\
\mathrm{V}_{\text {water }}=8 \mathrm{~m} / \mathrm{hr} \\
\text { 2. High Rate Water } \\
\text { Flush: } \\
\quad(1 \mathrm{~min}, 37 \mathrm{sec}) \\
\mathrm{V}_{\text {water }}=37 \mathrm{~m} / \mathrm{hr} \\
(40 \%) \\
\text { 3. Low Rate Water } \\
\text { Flush: }(2 \mathrm{~min}) \\
\mathrm{V}_{\text {water }}=12 \mathrm{~m} / \mathrm{hr} \\
(10 \%)\end{array}$ & $\begin{array}{c}\text { Without } \\
\text { ETSW: } \\
4.5 \\
\text { With ETSW: } \\
6.28\end{array}$ & $\begin{array}{c}\text { Without } \\
\text { ETSW: } \\
1 \\
\text { With } \\
\text { ETSW: } \\
1.4\end{array}$ \\
\hline
\end{tabular}




\begin{tabular}{|c|c|c|c|c|c|}
\hline $20 \%$ ST & 4 & $\begin{array}{c}\text { 25:5:1 } \\
\text { Turbidity } \\
\text { Addition } \\
\text { Phase }\end{array}$ & $\begin{array}{l}\text { 1. Collapse Pulsing } \\
(6 \mathrm{~min}) \\
\mathrm{V}_{\text {air }}=70 \mathrm{~m} / \mathrm{hr} \\
\mathrm{V}_{\text {water }}=8 \mathrm{~m} / \mathrm{hr} \\
\text { 2. High Rate Water } \\
\text { Flush: }(2 \mathrm{~min}) \\
\mathrm{V}_{\text {water }}=18 \mathrm{~m} / \mathrm{hr} \\
(20 \%) \\
\text { 3. Low Rate Water } \\
\text { Flush: }(2 \mathrm{~min}) \\
\mathrm{V}_{\text {water }}=12 \mathrm{~m} / \mathrm{hr} \\
(10 \%)\end{array}$ & $\begin{array}{c}\text { Without } \\
\text { ETSW: } \\
3.53 \\
\text { With ETSW: } \\
5.49\end{array}$ & $\begin{array}{c}\text { Without } \\
\text { ETSW: } \\
0.78 \\
\\
\text { With } \\
\text { ETSW: } \\
1.22\end{array}$ \\
\hline
\end{tabular}

\section{Analytical Methods}

DOC analysis was conducted based on Persulfate Ultraviolet Oxidation Method in Standard Methods 5310C (APHA, 2012). A SHIMADZU TOC-VCPH/ CPN total organic carbon analyzer was used. All samples were filtered through a $0.45 \mu \mathrm{m}$ filter prior to each analysis. DO measurements were conducted using Thermo Scientific ORION DO probe. Phospholipids measurements were based on the method described by Wang et al. (1995), it involves lipids extraction using a chloroform methanol mixture, followed by a digestion step using potassium persulfate and finally ammonium molybdate and malachite green addition followed by a calorimetric measurement at $610 \mathrm{~nm}$. ATP measurements were conducted using a Deposit and Surface Analysis test kit (LuminUltra Technologies Ltd) and a Luminometer. The test steps involve calibration, sample preparation, and total ATP analysis. Turbidity measurements: influent turbidity measurements were performed using a portable HACH turbidimeter. For each biofilter, the effluent turbidity prior to and post backwash was monitored by an inline low range turbidimeter (HACH, Filter Track 660). Particle counts measurements were carried out using a Bright Well Technologies INC. Dynamic Particle Analyzer (BP-4100-HEV). A BP-1400-FC-100-U flow cell was used. Temperature and $\mathbf{p H}$ were measured using Thermo Scientific ORION 087003 probe. In order to determine DOC removals, influent and effluent samples were collected three times per week during phase 1 ( $\mathrm{n}=63$ for each investigated backwash strategy). Starting from phase 2, samples were collected immediately before backwash and at different time intervals after backwash $(1,4,6,24$, and 48 hours) (phase 2: $\mathrm{n}=29$, phase $3: \mathrm{n}=24$, phase 4: $n=18$ ) 


\subsection{Results and Discussion}

\subsubsection{Impact of Backwashing Procedures on DOC Removals}

The impact of collapse pulsing backwash was investigated during the nutrient limited stage of the experiments. This phase had a C:N:P ratio of 546:24:1 on a weight basis. According to LeChevallier et al. (1991), a C:N:P ratio of 100:10:1 on a mol basis is required for organic carbon removal, this corresponds to a ratio of 39:4.5:1 on a weight basis. Therefore, a ratio of 546:24:1 would not lead to optimal biomass performance. Figure 4.2 compares the $\%$ DOC removals for $30 \% \mathrm{~W}$ and $30 \%$ Control in a box and whisker plot. Box and whisker plots give an enhanced representation of the data distribution as they show the median (the middle line in the square), and the first and third quartiles indicated by the bottom and top ends of the square respectively. In addition to that, the ends of the vertical lines represent the maximum and minimum values reported. Adding air to the backwashing strategy resulted in significantly higher $\%$ DOC removals $(\alpha=0.05)$. Median $\%$ DOC removals went from $13 \%$ when water only backwash was employed to approximately $21 \%$ when collapse pulsing was added to the backwash strategy. These findings indicate that collapse pulsing is a more efficient backwashing method even under conditions in which biological activity is stressed. A potential explanation for the success of collapse pulsing would be related to biofilm thickness; by the end of the filtration cycle biofilm thickness reaches a critical level that limits the diffusivity of the essential substrate and dissolved oxygen (Simpson, 2008). The combination of air and water provides for greater media collisions and abrasions during backwash (Amirtharajah, 1993). This would result in greater detachment of biomass as compared to a water only backwash. Therefore, collapse pulsing could successfully reduce the excess biofilm layer resulting in a thinner more active biofilm at the conclusion of the backwash step. Indeed, Ahmad and Amirtharajah (1998) reported higher effluent microbial counts when they adapted a backwash strategy that utilized water only as compared to when collapse pulsing was employed. This happened due to the shearing of the thick biofilm that was not successfully removed when air was absent. However, in contrast to the findings reported in this paper the authors did not observe any improvements with AOC removal when collapse pulsing was utilized. Similar conclusions emerged from (Liu et al., 2001), the authors observed no significant impact on BOM removal as a result of backwashing under collapse pulsing conditions in which the 
$\mathrm{C}: \mathrm{N}: \mathrm{P}$ ratio was 15:5:1 on w/w basis. On the other hand, Emelko et al. (2006) observed statistically higher oxalate removals when air scouring was utilized under cold water temperatures of 1 to $3^{\circ} \mathrm{C}$. This finding, in addition to the one reported in this paper, provide insight that the use of collapse pulsing can be beneficial under conditions of bacterial duress such as cold water temperatures or limited nutrients conditions.

It is also important to note that it was challenging to completely fluidize the media bed during the first two minutes of backwashing under the water only backwash due to the biofilter's wall effects. However, this phenomenon was eliminated when air was incorporated into the backwash strategy which might also explain the lower \% DOC removals obtained under $30 \% \mathrm{~W}$.

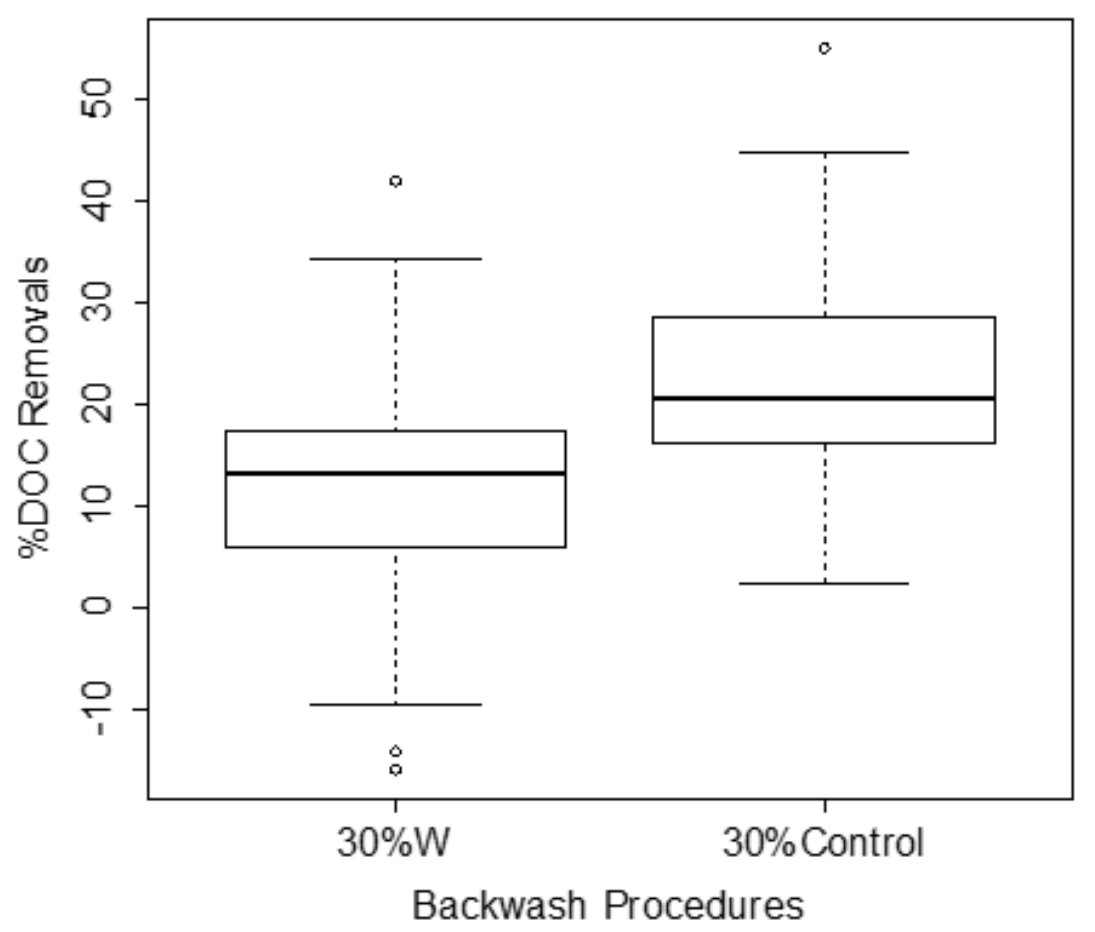

Figure 4.2- Impact of Collapse Pulsing on \% DOC Removals under Nutrient Limited Conditions 
Different bed expansions were investigated to study their impacts on biofiltration after employing collapse pulsing. These experiments were conducted under a C:N:P ratio of 25:5:1 on w/w basis to reflect the nonlimiting nutrient case and ensure DOC removal was not limited by low nutrient availability. Figure 4.3 compares the \% DOC removals associated with each investigated backwash with respect to the control backwash. The median DOC removal ranged from $24 \%$ to $38 \%$ throughout the experiments shown in figure 4.3. As it can be seen, $20 \% \mathrm{SV}$ resulted in a median $35 \%$ DOC removal which is comparable to the $34 \%$ median value observed with $30 \%$ Control. These results suggest that employing a low bed expansion while using the same amount of water volume as a higher bed expansion has no significant impact on the DOC removal. When the bed expansion was increased to $40 \% \mathrm{SV}$, it caused an adverse result with regards to DOC removal $(\mathrm{p}<0.05)$. The median DOC removal decreased to $24 \%$ compared to $30 \%$ DOC removal with the 30\%Control condition. In contrast Ahmad et al. (1998) observed improved AOC removals with increasing \% bed expansions (15\%, 25\%, and 50\%). Their results indicated that the lowest effluent AOC and NPOC values corresponding to $10 \mu \mathrm{g} / \mathrm{L}$ and $1.74 \mathrm{mg} / \mathrm{L}$ respectively were observed under $50 \%$ expansion. However, the authors argued that the variations in influent AOC concentrations may have impacted the results.

$20 \% \mathrm{SV}$ lead to the same results as $30 \%$ Control with respect to DOC removals. Therefore, the next step was to investigate if savings on backwash water volume could be achieved by decreasing the time duration of the $20 \%$ bed expansion to follow the same 2 minutes duration as the $30 \%$ expansion employed in the control backwash. In addition to that, because the influent turbidity was low, turbidity was added into the influent in the form of kaolin clay to increase it from an average of 0.3 NTU to about 4 NTU. However, flow control issues lead to variations in influent turbidity which was as high as 24 NTU during certain experiments. Nevertheless, this was believed to mimic real situations where spring runoffs and heavy rain events may lead to high particles load and sudden turbidity increase. High particles concentration could impact biofiltration performance by interfering with the biomass substrate uptake (Liu et al., 2001). In this study, similar (35\% versus 36\%) \% DOC removals were obtained with both low (0.3 NTU) and high (12 NTU) turbidity water respectively. As illustrated in figure 4.3, 20\%ST removals are not significantly lower (p>0.05) than $30 \%$ Control removals with them ranging from $15 \%$ to $50 \%$ and from $20 \%$ 
to $52 \%$ for $20 \% \mathrm{ST}$ and $30 \%$ Control respectively suggesting that under these conditions backwash optimization based on overall productivity could be achieved without compromising DOC removal. Savings of $22 \%$ on the use of total backwash water volume could be achieved when employing $20 \%$ ST versus employing 30\%Control (Table4.1).

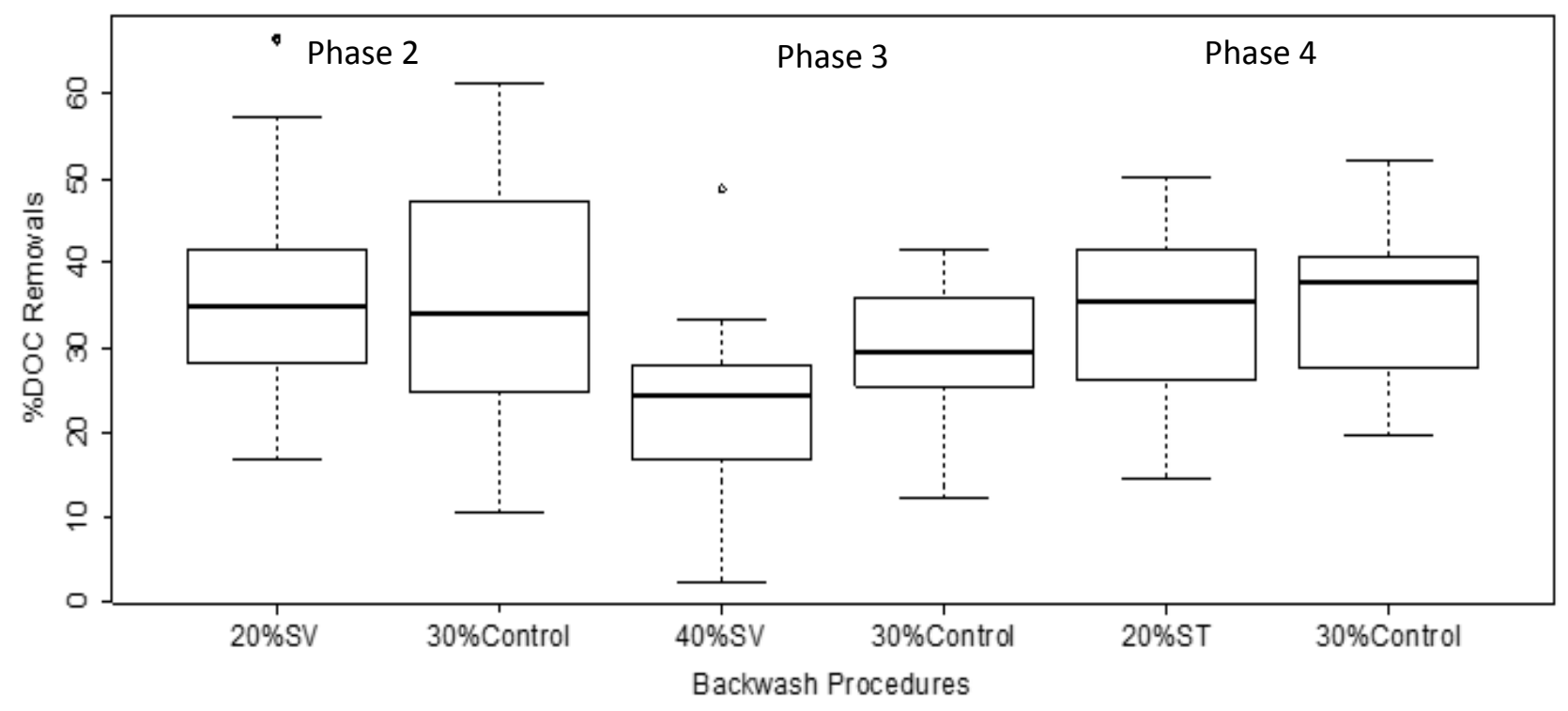

Figure 4.3- Impact of Different Bed Expansions on \% DOC Removals

ETSW is an additional flushing step performed at the conclusion of the normal backwashing procedure in which the media is subfluidized for sufficient time duration to pass one theoretical volume of water upward through the filter bed to minimize or prevent the filter ripening time period (Amburgey and Amirtharajah, 2005). Although this additional flushing step lengthens the duration of the backwashing stage and requires a higher quantity of backwash water, the extra water usage and time out of service are compensated by savings after restart when taking into account the overall productivity of the process. Figure 4.4 shows the $\%$ DOC removals associated with $20 \% \mathrm{SV}, 40 \% \mathrm{SV}$, and $20 \%$ ST with and without ETSW. The median $\%$ DOC removal for $20 \%$ SV was $35 \%$ when ETSW was absent and 34\% when ETSW was added. Similarly, $40 \%$ SV had a median of $24 \%$ without ETSW and $22 \%$ with ETSW. While the ETSW step for $20 \%$ ST gave a median 
of 33\% compared to 36\% when ETSW was absent. Clearly, the additional flushing stage due to the ETSW procedure does not impair nor improve DOC removal. These findings provide insight on the fact that ETSW could be optimized for a successful filter ripening sequence elimination without the fear of compromising BOM removal.

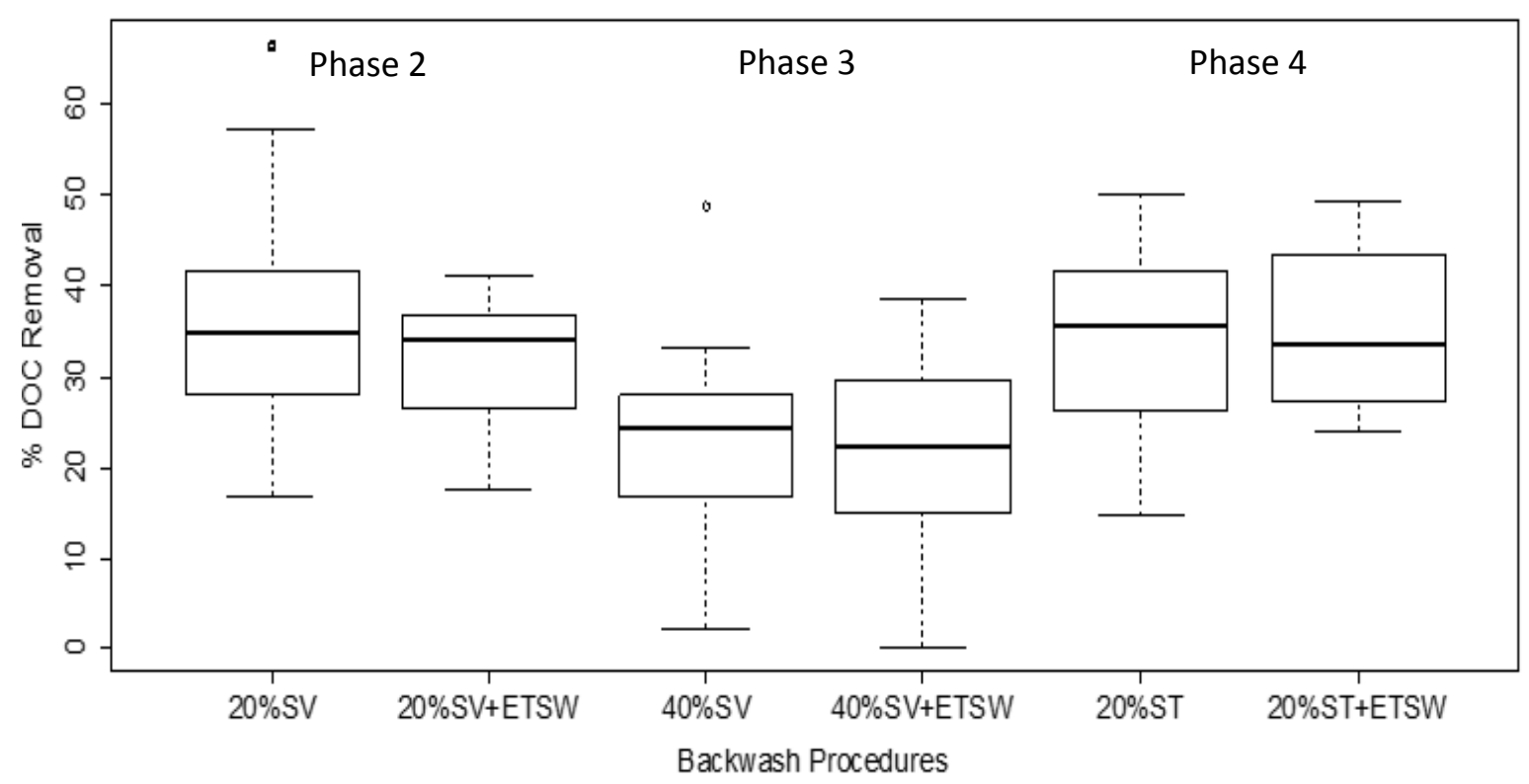

Figure 4.4- Impact of ETSW Addition on \% DOC Removals

$$
E T S W V_{\mathrm{m} \mathfrak{a} @ 20^{\circ} \mathrm{C}}=9.5 \mathrm{~m} / \mathrm{hr}
$$

\subsubsection{Indirect Measurements of DOC Uptake: Biomass and Dissolved Oxygen}

In order to better understand and optimize biological filters performance, it is necessary to monitor for a secondary parameter that directly correlates to DOC removal. It is well established that biofiltration performance in terms of organics removal is highly dependent on microbial activity (Simpson, 2008). Therefore, several attempts with varying levels of success have been carried out to estimate substrate removal in biological filters through directly measuring the amount of biomass attached to the media (Emelko et al., 2006; Liu et al., 2001; Huck et al., 2000; Wang et al., 1995), by measuring the quantity of ATP present in the biofilm (Gibert et al., 2013; Velten et al., 2007; Knezev et al., 2004), and by measuring the DO uptake rate (Urfer and Huck, 2001). In this study, three potential 
measurements that could correlate to DOC removals were monitored for; phospholipids, ATP, and dissolved oxygen uptake.

\section{Biomass (Phospholipids and ATP)}

Media samples were taken from the top sampling port (located at $5 \mathrm{~cm}$ below the media surface) for each biofilter before and 1 hour after backwash to carry out phospholipids analysis. Along with that, DOC samples were taken at the same time steps to examine if a relationship between DOC removal and top of filter phospholipids concentrations could be established. Backwashing did not show any apparent trend regarding its impact on biomass concentration for all the procedures investigated in this study including the ones that were terminated by the ETSW. Phospholipids concentrations ranged between 7 to $490 \mathrm{nmol} \mathrm{P} / \mathrm{g}$ media before backwash and from 8 to $331 \mathrm{nmol} \mathrm{P/g}$ media after backwash for both biofilter columns. Biomass concentrations, decreased, increased, or remained unchanged after backwash. The reasons behind these unexpected findings are not well understood. Media collisions and abrasions caused by collapse pulsing are expected to result in an intense media cleaning hence higher biofilm detachment resulting in lower biomass concentrations after backwash (Huck et al. 2000; Ahamd et al., 1998; Emelko et al., 2006; Servais et al., 1991; Liu et al., 2001). In this study collapse pulsing was followed by a primary $(20 \%$, $30 \%$, or $40 \%$ bed expansion) high water wash, and then a lower water wash at $10 \%$ bed expansion which is similar to full scale plant operation, perhaps these two consecutive washes redistributed the loose biomass that was detached from different media depths. The loose biomass aggregates may have ended up near the top media surface by the end of the backwashing step which resulted in an increase in some of the biomass readings following backwash.

Figure 4.5 (A) shows the phospholipids concentration versus the difference between influent and effluent DOC. As can be seen, regardless of the biomass concentration, most of the DOC removal lies between 2 to $6 \mathrm{mg} / \mathrm{L}$, therefore it is evident that there is no direct correlation between surface biomass as measured by the phospholipids method and DOC removal. In contrast, in a pilot scale study, Wang et al. (1995) observed 25\% higher TOC removals with a sand biofilter that had $30 \%$ higher biomass concentrations compared to a dual media anthracite-sand biofilter. However, in the same study, the authors argued that the relationship between phospholipids and biofiltration performance is unclear as the 
removal of other parameters did not improve under the higher biomass concentrations (AOC-NOX, THMFP, and TOXFP). Huck et al. (2000) observed a drop in phospholipids biomass concentration in the first $4 \mathrm{~cm}$ of the filter media by about $52 \%$ following backwashing under collapse pulsing conditions, however, this significant drop had no major impact on BOM removal and similar to this research no direct relationship was established between phospholipids concentrations and biofiltration performance.

Analogous to the phospholipids measurements, media sampling for ATP quantification was conducted immediately before and 1 hour after backwash along with the DOC sampling. Impact of backwashing conditions on biofilter biomass in terms of the ATP concentration is very limited in literature (Pharand et al., 2014). ATP is the main energy carrier by all cell organisms; it is only formed by the energy obtained from oxidation reduction reactions and is depleted rapidly following cell death or substrate limitation (Pharand et al., 2014). Therefore, ATP quantification could represent a reliable method for active biomass estimation contributing to the DOC removal. Figure 4.5 (B) shows the combined before and after backwash top of media ATP data for both biofilters versus DOC removal. Similar to the phospholipid data, none of the backwashing procedures investigated had a clear impact on the biomass measured in terms of ATP. ATP concentration decreased, increased, or remained unchanged following backwashing. Top of media ATP concentrations ranged between 12 to $7777 \mathrm{ng} \mathrm{ATP/g}$ media before backwash and from 16 to $2401 \mathrm{ng} \mathrm{ATP} / \mathrm{g}$ media after backwash.

Interpretation of these data provides evidence that no direct relationship exists between DOC removal and biomass concentration as measured by the ATP method. Unlike the results obtained from this study, Lauderdale et al. (2012) observed a correlation between ATP measurements and biofiltration performance, as increased ATP concentrations corresponded to higher $\mathrm{DOC}, \mathrm{Mn}$, and MIB removals under nutrient supplemented conditions. Similarly, Nadiu et al. (2013) observed higher AOC removals associated with higher ATP values for biofilters used for seawater desalination. On the other hand, some other research reported no apparent correlation between ATP and biofiltration performance (Velten et al., 2011; Pharand et al., 2014; Vahala et al., 1998). It is important to note that measurements taken from the media surface do not necessarily represent ATP 
concentration throughout the entire filter depth. A pilot scale study conducted by Zhang et al. (2010) revealed that as biofiltration performance reached steady state, ATP concentrations at three different bed depths did not show any variations with them being $1024 \mathrm{ng} \mathrm{ATP} / \mathrm{g}$ media at the top, $995 \mathrm{ng} \mathrm{ATP} / \mathrm{g}$ media at the middle, and $935 \mathrm{ng}$ ATP/g media at the bottom. This indicates that DOC removal might take place at multiple locations within the filter bed. Similarly, in this research ATP values taken from the middle sampling port located at $18 \mathrm{~cm}$ media depth (not shown) ranged between 16 to $785 \mathrm{ng}$ ATP/g media before backwash and 27 to $1972 \mathrm{ng}$ ATP/g media after backwash for both biofilter columns. In addition to that, caution must be taken when interpreting ATP data as there could be a potential contribution in the measurements from the free extracellular ATP which is not easily distinguished from the microbial ATP (Hammes et al., 2010).
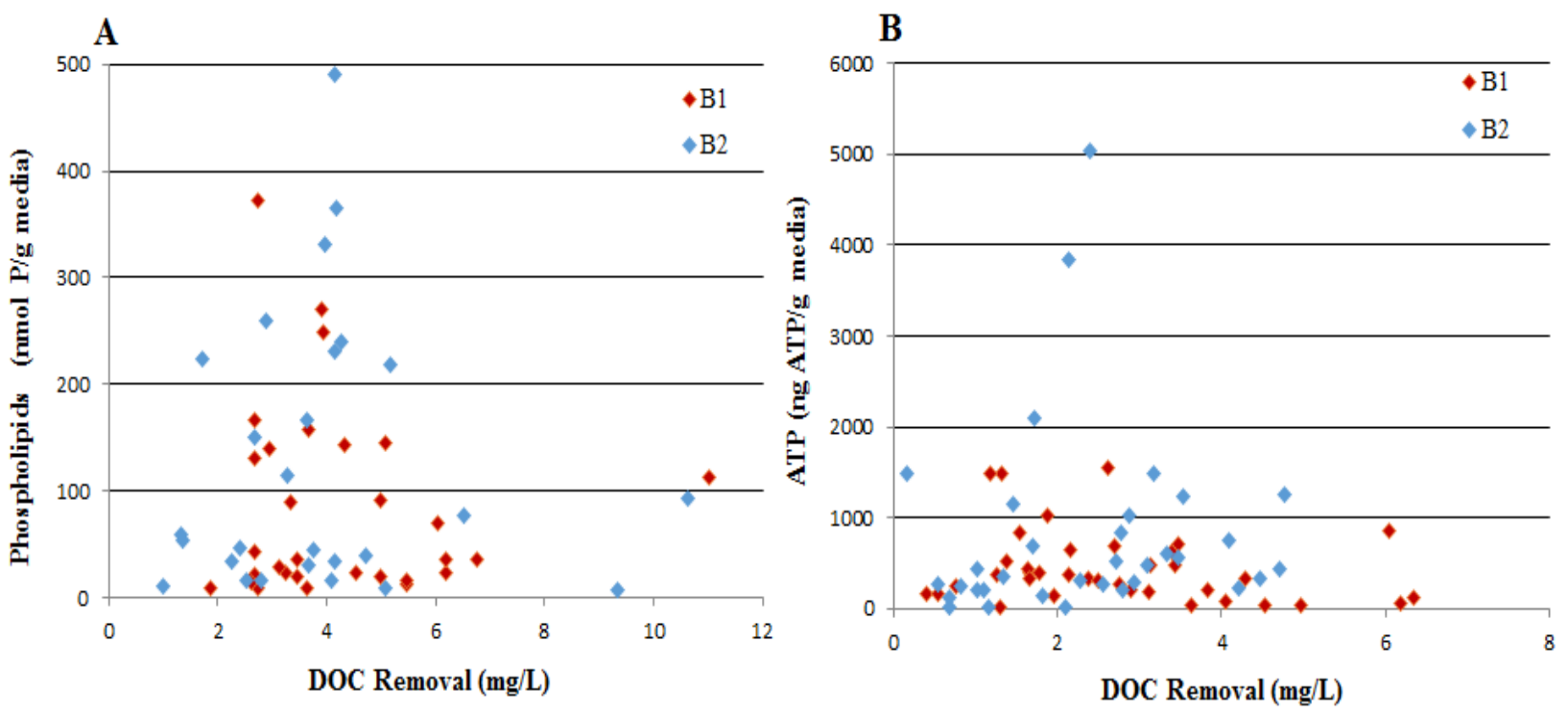

Figure 4.5- Relationship between Biomass and DOC Removal: A- Relationship between Phospholipids and DOC Removal and B- Relationship between ATP and DOC Removal 
Phospholipids and ATP findings point out to the need of a more reliable technique for estimating microbial activity across the biofilter. The next section highlights on the use of dissolved oxygen uptake as a method to predict biofiltration performance in terms of dissolved organic carbon removal.

\section{Dissolved Oxygen Uptake}

Biofiltration for the purpose of biodegradable organic matter removal is an aerobic process in which oxygen acts as the electron donor for the heterotrophic bacteria (Ghannoum and O'Toole, 2004). Therefore, oxygen uptake could be directly related to microbial activity with regards to dissolved organic carbon removal. The use of oxygen consumption as a method for estimating biological activity of biofilms has been used extensively in wastewater treatment studies specifically in activated sludge processes (Shariati et al., 2013; Meric et al., 2003; Orupold et al., 1999; Yoong et al., 1999). However, this technique has received little attention in drinking water treatment studies.

In this research, influent and effluent dissolved oxygen measurements were obtained at the same time intervals in which DOC sampling was conducted to assess if a direct relationship exists between these two parameters. Figure 4.6 and figure 4.7 represent DOC removal versus DO uptake in $\mathrm{mg} / \mathrm{L}$. Figure 4.6 also demonstrates the DO and DOC removals associated with each backwash strategy. The increasing pattern of DOC removal with respect to DO uptake illustrated in these figures provides evidence on the dependent relationship that exists between these two parameters. At DO uptake levels of less than 4 $\mathrm{mg} / \mathrm{L}$, DOC removals ranged between 0.5 to $2 \mathrm{mg} / \mathrm{L}$, whereas at DO uptake levels larger than $8 \mathrm{mg} / \mathrm{L}$ DOC removals ranged between 1.5 to $6 \mathrm{mg} / \mathrm{L}$ (figure 4.7). This signifies that tracking dissolved oxygen at the influent and effluent levels of the biofilters provides a useful tool for assessing biofiltration performance and estimating microbial activity throughout the entire bed depth.

In addition to that, these findings may shed light on the need for sufficient dissolved oxygen concentration to allow for efficient DOC removal. Careful interpretation of these data indicates that with increasing DO concentrations increasing DOC removal is observed. This suggests that substrate utilization is linked to the presence of certain dissolved oxygen concentrations. These findings refer to the need for more research in which influent 
dissolved oxygen concentration is varied in biofilters to be able to identify the critical DO concentration that allows for optimum DOC removal. Nevertheless, based on these results, it is believed that when sufficient oxygen concentrations are present, DO uptake represents a helpful and easy tool for assessing the presence of microbial activity in biofilters without the need of conducting other measurements that require sophisticated devices in many situations.

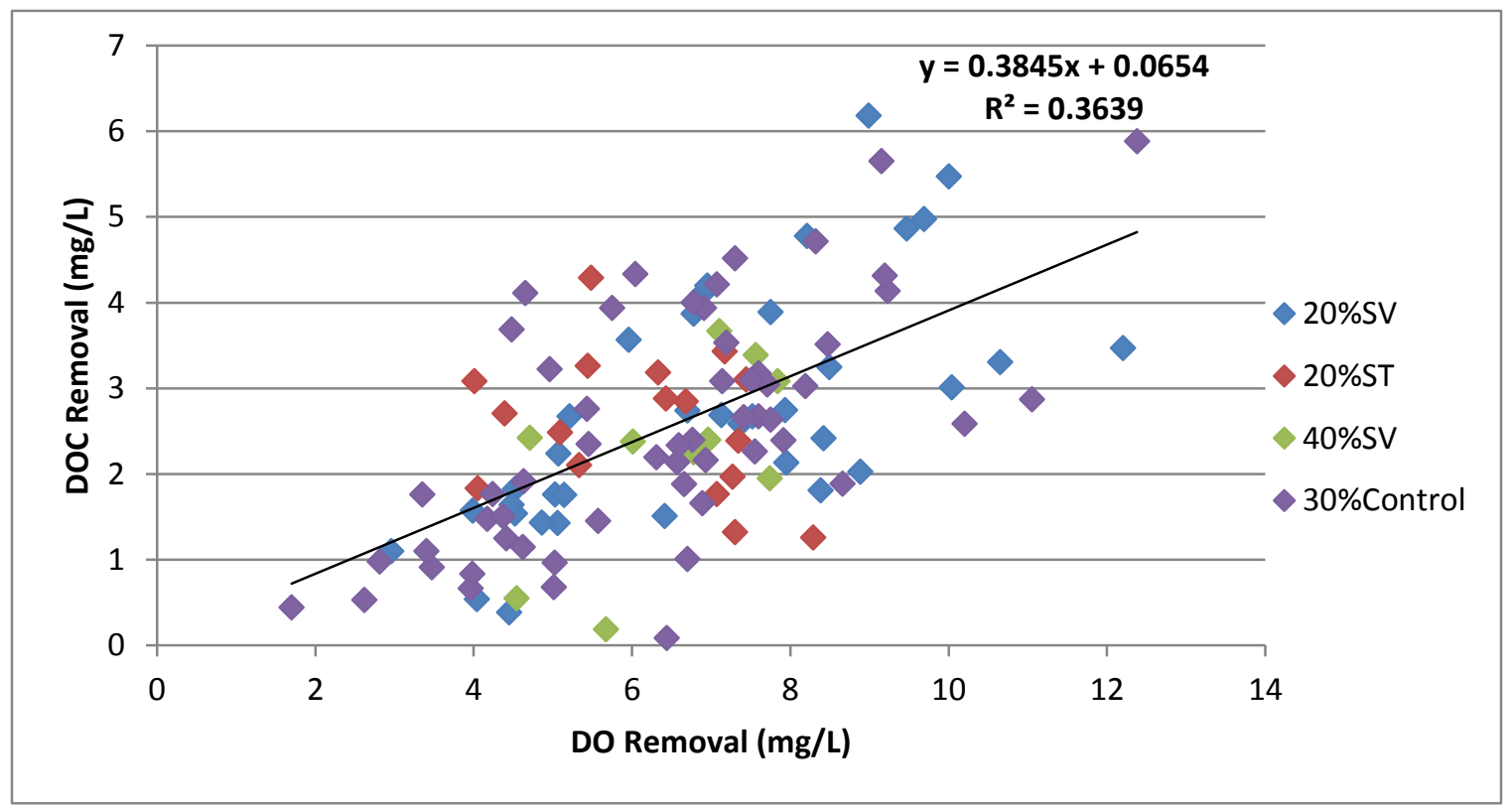

Figure 4.6- Relationship between DOC Removal and DO Uptake 


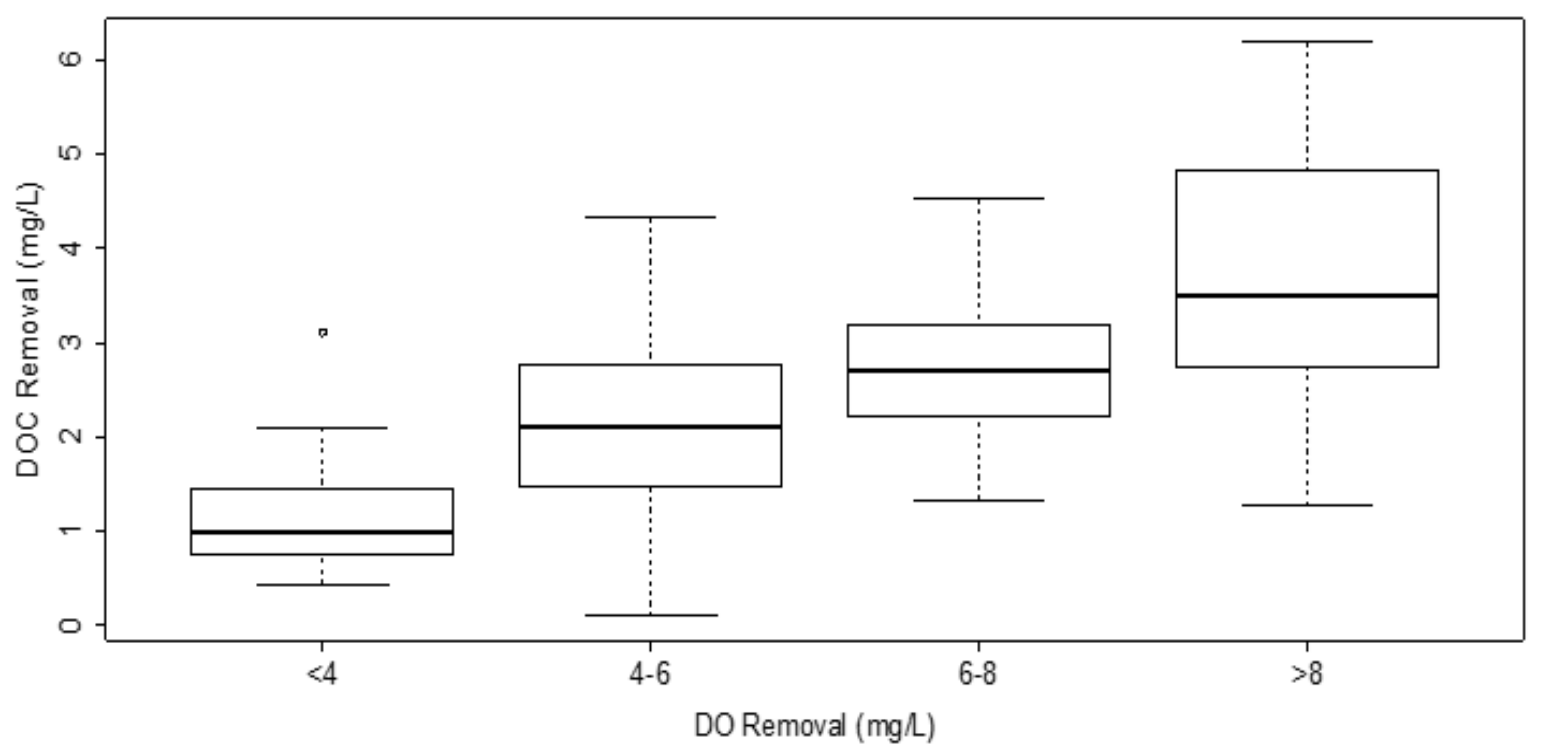

Figure 4.7- Relationship between DOC Removal and DO Uptake

\subsubsection{Impact of Backwashing Procedures on Particles Removal}

Turbidity is one of the main parameters monitored on a continuous basis for assessing a filters' performance. Filter ripening, a problem that is common to all drinking water treatment facilities, is a stage of high effluent turbidity observed following backwashing (Amburgey and Amirtharajah, 2005). The main concern associated with this period is the potential breakthrough of pathogens of public health concern such as Cryptosporidium and Giardia (Emelko et al., 2003). Because of the guidelines requirements, and the risks associated with the ripening period, drinking water treatment facilities strive to minimize the duration and intensity of this stage as much as possible. In this study, effluent turbidity was monitored using a low range online laser turbidity meter for several backwashing experiments. Figure 4.8 (A and B) compares the results of effluent turbidities following $30 \%$ Control, $20 \% \mathrm{SV}$, and $20 \% \mathrm{SV}+\mathrm{ETSW}$ for two experimental trials. Filter to waste (FTW) was defined as the period starting immediately after restart until effluent turbidity starts improving and reaches 0.3 NTU. In the two experimental trials shown in figure 4.8, FTW duration for $20 \% \mathrm{SV}$ was $75 \mathrm{~min}$ in trial 1 and $90 \mathrm{~min}$ in trial 2. Similarly FTW duration was $60 \mathrm{~min}$ for $30 \%$ Control at trial 1 and $75 \mathrm{~min}$ at trial 2 . These results indicate that both backwashing strategies investigated result in similar biofilter performance and 
that they are equally effective in meeting the current guideline of $0.3 \mathrm{NTU}$ following the ripening period (Health Canada, 2014). However, it should be noted that neither $20 \% \mathrm{SV}$ nor the $30 \%$ Control showed consistency in terms of FTW duration and the maximum turbidity reached. Similarly, although in general the $40 \% \mathrm{SV}$ resulted in lower turbidity peaks compared to the $30 \%$ Control (figure $4.8 \mathrm{C}$ and D), neither of the two monitored backwashes showed consistency in terms of turbidity peaks and FTW duration. The reasons behind this behavior are not well understood. A possible explanation for that would be the absence of coagulation prior to the filtration step. It is well established that conventional water treatment plants employ coagulation prior to filtration for the removal of turbidity and organic matter (Yu et al., 2007). Zhu et al. (1996) observed higher turbidity peaks and longer FRS durations when coagulation was absent compared to when influent water was coagulated using different polymers. Similarly, Amburgey and Amirtharajah (2005) reported long ripening periods' durations of approximately 2 hours under cold water temperatures $\left(8^{\circ} \mathrm{C}\right)$ which was associated with an improper alum coagulation step.

Figure 4.8 also depict the impact of adding the ETSW on effluent turbidity following restart. The concern with adding ETSW in biological filters is related to the possibility that the biofilm present on the media could play a role in retaining particles thus preventing them from being flushed out (Amburgey, 2004). As shown in both figures, excellent turbidity removal is obtained when the ETSW is employed. The $300 \mathrm{mNTU}$ (0.3 NTU) threshold value is never exceeded in any of the ETSW experiments. Although adding this step requires additional water usage this increase in backwash water volume is offset by the absence of FRS that may take up to two hours and result in wasting treated water. 

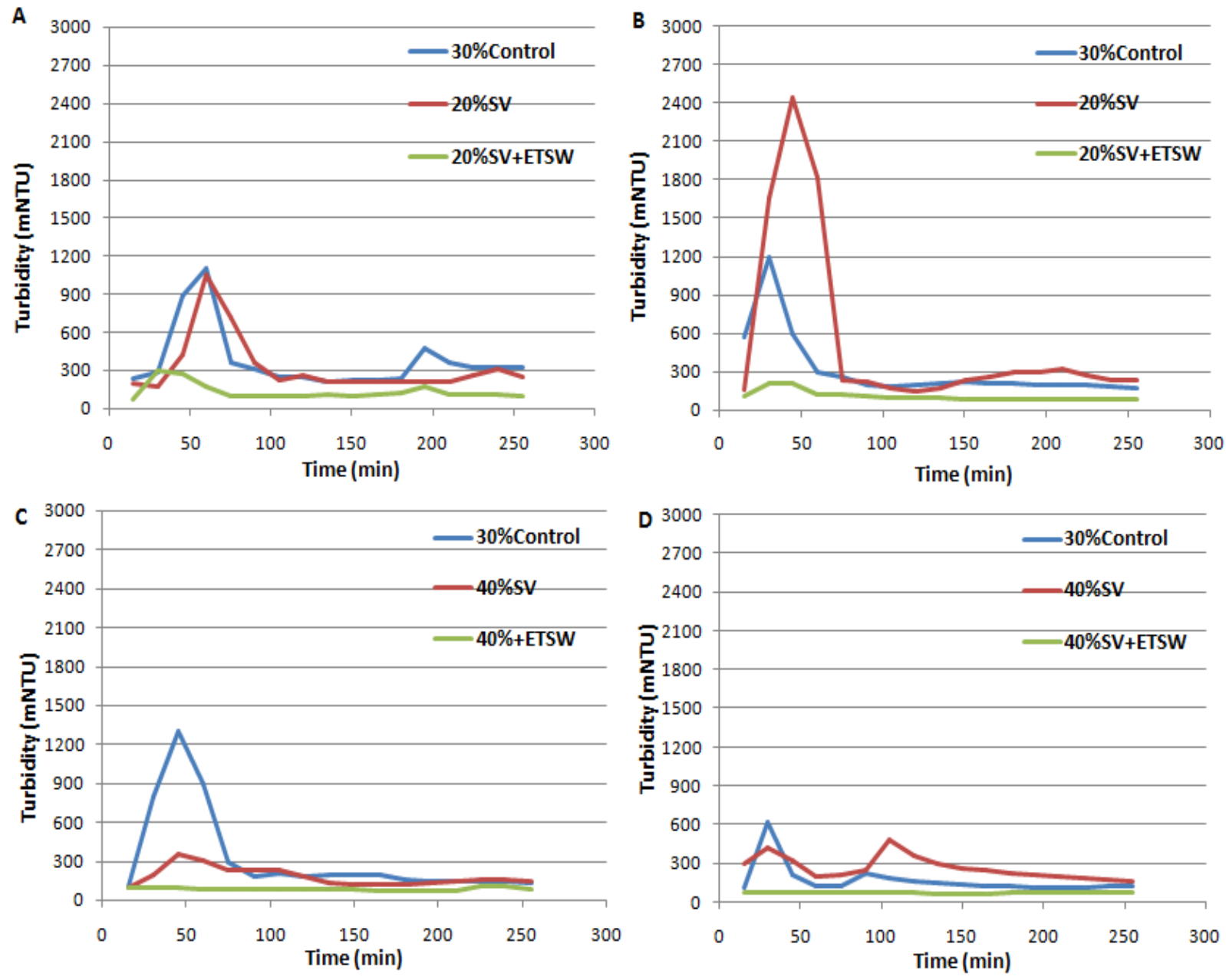

Figure 4.8- Impact of Backwash Procedures on Effluent Turbidity: A- Phase 2 Trial 1, B- Phase 2 Trial 2, C- Phase 3 Trial 1, and D- Phase 3 Trial 2

Table 4.2 shows the average effluent particle counts along with their relative standard deviations (RSD) after backwash for the experiments conducted in phase 2. Among the three investigated backwash strategies during phase 2, 20\%SV followed by the ETSW showed the lowest particle counts values and the lowest relative standard deviations. These low RSD values indicate lower fluctuations in the particles concentrations exiting the biofilter following restart when ETSW is added as compared to when ETSW is absent. These findings are consistent with the turbidity results that showed more stable biofilter performance during the FRS when ETSW was employed. Another important observation here is that in general the $20 \% \mathrm{SV}$ backwash procedure resulted in higher effluent particle 
counts concentrations compared to $30 \%$ Control. Even at 1 hour after restart the average particle counts values were still higher for $20 \% \mathrm{SV}$ as compared to $30 \%$ Control (10482 versus $15987 \mathrm{particles} / \mathrm{mL}$ for $30 \%$ Control and $20 \% \mathrm{SV}$ respectively). Therefore, although no apparent differences existed between $30 \%$ Control and $20 \% \mathrm{SV}$ in terms of DOC removal, however, backwash optimization in terms of DOC removal cannot be achieved while compensating particles removal. As a results when the implementation of ETSW is not feasible for a certain water treatment facility it is recommended to employ a higher bed expansion to avoid the risks that are associated with higher effluent particles concentrations.

Table 4.2- Comparison of Effluent Particle Counts for Phase 2 Backwash Strategies $(0.75-100 \mu \mathrm{m})$

\begin{tabular}{|c|c|c|c|c|c|c|}
\hline \multicolumn{7}{|c|}{ Effluent Particle Counts (\#/mL) } \\
\hline \multirow{2}{*}{$\begin{array}{c}\text { Time } \\
\text { After } \\
\text { Restart } \\
(\text { min) }\end{array}$} & \multicolumn{2}{|c|}{ 30\%Control } & \multicolumn{2}{|c|}{$20 \%$ SV } & \multicolumn{2}{|c|}{$20 \%$ SV + ETSW } \\
\hline & Mean & RSD & Mean & RSD & Mean & RSD \\
\hline 5 & 208,631 & 0.98 & $1,683,872$ & 1.93 & 39,682 & 0.83 \\
\hline 10 & 389,631 & 1.14 & 394,777 & 1.18 & 14,215 & 0.81 \\
\hline 15 & 62,629 & 0.80 & 372,358 & 1.53 & 12,871 & 0.52 \\
\hline 20 & 60,439 & 1.52 & 136,617 & 1.85 & 18,052 & 1.04 \\
\hline 30 & 28,276 & 1.04 & 130,326 & 1.93 & 18,854 & 0.70 \\
\hline 40 & 16,936 & 0.66 & 109,396 & 2.03 & 11,714 & 0.62 \\
\hline 50 & 10,559 & 0.36 & 11,975 & 0.69 & 9,482 & 0.51 \\
\hline 60 & 10,482 & 0.57 & 15,987 & 1.45 & 5,569 & 0.37 \\
\hline
\end{tabular}




\subsection{Summary and Conclusions}

In this study, a lab scale biofiltration system was used to examine the implications of different backwash strategies on DOC removal, backwash water usage, and effluent turbidity. The following conclusions can be made from these investigations:

- Adding collapse pulsing to the backwash strategy under nutrient limited conditions improved DOC removals compared to a water only backwash (13\% versus $21 \%$, respectively).

- Employing a lower bed expansion, $20 \%$ versus $30 \%$, while using the same amount of water demonstrated no impact on DOC removal (35\%). However, employing a $40 \%$ bed expansion while using the same amount of backwash water volume as the $30 \%$ control lead to significantly lower DOC removals (6\% decrease).

- Employing a $20 \%$ bed expansion under the same duration of backwash fluidization as the $30 \%$ also had no impact on DOC removal resulting in approximately a $20 \%$ savings in water required to backwash the biofilters.

- DO uptake demonstrated a direct correlation to DOC removal. Influent DO concentrations may have a potential impact on biomass substrate uptake and more research is needed to clarify this. Biomass concentrations as measured by phospholipids and ATP analyses showed no direct correlation with DOC removals.

- ETSW successfully eliminated the filter ripening period, and resulted in lower number of particles exiting the biofilters compared to backwashes that did not employ the ETSW. In addition, the ETSW step did not impact the DOC removal when the filters were back in service. 


\section{References}

1. Ahmad, R., \&Amirtharajah, A. (1998). Detachment of particles during biofilter backwashing. Journal of American Water Works Association, 90 (11), 74-85.

2. Ahmad, R., Amirtharajah, A., Al-Shawwa, A., \& Peter, M. (1998). Effects of backwashing on biological filters. Journal of American Water Works Association, 90 (12), 62-73.

3. Amburgey, J. E., Amirtharajah, A. (2005). Strategic filter backwashing techniques and resulting particle passage. Journal of Environmental Engineering, 131 (4), $535-547$.

4. Amburgey,J.E. (2004). Optimization of the extended terminal subfluidization wash (ETSW) filter backwashing procedure. Water Research, 39 (2-3), 314-330.

5. Amirtharajah, A. (1993). Optimum backwashing of filters with air scour: a review. Water Science \& Technology, 27 (10), 195-211.

6. Amirtharajah, A. (1988). Some theoretical and conceptual views of filtration. Journal of American Water Works Association, 80 (12), 36-46.

7. Amirtharajah, A., (1985). The interface between filtration and backwashing. Water Research, 19 (5), 581-588.

8. Chaudhary, D. S., Vigneswaran, S., Ngo, H. H., Shim, W. G., \& Moon, H. (2003). Biofilter in water and wastewater treatment. Korean Journal of Chemical Engineering, 20 (6), 1054-1065.

9. Colton, J. F., Hillis, P., \& Filtzpatrick, C. S.B. (1996). Filter backwash and startup strategies for enhanced particulate removal. Water Research, 30 (10), 25022507.

10. Emelko, M. B., Huck, P. M., \& Douglas, I. P. (2003). Cryptosporidium and microsphere removal during late in-cycle filtration. Journal of American Water Works Association, 95 (5), 173-182.

11. Emelko, M. B., Huck, P. M., Coffey, B. M., \& Smith, E. F. (2006). Effects of media, backwash, and temperature on full-scale biological filtration. Journal of American Water Works Association, 98 (12), 61-73.

12. François, R. J., \& Van Haute, A. A. (1985). Backwashing and conditioning of a 
deep bed filter. Water Research, 19 (11), 1357-1362.

13. Ghannoum, M. \& O'Toole, G.A. (2004). Microbial Biofilms, ASM Press, Washington, USA.

14. Gibert, O., Benoit, L., Fernandez, M., Bernat, X., Paraira, M., Galderer, M., \& Martinez-Liado, X. (2013). Characterising biofilm development on granular activated carbon used for drinking water production. Water Research, 47 (3), $1101-1110$.

15. Hammes, F., Goldschmidt, F., Vital, M., Wang, Y., \& Egli, T. (2010). Measurement and interpretation of microbial adenosine tri-phosphate (ATP) in aquatic environments. Water Research, 44 (13), 3915-3923.

16. Health Canada. (2014). Guidelines for Canadian Drinking Water Quality Summary Table. Water and Air Quality Bureau, Healthy Enviroments and Consumer Safety Branch, Health Canada, Ottawa, Ontario, 1-25.

17. Hozalski, R., Goel, S., \& Bouwer, E. (1995). TOC removal in biological filters. Journal of American Water Works Association, 87 (12), 40-54.

18. Huck, P.M., B.M. Coffey, A. Amirtharajah and E.J. Bouwer. (2000). Optimizing filtration in biological filters, American Water Works Association Research Foundation Project 252, Report 90793, Denver

19. Kaur, P., \& Fitzpatrick, C. S. B. (2003). Biofllm formation in granular-bed filters. Water and Environmental Journal, 17 (3), 145-148.

20. Kim, T. G., Yun, J., \& Hong, S. (2014). Effects of water temperature and backwashing on bacterial population and community in a biological activated carbon process at a water treatment plant. Applied Microbial Biotechnology, 98 (3), 1417-1427.

21. Lauderdale, C.; Chadik, P.; Kirisits, M.J.; \& Brown, J. (2012). Engineered biofiltration: enhanced biofilter performance through nutrient and peroxide addition. Journal of American Water Works Association, 104 (5), E298-E309.

22. LeChevallier, M. W., Schulz, W., \& Lee, R. G. (1991). Bacterial nutrients in drinking water. Applied and Environmental Microbiology, 57 (3), 857-862. 
23. Liu, X., Huck, P. M., \&Slawson, R. M. (2001). Factors affecting drinking water biofiltration: Filtration. Journal American Water Works Association, 93 (12), 90101.

24. Magic-Knezev, A. \& van der Kooij, D. (2004). Optimization and significance of ATP analysis for measuring active biomass in granular activated carbon filters used in water treatment. Water Research, (38) 18, 3971-3979.

25. Meric, S., Ovez, S., Kaptan, D., \& Orhon, D. (2003). Operational strategies for a small wastewater treatment plant using OUR, microscopic analysis, and toxicity test. Journal of Environmental Science and Health Part a-Toxic/Hazardous Substances \& Environmental Engineering, 38 (10), 2329-2338.

26. Miltner, R. J., Summers, R. S., \& Wang, J. Z. (1995). Biofiltration performance: part 2, effect of backwashing. Journal of American Water Works Association, 87 (12), 64-70.

27. Moll, D. M., Summers, R. S., Fonseca, A. C., \&Matheis, W. (1999). Impact of temperature on drinking water biofilter performance and microbial community structure. Environmental Science \& Technology, 33 (14), 2377-2382.

28. Naidu, G.; Jeong, S.; Vigneswaran, S.; \& Rice, S.A. (2013). Microbial activity in biofilter used as a pretreatment for seawater desalination. Desalination, 309 (0), 254-260.

29. Orupold, K., Hellat, K., \& Tenno, T. (1999). Estimation of treatability of different industrial wastewater by activated sludge oxygen uptake measurement. Water Science Technology, 40 (1), 31-36.

30. Pharand, L., Dyke, M. Van, Anderson, W., \& Huck, P. (2014). Assessment of biomass in drinking water biofilters by adenosine triphosphate. Journal of American Water Works Association, 106 (10), 433-444.

31. Servais, P., Billen, G., Bablon, G. P., \& Ven, C. (1991). Microbial activity in GAC filters at the CHOISY-LE-ROI TREATMENT PLANT. Journal of American Water Works Association, 83 (2), 62-68.

32. Shariati, F. P., Heran, M., Sarrafzadeh, M. H., Mehrnia, M. R., Sarzana, G., Ghommidh, C., \& Grasmick, A. (2013). Biomass characterization by dielectric monitoring of viability and oxygen uptake rate measurements in a novel 
membrane bioreactor. Bioresource Technology, 140 (0), 357-362.

33. Simpson, D. R. (2008). Biofilm processes in biologically active carbon water purification. Water Research, 42(12), 2839-2848.

34. Soucie, W. \& Sheen, B. (2007). Filter-to-waste optimization. Journal of American Water Works Association, 99 (5), 148-157.

35. Standard Methods for the Examination of Water and Wastewater. (2012). American Public Health Association/American Water Works Association/Water Environment Federation, Washington DC, USA.

36. Tchobanoglous, G., Burton, F.L., \&Stensel, H.D. (2003). Wastewater Engineering: Treatment and reuse, McGraw Hill, New York, USA.

37. Urfer, D., \& Huck, P. M. (2001). Measurement of biomass activity in drinking water biofilters using a respirometric method. Water Research, 35 (6), 1469-1477.

38. Urfer, D., Huck, P. M., Booth, S. D. J., \& Coffey, B. M. (1997). Biological filtration for BOM and particle removal: a critical review. Journal of American Water Works Association, 89 (12), 83-98.

39. Vahala, R.; Moramarco, V.; Niemi, R.M.; Rintala, J.; \& Laukkanen, R., (1998). The effects of nutrients on natural organic matter (NOM) removal in biological activated carbon (BAC) filtration. Acta Hydrochim Hydrobiol, 26 (3), 169-199.

40. Velten, S., Hammes, F., Boller, M., \& Egli, T. (2007). Rapid and direct estimation of active biomass on granular activated carbon through adenosine tri-phosphate (ATP) determination. Water Research, 41 (9), 1973-1983.

41. Wang, J. Z., Summers, R. S., \& Miltner, R. J. (1995). Biofiltration performance: part 1, relationship to biomass. Journal of American Water Works Association, 87 (12), 55-63.

42. Yoong, E. T., Lant, P. a., \& Greenfield, P. F. (2000). In situ respirometry in an SBR treating wastewater with high phenol concentrations. Water Research, 34 (1), 239-245.

43. Yu, J., Wang, D., Yan, M.,Ye, C., Yang, M., \& Ge, X. (2007). Optimized coagulation of high alkalinity, low temperature and particle water: $\mathrm{pH}$ adjustment and Polyelectrolytes as Coagulant Aids. Environmental Monitoring and Assessment, 131 (1), 377-386. 
44. Zhang, D.; Li, W.; Wang, K.; Zhang, L.; \& Gong, H., (2010). Bacterial community dynamics and its effects during biological activated carbon filter process for drinking water treatment. 2nd International Conference on Chemical, Biological, and Environmental Engineering, Cairo, Egypt, 137-142.

45. Zhu, H., Smith, D.W., Zhou, H., \& Stanley, S. J. (1996). Improving removal of turbidity causing materials by using polymers as a filter aid. Water Research, 30 (1), 103-114. 


\section{CHAPTER 5 -CONCLUSION AND RECOMMENDATIONS}

This chapter provides an overall summary about the purpose of this research, concludes the main findings and discusses their significance on full scale biological filters, and finally provides recommendations for future work.

\subsection{Overall Summary}

The use of biological filtration in drinking water treatment has become increasingly popular for the past few years. Biological filters have the ability to effectively remove NOM from water resulting in a water that is biologically stable, that has a lower DBPs formation potential, and that requires a lower disinfectant dose (Urfer et al., 1997). In addition to that, biological filtration is one of the most sustainable and cost effective processes that are employed in drinking water treatment industry. As a result, over the years, research has focused on optimizing drinking water treatment plants performance through optimizing biological filters performance. This was achieved by mainly studying the impact of employing different media, varying the EBCTs, and examining the process effectiveness under varying temperatures (Chaudhary et al., 2007). On the other hand, the impact of backwashing hasn't been studied extensively. Similar to conventional filters, biological filters have to be backwashed on a periodic basis to prevent excessive headloss buildup, to regenerate the filtration removal capacity, and to maintain a heathy biomass level. The effectiveness of the backwashing step determines the effectiveness of the entire biological filtration process. Therefore, the overall goal of this research was to develop a better understanding of the biological filtration process by examining the effectiveness of different backwash procedures on biological filters' performance. The backwash strategies investigated in this study were assessed based on their impacts on biofilters' effluent quality in terms of DOC, turbidity, and particles counts. The overall process productivity was also taken into account by examining the duration of the backwash procedure, the backwash water volume used, and the duration of the FTW step. To further increase the overall understanding of biological filtration, the relationship between bifilters' biomass (in terms of phospholipids and ATP) and DOC removal along with the correlation between 
DO uptake and DOC removal were examined. To achieve all of that, a lab scale system consisting of 4 biologically active filters has been used.

The next section highlights on the main findings of this study along with their significance on full scale biological filters.

\subsection{Main Findings}

The outcomes obtained from this study have several implications on future backwash optimizations studies and may provide a useful insight to how existing treatment plants should optimize their backwashing procedures, the outcomes include:

1. Collapse pulsing was found to result in higher DOC removals compared to water only backwash under nutrient limited conditions. Therefore, collapse pulsing may offer a more efficient backwash method for existing utilities that seek to improve their NOM removal, that treat water that is relatively low in nutrients concentrations, and that backwash their biological filters using water only.

2. The optimization of the reference backwash was examined by fixing the amount of backwash water volume used and varying the bed expansions. The higher bed expansion was found to impair DOC removals whereas the lower bed expansion had no impact on DOC removal. The downside of employing the lower bed expansion would be a longer biofilters' time out of service duration which results in less drinking water production. Therefore, the lower bed expansion backwash strategy was further optimized to result in a filters' time out of service that is equal to the duration of the existing reference backwash strategy. This resulted in backwash water savings of $22 \%$. Therefore, it is recommended that water treatment utilities follow this approach when they are optimizing their biological filters performance and when they are optimizing the overall drinking water treatment process.

3. ETSW did not show any impact on DOC removal. However, ETSW was successful in completely eliminating the filter ripening sequence. Adding ETSW to an existing backwash strategy requires additional water usage and increases the duration of the backwash step. Nevertheless, this is compensated by savings after restart as some water treatment utilities waste their water after backwash until effluent turbidity 
meets the required criteria. In addition to that, it is recommended to add ETSW for small water treatment plants that do not coagulate their water prior to the biological filtration step as in this study ETSW was successful even though the influent water did not receive any coagulation. Doing this will eliminate the pathogenic microorganism breakthrough risks that are associated with the ripening period.

4. All the backwash strategies that were investigated did not show any apparent impact on biofilters's biomass as measured by the ATP and phospholipids methods. This indicates that the use of collapse pulsing does not result in the loss of biomass that is responsible for NOM removal as claimed by some previous studies. However, it should be noted here that collapse pulsing backwash was initiated once sufficient biomass concentrations have developed in the biological filters and once steady state removal was observed. Therefore, the use of air may have a negative impact during the conditioning phase when the aim is to develop an active biofilm and when steady state removal is not reached yet.

5. Top of media biomass concentration as measured by the ATP and phospholipids methods did not show any correlation with DOC removal. On the other hand, DO uptake showed a direct relationship with DOC removal. This may provide an easy and a direct tool for estimating biological activity across the biofilter without the need of measuring other parameters that may require sophisticated instruments in certain situations.

\subsection{Recommendations for Future Work}

1. It is well documented that water temperatures change with seasonal variations in Canada and that a temperature drop could be accompanied by a drop in biological activity and DOC removal. Therefore, it is recommended to investigate the reproducibility of the results obtained in this study under cold water temperatures $\left(5^{\circ} \mathrm{C}\right)$.

2. The influent water did not receive any coagulation in this study. As a result, no conclusions were drawn regarding the impact of the backwash strategies -in which ETSW was absent- on the ripening period's intensity and duration. It is recommended to coagulate biological filters' influent water for future studies that 
seek to investigate the relationship between backwashing effects and effluent turbidity during the ripening period.

3. Only two different bed expansions have been investigated in this research with respect to the control $30 \%$ bed expansion. It is therefore recommended to investigate the potential impacts of other bed expansions such as $15 \%, 25 \%$, and $35 \%$.

4. It is possible that DOC removal is related to influent DO concentrations. Therefore, it is recommended to carry out investigations that assess DOC removal under varying DO concentrations.

5. To further develop a better understanding of the biological filtration process, it is recommended to identify the bacterial species that are present in the biofilm using molecular tools such as DNA sequencing. 


\section{REFERENCES}

1. Ahmad, R., \& Amirtharajah, A. (1998). Detachment of particles during biofilter backwashing. Journal of American Water Works Association, 90(11), 74-85.

2. Ahmad, R., Amirtharajah, A., Al-Shawwa, A., \& Peter, M. (1998). Effects of backwashing on biological filters. Journal of American Water Works Association, $90(12), 62-73$.

3. Amburgey, J. E., Amirtharajah, A. (2005). Strategic filter backwashing techniques and resulting particle passage. Journal of Environmental Engineering, 131 (4), $535-547$.

4. Amburgey, J.E. (2004). Optimization of the extended terminal subfluidization wash (ETSW) filter backwashing procedure. Water Research, 39 (2-3), 314-330.

5. Amirtharajah, A. (1993). Optimum backwashing of filters with air scour: a review. Water Science \& Technology, 27 (10), 195-211.

6. Amirtharajah, A. (1988). Some theoretical and conceptual views of filtration. Journal of American Water Works Association, 80 (12), 36-46.

7. Amirtharajah, A. (1985). The interface between filtration and backwashing. Water Research. 19 (5), 581-588.

8. Andersson, A., Laurent, P., Kihn, A., Prevost, M., \& Servais, P. (2001). Impact of temperature on nitrification in biological activated carbon (BAC) filters used for drinking water treatment. Water Research, 35 (12), 2923-2934.

9. Binnie, C., \& Kimber, M. (2009). Basic water treatment fourth edition, Thomas Telford Limited, London, United Kingdom

10. Chaudhary, D. S., Vigneswaran, S., Ngo, H. H., Shim, W. G., \& Moon, H. (2003). Biofilter in water and wastewater treatment. Korean Journal of Chemical Engineering, 20 (6), 1054-1065.

11. Choi, Y.C., Li, X., Raskin, L., \& Morgenroth, E. (2007). Effect of backwashing on perchlorate removal in fixed bed biofilm reactors, Water Research, 41(9), 1949-1959.

12. Colton, J. F., Hillis, P., \& Filtzpatrick, C. S.B. (1996). Filter backwash and startup strategies for enhanced particulate removal. Water Research, 30 (10), 25022507. 
13. Emelko, M. B., Huck, P. M., \& Douglas, I. P. (2003). Cryptosporidium and microsphere removal during late in-cycle filtration. Journal of American Water Works Association, 95 (5), 173-182.

14. Emelko, M. B., Huck, P. M., Coffey, B. M., \& Smith, E. F. (2006). Effects of media, backwash, and temperature on full-scale biological filtration. Journal of American Water Works Association, 98 (12), 61-73.

15. François, R. J., \& Van Haute, A. A. (1985). Backwashing and conditioning of a deep bed filter. Water Research, 19 (11), 1357-1362.

16. Ghannoum, M. \& O'Toole, G.A. (2004). Microbial Biofilms, ASM Press, Washington, USA.

17. Gibert, O., Benoit, L., Fernandez, M., Bernat, X., Paraira, M., Galderer, M., \& Martinez-Liado, X. (2013). Characterising biofilm development on granular activated carbon used for drinking water production. Water Research, 47 (3), 1101-1110.

18. Hammes, F., Goldschmidt, F., Vital, M., Wang, Y., \& Egli, T. (2010). Measurement and interpretation of microbial adenosine tri-phosphate (ATP) in aquatic environments. Water Research, 44 (13), 3915-3923.

19. Health Canada. (2014). Guidelines for Canadian Drinking Water Quality Summary Table. Water and Air Quality Bureau, Healthy Enviroments and Consumer Safety Branch, Health Canada, Ottawa, Ontario, 1-25.

20. Howe, K.J., Hand, D.W., Crittenden, J.C., Trussell, R.R., \&Tchobangolous, D. (2012). Principles of water treatment. John Wiley \& Sons Inc. USA.

21. Hozalski, R., Goel, S., \& Bouwer, E. (1995). TOC removal in biological filters. AWWA, 87 (12), 40-54.

22. Huck, P.M, Fedorak, P.M, \& Anderson, W.B. (1991). Formation and removal of assimilable organic carbon during biological treatment. Journal of American Water Works Association, 83(12), 69-80

23. Huck, P.M., B.M. Coffey, A. Amirtharajah and E.J. Bouwer. (2000). Optimizing filtration in biological filters, American Water Works Association Research Foundation Project 252, Report 90793, Denver. 
24. Huisman, L. \& Wood, W.E. Slow sand filtration. World Health OrganizationGeneva 1974.

25. Kaur, P., \& Fitzpatrick, C. S. B. (2003). Biofllm formation in granular-bed filters. Water and Environmental Journal, 17 (3), 145-148.

26. Kim, T. G., Yun, J., \& Hong, S. (2014). Effects of water temperature and backwashing on bacterial population and community in a biological activated carbon process at a water treatment plant. Applied Microbial Biotechnology, 98 (3), 1417-1427.

27. Lauderdale, C.; Chadik, P.; Kirisits, M.J.; \& Brown, J. (2012). Engineered biofiltration: enhanced biofilter performance through nutrient and peroxide addition. Journal of American Water Works Association, 104 (5), E298-E309.

28. LeChevallier, M. W., Schulz, W., \& Lee, R. G. (1991). Bacterial nutrients in drinking water. Applied and Environmental Microbiology, 57 (3), 857-862.

29. Liu, X., Huck, P. M., \&Slawson, R. M. (2001). Factors affecting drinking water biofiltration: Filtration. Journal American Water Works Association, 93 (12), 90101.

30. Magic-Knezev, A. \& van der Kooij, D. (2004). Optimization and significance of ATP analysis for measuring active biomass in granular activated carbon filters used in water treatment. Water Research, (38) 18, 3971-3979.

31. Matilainen, A., Vepsalainen, M., \& Sillanpaa M. (2010). Natural organic matter removal by coagulation during drinking water treatment: a review. Advances in Colloid and Interface Science, 159 (2), 189-197.

32. Melin, E.S., \& Odegaard, H. (2000). The effect of biofilter loading rate on the removal of organic ozonation by products, Water Research, 34 (18), 4464-4476.

33. Meric, S., Ovez, S., Kaptan, D., \& Orhon, D. (2003). Operational strategies for a small wastewater treatment plant using OUR, microscopic analysis, and toxicity test. Journal of Environmental Science and Health Part a-Toxic/Hazardous Substances \& Environmental Engineering, 38 (10), 2329-2338.

34. Miltner, R. J., Summers, R. S., \& Wang, J. Z. (1995). Biofiltration performance: part 2, effect of backwashing. Journal of American Water Works Association, 87 (12), 64-70. 
35. Moll, D. M., Summers, R. S., Fonseca, A. C., \&Matheis, W. (1999). Impact of temperature on drinking water biofilter performance and microbial community structure. Environmental Science \& Technology, 33 (14), 2377-2382.

36. Mulkerrins, D., Dobson, A.D.W, \& Colleran, E. (2004). Parameters affecting biological phosphate removal from wastewaters. Environment International, 30 (2), 249-259.

37. Naidu, G.; Jeong, S.; Vigneswaran, S.; \& Rice, S.A. (2013). Microbial activity in biofilter used as a pretreatment for seawater desalination. Desalination, 309 (0), 254-260.

38. Ontario Ministry of the Environment (2008). Design Guidelines for Drinking Water Systems.

39. Orupold, K., Hellat, K., \& Tenno, T. (1999). Estimation of treatability of different industrial wastewater by activated sludge oxygen uptake measurement. Water Science Technology, 40 (1), 31-36.

40. Pharand, L., Dyke, M. Van, Anderson, W., \& Huck, P. (2014). Assessment of biomass in drinking water biofilters by adenosine triphosphate. Journal of American Water Works Association, 106 (10), 433-444.

41. Prevost, M., Laurent, P., Servais, P., \& Joret, J.C . (2005). Biodegradable organic matter in drinking water treatment and distribution, American Water Works Association, Denver, USA.

42. Salvik, I., Jehmlich, A., \& Uhl, W. (2013). Impact of backwashing procedures on deep bed filtration productivity in drinking water treatment, Water Research, 47 (16), 6348-6357.

43. Satterfield, Z. (2005). Filter backwashing. National Environmental Services Center,5 ( 3).

44. Servais, P., Billen, G., Bablon, G. P., \& Ven, C. (1991). Microbial activity in GAC filters at the Choisy-Le-Roi Treatment Plant. Journal of American Water Works Association, 83 (2), 62-68.

45. Shariati, F. P., Heran, M., Sarrafzadeh, M. H., Mehrnia, M. R., Sarzana, G., Ghommidh, C., \& Grasmick, A. (2013). Biomass characterization by dielectric monitoring of viability and oxygen uptake rate measurements in a novel 
membrane bioreactor. Bioresource Technology, 140 (0), 357-362.

46. Siddiqui,M.S., Gary,L.M, \& Murphay,B.D. (1997). Ozone enhanced removal of natural organic matter from drinking water sources. Water Research, 31 (12), 3089-3105.

47. Simpson, D. R. (2008). Biofilm processes in biologically active carbon water purification. Water Research, 42 (12), 2839-2848.

48. Soucie, W. \& Sheen, B. (2007). Filter-to-waste optimization. Journal of American Water Works Association, 99 (5), 148-157.

49. Standard Methods for the Examination of Water and Wastewater. (2012). American Public Health Association/American Water Works Association/Water Environment Federation, Washington DC, USA.

50. Tchobanoglous, G., Burton, F.L., \& Stensel, H.D. (2003). Wastewater Engineering: Treatment and reuse, McGraw Hill, New York, USA.

51. Urfer, D., \& Huck, P. M. (2001). Measurement of biomass activity in drinking water biofilters using a respirometric method. Water Research, 35 (6), 1469-1477.

52. Urfer, D., Huck, P. M., Booth, S. D. J., \& Coffey, B. M. (1997). Biological filtration for BOM and particle removal: a critical review. Journal of American Water Works Association, 89 (12), 83-98.

53. Vahala, R.; Moramarco, V.; Niemi, R.M.; Rintala, J.; \& Laukkanen, R., (1998). The effects of nutrients on natural organic matter (NOM) removal in biological activated carbon (BAC) filtration. Acta Hydrochim Hydrobiol, 26 (3), 169-199.

54. Velten, S., Hammes, F., Boller, M., \& Egli, T. (2007). Rapid and direct estimation of active biomass on granular activated carbon through adenosine tri-phosphate (ATP) determination. Water Research, 41 (9), 1973-1983.

55. Wand, J.Z, \& Summers, R.S. (1996). Biodegradation behavior of natural organic matter in sand filters. Journal of Water Science, 9 (1), 3-16.

56. Wang, J. Z., Summers, R. S., \& Miltner, R. J. (1995). Biofiltration performance: part 1, relationship to biomass. Journal of American Water Works Association, 87 (12), 55-63.

57. Xue, F. Master's Thesis (2011). The effect of backwashing procedures on filter ripening and general effluent quality. 
58. Yoong, E. T., Lant, P. a., \& Greenfield, P. F. (2000). In situ respirometry in an SBR treating wastewater with high phenol concentrations. Water Research, 34 (1), 239-245.

59. Yu, J., Wang, D., Yan, M., Ye, C., Yang, M., \& Ge, X. (2007). Optimized coagulation of high alkalinity, low temperature and particle water: $\mathrm{pH}$ adjustment and Polyelectrolytes as Coagulant Aids. Environmental Monitoring and Assessment, 131 (1), 377-386.

60. Zhang, D., Li, W., Wang, K., Zhang, L., \& Gong, H., (2010). Bacterial community dynamics and its effects during biological activated carbon filter process for drinking water treatment. 2nd International Conference on Chemical, Biological, and Environmental Engineering, Cairo, Egypt, 137-142.

61. Zhu, H., Smith, D.W., Zhou, H., \& Stanley, S. J. (1996). Improving removal of turbidity causing materials by using polymers as a filter aid. Water Research, 30 (1), 103-114. 


\section{Appendix A- DOSING SOLUTIONS CALCULATIONS}

\section{Carbon Dosing Solution}

$7.1 \mathrm{mg} / \mathrm{L}$ of carbon is needed in the biofilters' influent

Three chemicals are to be used, therefore:

$7.1 / 3=2.37 \mathrm{mg} / \mathrm{L}$ from each chemical is needed.

Define:

$\mathrm{Q}_{0}=$ volumetric flow rate from nutrients dosing tank $(5 \mathrm{ml} / \mathrm{min})$

$\mathrm{Q}_{1}=$ tap water volumetric flow rate $(400 \mathrm{ml} / \mathrm{min})$

$\mathrm{Q}_{2}=$ volumetric flow rate from the carbon dosing tank $(5 \mathrm{ml} / \mathrm{min})$

$\mathrm{Q}_{3}=$ overall volumetric flow rate to the biofilters $(410 \mathrm{ml} / \mathrm{min})$

$\mathrm{C}=$ carbon concentration $(\mathrm{mg} / \mathrm{L})$

Q/. $/ \mathrm{C}_{\mathrm{o}}+\mathrm{Q} / \mathrm{C}_{1}+\mathrm{Q}_{2} \mathrm{C}_{2}=\mathrm{Q}_{3} \mathrm{C}_{3}$

$\mathrm{Q}_{2} \mathrm{C}_{2}=\mathrm{Q}_{3} \mathrm{C}_{3}$

$5 \mathrm{Ml} / \mathrm{min}\left(\mathrm{C}_{2}\right)=410 \mathrm{~mL} / \mathrm{min}(2.37 \mathrm{mg} / \mathrm{L})$

$\mathrm{C}_{2}=194.34 \mathrm{mg} / \mathrm{L}$

A carbon concentration of $194.34 \mathrm{mg} / \mathrm{L}$ needs to be present from each chemical in the 50

L carbon dosing tank

\section{Glyoxal}

$149.34 \mathrm{mg} \mathrm{C} / \mathrm{L}$. (1 mmol C/ $12 \mathrm{mg} \mathrm{C})$. (58 mg glyoxal $/ 1 \mathrm{mmolglyoxal})=470 \mathrm{mg}$ glyoxal/L needed in the $50 \mathrm{~L}$ dosing solution

- $500 \mathrm{~mL}$ stock solutions are prepared to make up the 50L dosing tank 
- To determine the concentration of stock solutions:

(470 mg/L. 50L. $1000 \mathrm{ml} / \mathrm{L}) / 500 \mathrm{~mL}=47000 \mathrm{mg} / \mathrm{L}$ of glyoxal are needed in the stock solution

- Purity of glyoxal used (provided by the manufacturer) $=40000 \mathrm{mg} / \mathrm{L}$

- Volume of glyoxal to be added to the $500 \mathrm{ml}$ stock solution:

$(47000 \mathrm{mg} / \mathrm{L} .500 \mathrm{~mL}) / 40000 \mathrm{mg} / \mathrm{L}=58.75 \mathrm{ml}$ of glyoxal

\section{Formic Acid}

Similar calculations are performed to determine formic acid concentration

- Volume of formic acid to be added to the $500 \mathrm{ml}$ stock solution $=42.32 \mathrm{ml}$ of formic acid

\section{Acetic Acid}

Similar steps are performed to determine acetic acid concentration

- Volume of acetic acid to be added directly to the $50 \mathrm{~L}$ dosing solution $=9 \mathrm{ml}$ of acetic acid

\section{Nutrients Dosing Solution}

\section{Magnesium Sulphate}

$2.1 \mathrm{mg} / \mathrm{L}$ of $\mathrm{Mg}$ are needed in the biofilters' influent

$2.1 \mathrm{mg} / \mathrm{L} .(1 \mathrm{mmolMg} / 24 \mathrm{mg} \mathrm{Mg})$. (120.4 mg Mg/1mmol $\left.\mathrm{MgSO}_{4}\right)=10.5 \mathrm{mg} / \mathrm{L}$

- Mass of $\mathrm{MgSO}_{4}$ needed to be added to the 50L dosing tank:

$(10.5 \mathrm{mg} / \mathrm{L} .410 \mathrm{ml} / \mathrm{min} .50 \mathrm{~L}) /(5 \mathrm{ml} / \mathrm{min} .1000 \mathrm{mg} / \mathrm{g})=43.05 \mathrm{~g}$ of MgSO 4
Aluminum Nitrate
$0.184 \mathrm{mg} / \mathrm{L}$ of $\mathrm{Al}$ are needed in the biofilters' influent 
$0.184 \mathrm{mg} / \mathrm{L} .(1 \mathrm{mmol} \mathrm{Al} / 27 \mathrm{mg} \mathrm{Al}) .\left(213 \mathrm{mg} \mathrm{Al} / 1 \mathrm{mmol} \mathrm{AlNO}_{3}\right)=1.45 \mathrm{mg} / \mathrm{L}$

- Mass of $\mathrm{AlNO}_{3}$ needed to be added to the 50L dosing tank:

$(1.45 \mathrm{mg} / \mathrm{L} .410 \mathrm{ml} / \mathrm{min} .50 \mathrm{~L}) /(5 \mathrm{ml} / \mathrm{min} .1000 \mathrm{mg} / \mathrm{g})=5.95 \mathrm{~g}$ of $\mathrm{AlNO}_{3}$

\section{Sodium Nitrate}

\section{$\mathrm{NaNO}_{3}$ was added to the $26 \mathrm{~L}$ supplementary dosing solution}

$0.31 \mathrm{~g} \mathrm{~N}$ are needed in the biofilters' influent

Similar calculations are performed to determine amount of $\mathrm{NaNO}_{3}$ needed while taking into account amount of $\mathrm{N}$ present in $\mathrm{AlNO}_{3}$

- Mass of $\mathrm{NaNO}_{3}$ to be added to the $26 \mathrm{~L}$ dosing solution: $4.16 \mathrm{~g}$ of $\mathrm{NaNO}_{3}$

\section{Sodium Carbonate}

$3.1 \mathrm{~g}$ of Na re needed in the biofilters' influent

Similar calculations are performed to determine amount of $\mathrm{Na}_{2} \mathrm{CO}_{3}$ needed while taking into account amount of $\mathrm{Na}$ present in $\mathrm{NaNO}_{3}$

- Mass of $\mathrm{Na}_{2} \mathrm{CO}_{3}$ to be added to the $50 \mathrm{~L}$ dosing solution: $29.3 \mathrm{~g}$ of $\mathrm{Na}_{2} \mathrm{CO}_{3}$

\section{Potassium Dihydrogen Phosphate}

$0.031 \mathrm{~g}$ of $\mathrm{P}$ are needed in the biofilters' influent

$0.315 \mathrm{~mol} \mathrm{~K} / \mathrm{mol} \mathrm{P}$ are needed in the biofilters' influent

Similar calculations are performed to determine amount of $\mathrm{KH}_{2} \mathrm{PO}_{4}$ needed

- Mass of $\mathrm{KH}_{2} \mathrm{PO}_{4}$ to be added to the $50 \mathrm{~L}$ dosing solution: $023 \mathrm{~g}$ of $\mathrm{KH}_{2} \mathrm{PO}_{4}$

- Mass of $\mathrm{KH}_{2} \mathrm{PO}_{4}$ to be added to the $26 \mathrm{~L}$ dosing solution 


\title{
Appendix B- EXTENDED TERMINAL SUBFLUIDIZATION WASH CALCULATION
}

\author{
GAC media specifications \\ $\mathrm{L}_{\mathrm{F}}=520 \mathrm{~mm}$ \\ $\rho_{\mathrm{p}}=1500 \mathrm{~kg} / \mathrm{m}^{3}$ \\ $\mathrm{d}_{10}=0.7 \mathrm{~mm}$ \\ $\mathrm{d}_{60}=0.85 \mathrm{~mm}$ \\ $\mathrm{d}_{90}=0.96 \mathrm{~mm}$ \\ $\mathrm{k}_{\mathrm{l}}=4.4$ \\ $\mathrm{k}_{\mathrm{V}}=228$ \\ $\rho_{\mathrm{w} @ 20 \mathrm{C}}=998.3 \mathrm{~kg} / \mathrm{m}^{3}$ \\ $\mu_{\mathrm{w} @ 20 \mathrm{C}}=0.001002 \mathrm{~kg} / \mathrm{m} . \mathrm{s}$
}

\section{ETSW flow rate}

$\mathrm{Ga}=\frac{\left(0.96 \times 10^{-3}\right)^{3} 998.3(1500-998.3) 9.8}{(0.001002)^{2}}=4325.3$

$\mathrm{R}_{\mathrm{mf}}=\left[33.7^{2}+0.0408(4325.3)\right]^{0.5}-33.7=2.5$

$V_{m f}=\frac{2.5(0.001002) .3600}{\left(0.96 \times 10^{-3}\right) \times 998.3}=9.4 \mathrm{~m} / \mathrm{h}$

\section{ETSW duration}

$\frac{\pi\left(25 \times 10^{-3}\right)^{2} \times 1.04 m}{9 / 60}=7$ minutes 


\section{APPENDIX C- CONDITIONING PHASE RESULTS}

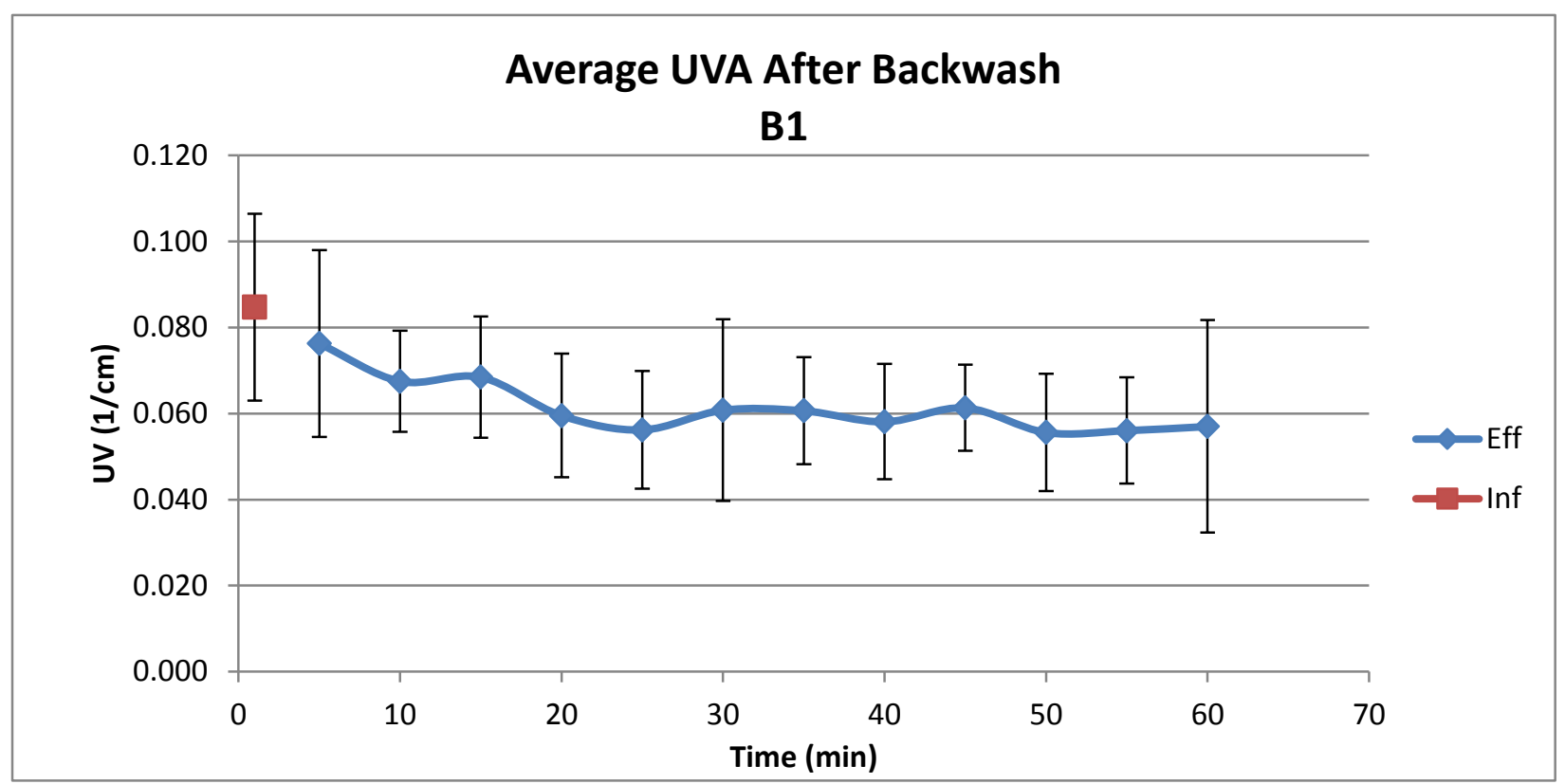

\section{Average UVA After Backwash}

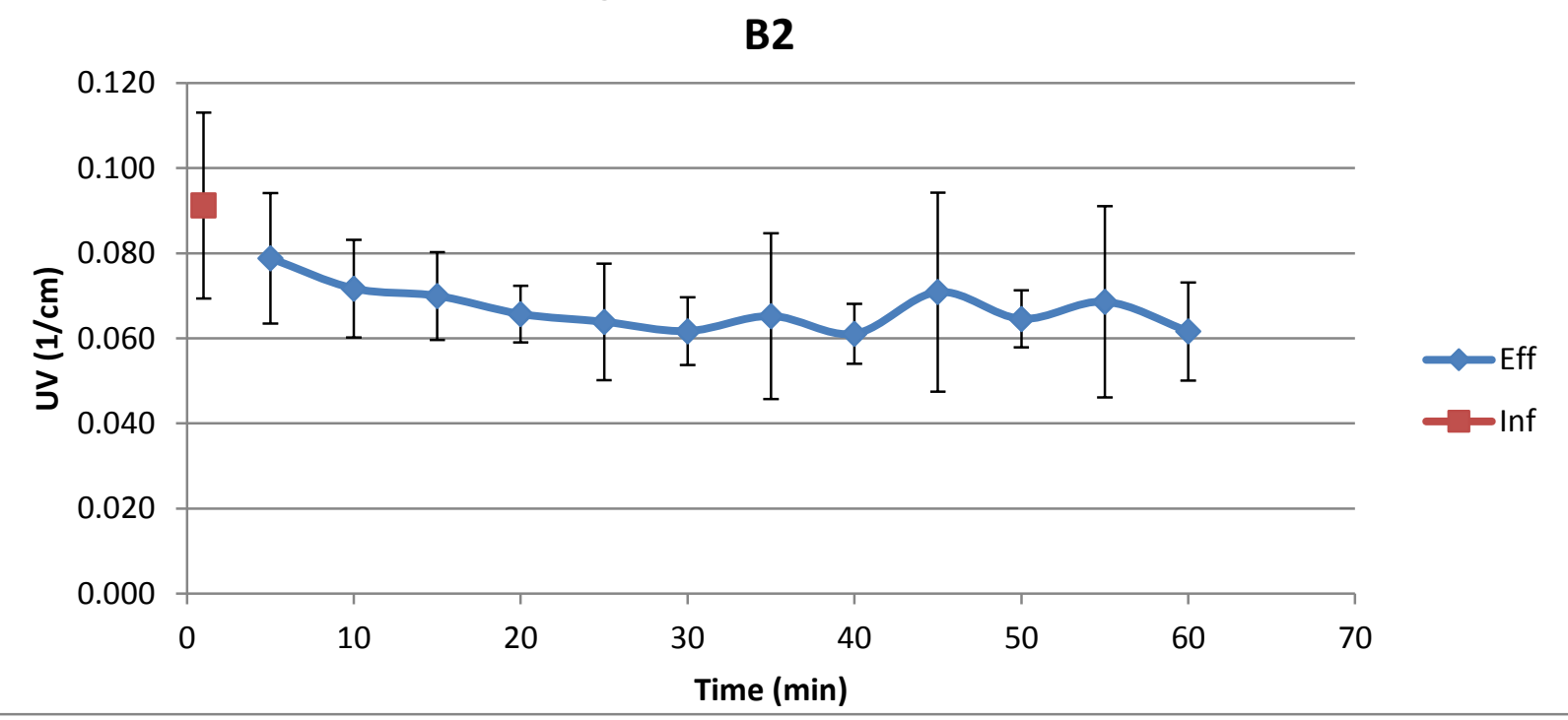



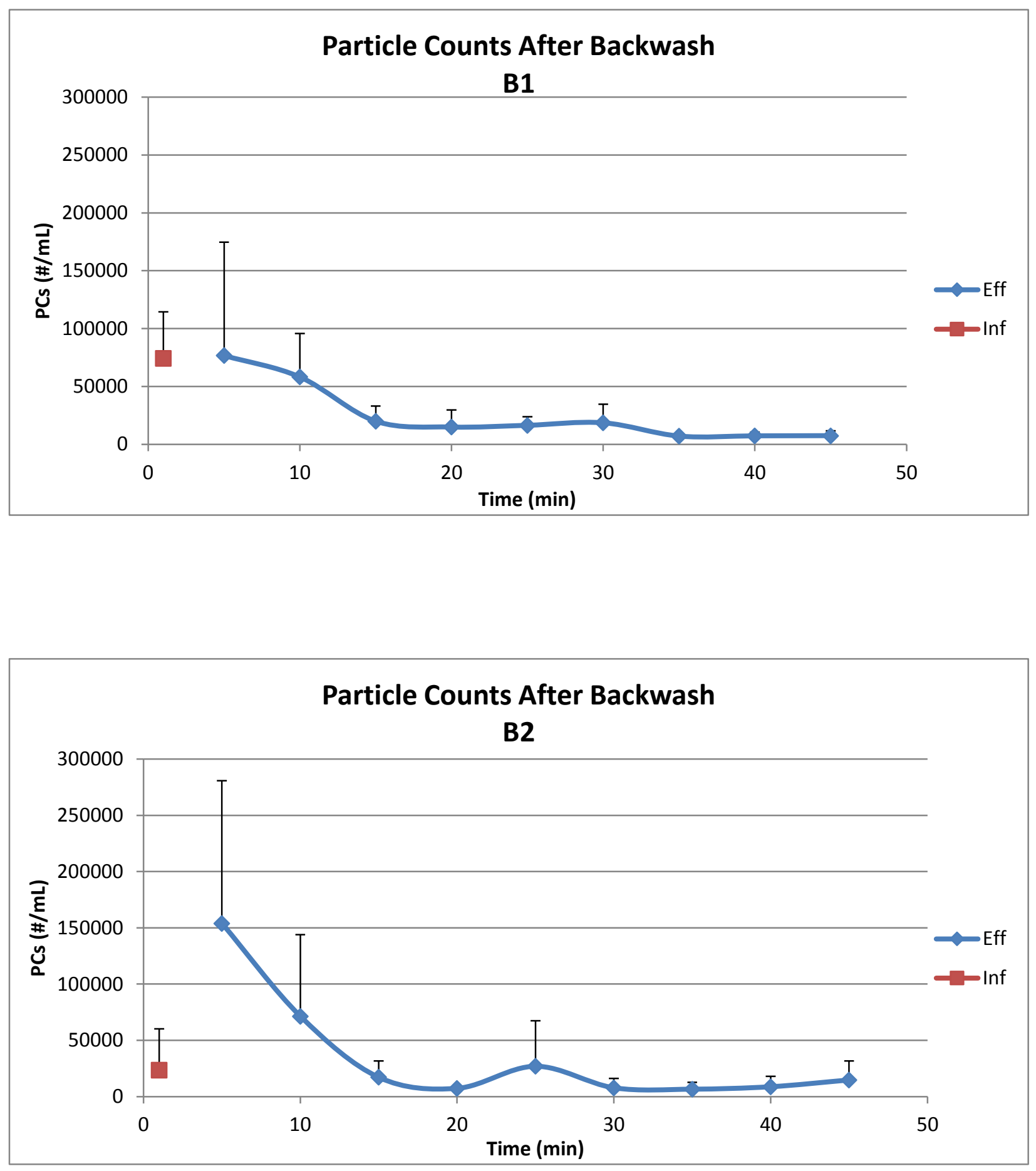


\section{APPENDIX D- POTASSIUM SUPPLEMENTATION PHASE RESULTS}

The purpose of Appendix D is to present the results associated with the potassium addition phase that were not included in chapter 4. Potassium addition was initiated at phase 5 in order to investigate whether potassium presence could enhance DOC removal. In wastewater treatment, potassium is an important parameter that promotes biological phosphorous uptake (Mulkerrins et al., 2004) and there is no information about the impact of potassium addition on the microbial activity of biofilms used to treat dirking water. As shown in the below figures, potassium had a significant negative impact $(\mathrm{p}<0.05)$ on DOC removals for both $\mathrm{B} 1$ and $\mathrm{B} 2$.The reasons for that are not clearly understood, a potential explanation could be related to the fact that the dosed potassium concentration might be higher than what is required for biofilm activity in drinking water treatment.

\section{Impact of Potassium Addition on B1}

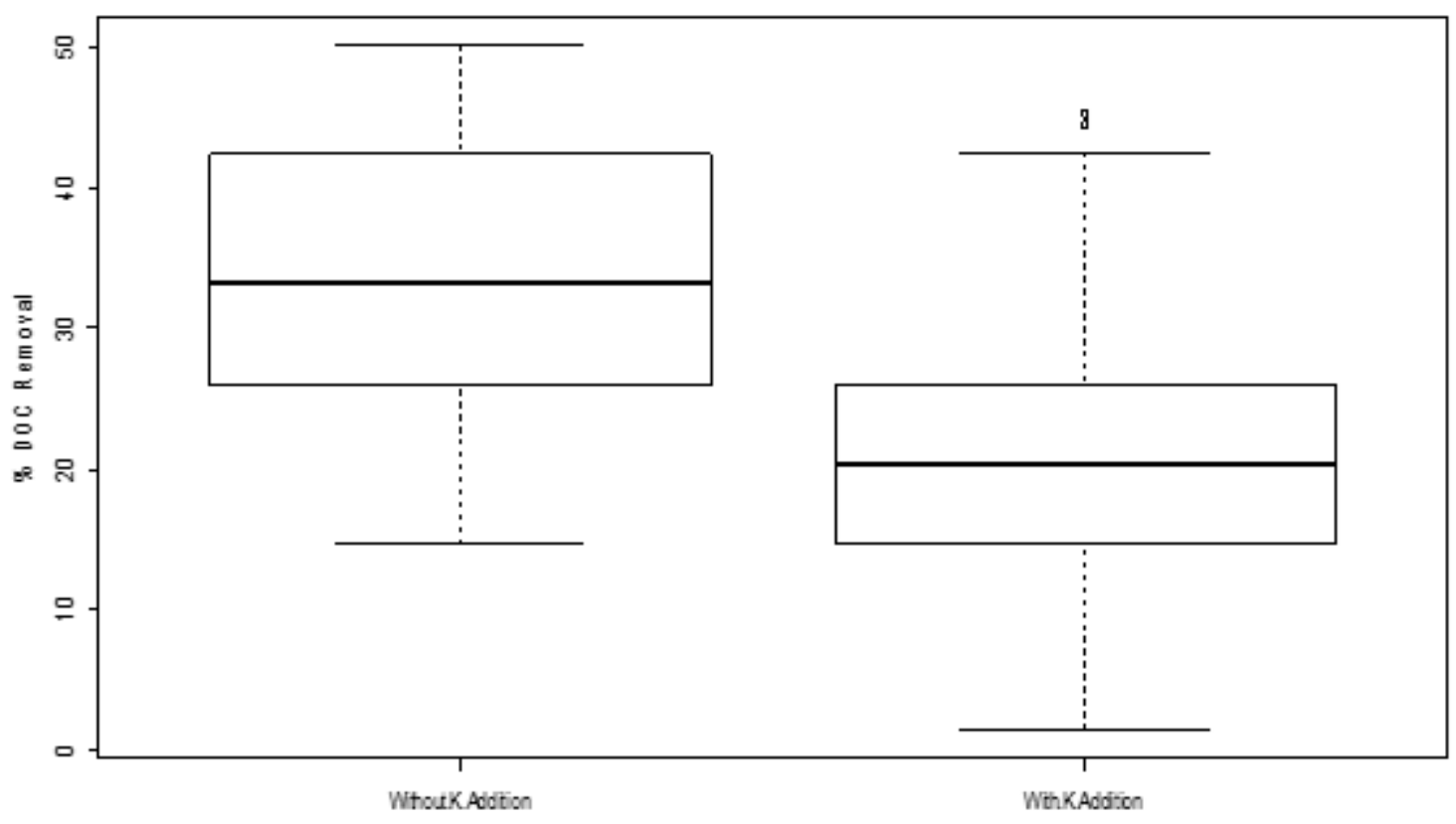


Impact of Potassium Addition on B2

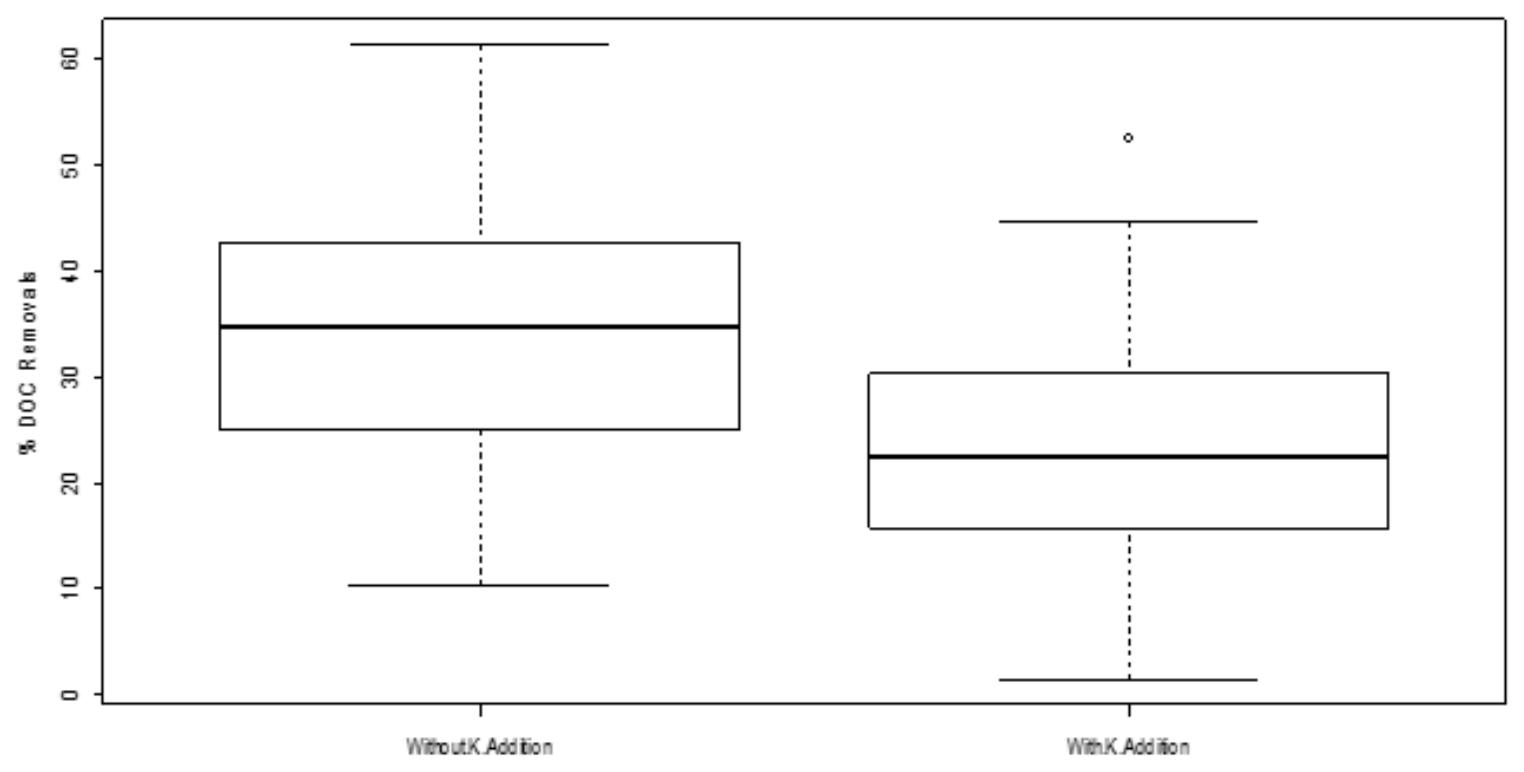




\section{APPENDIX E- ADDITIONAL TURBIDITY RESULTS}
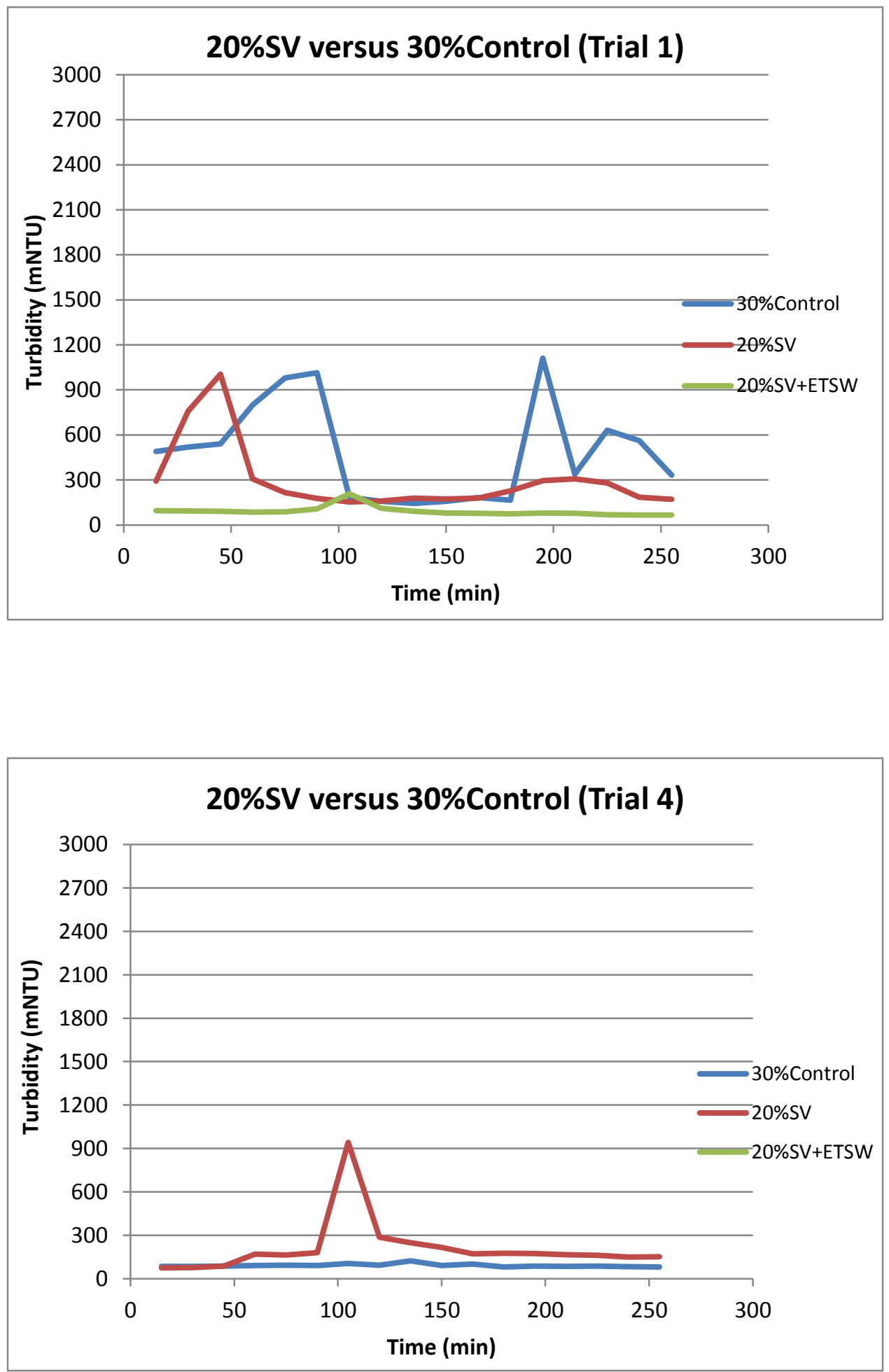

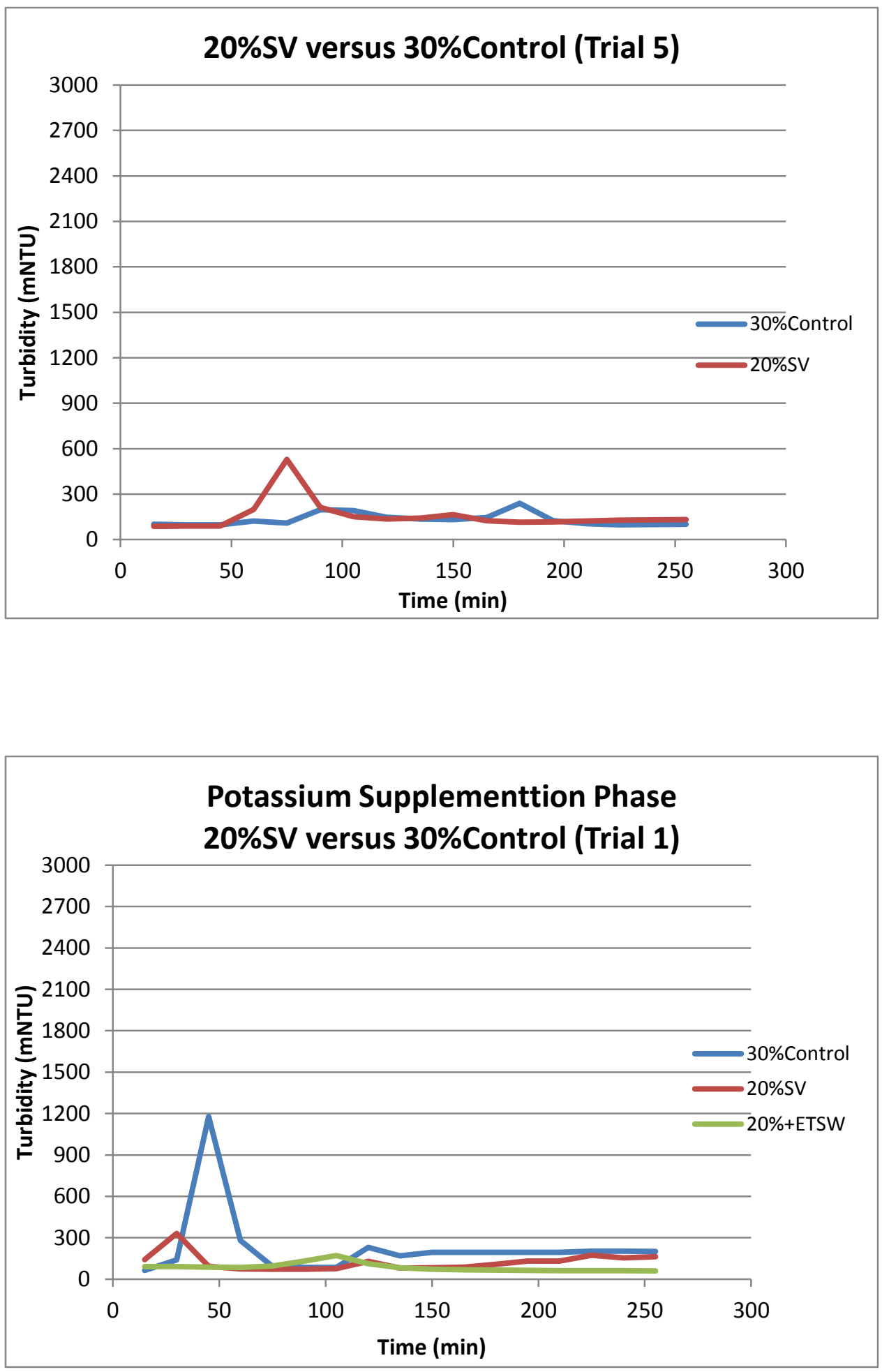

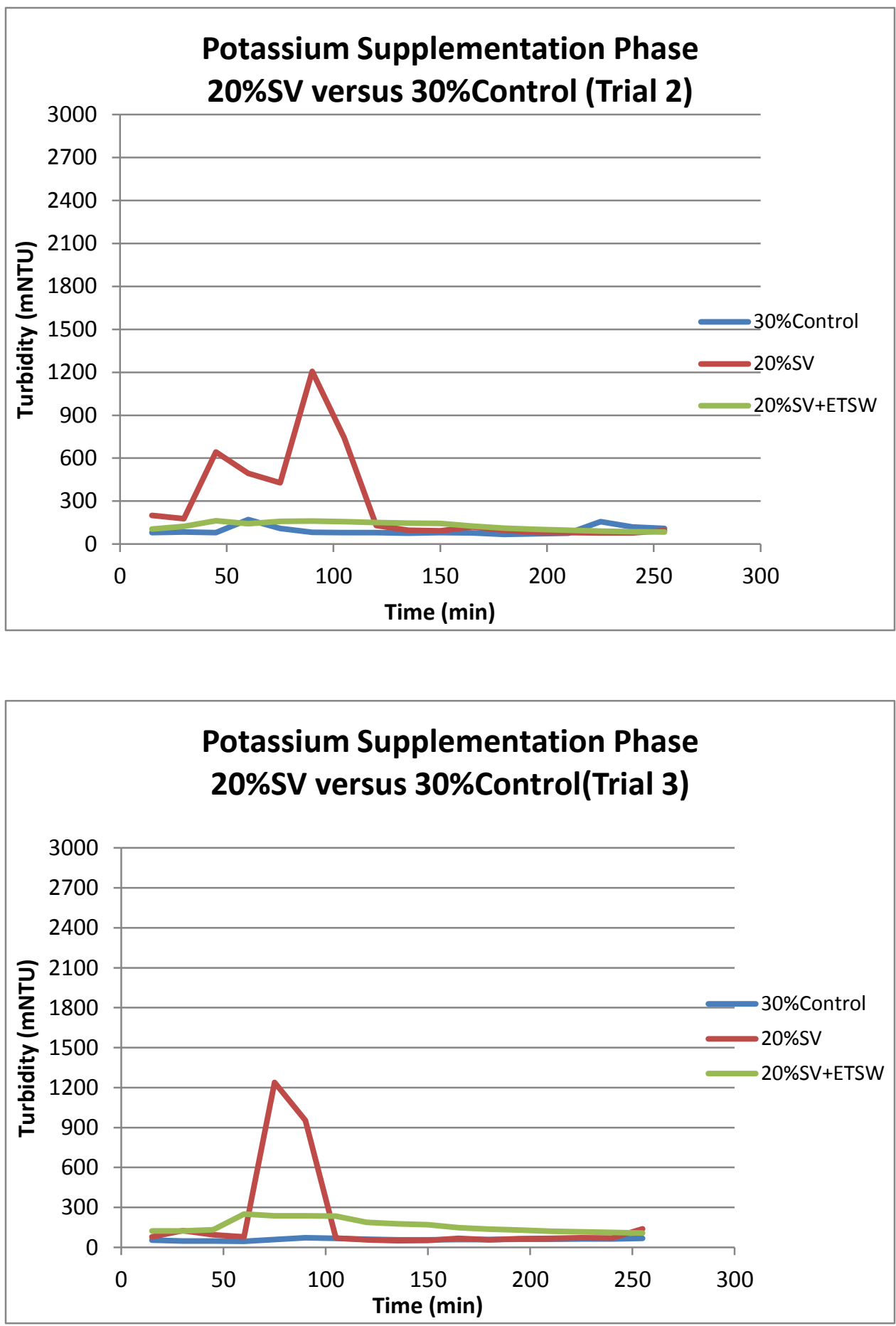

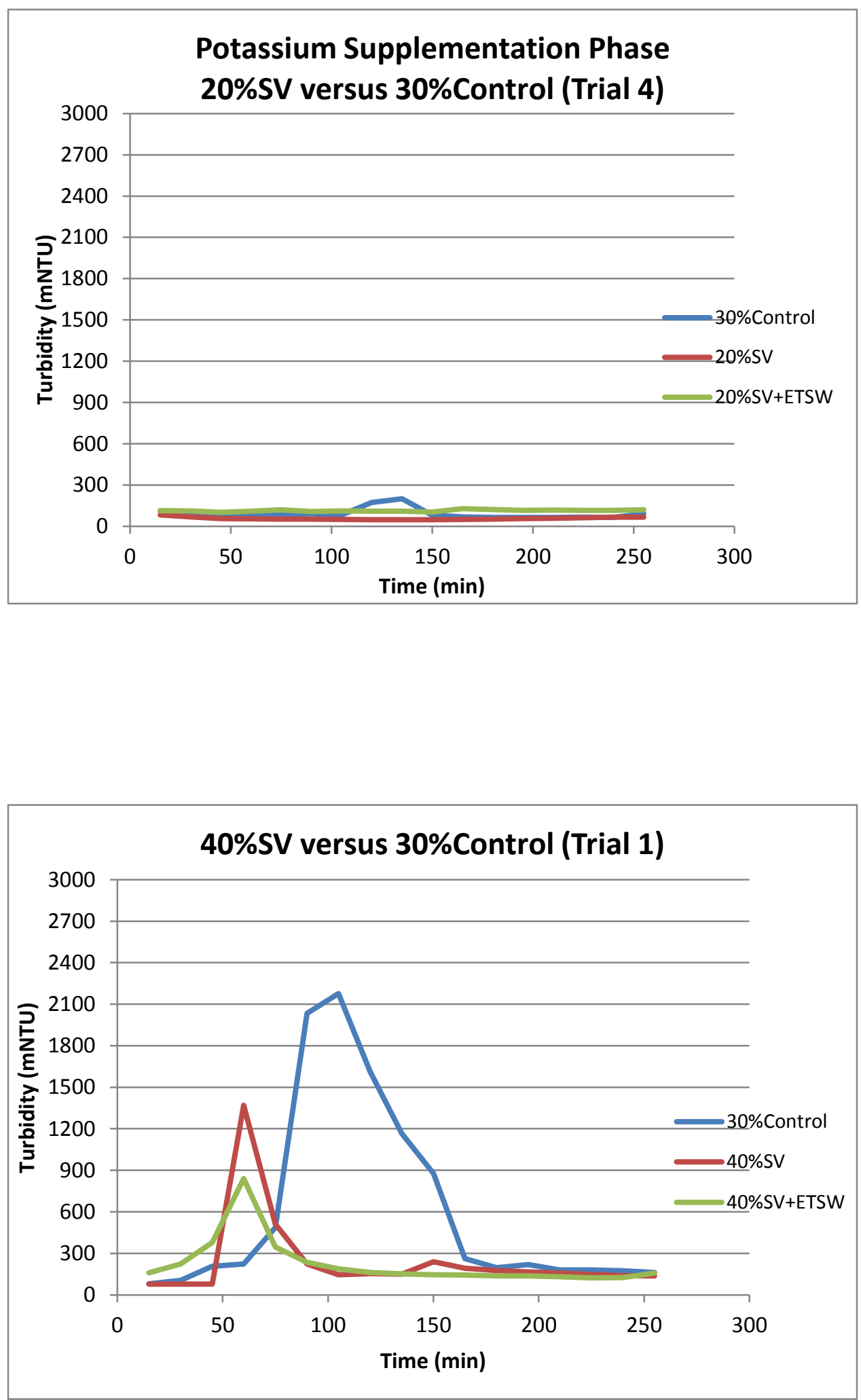

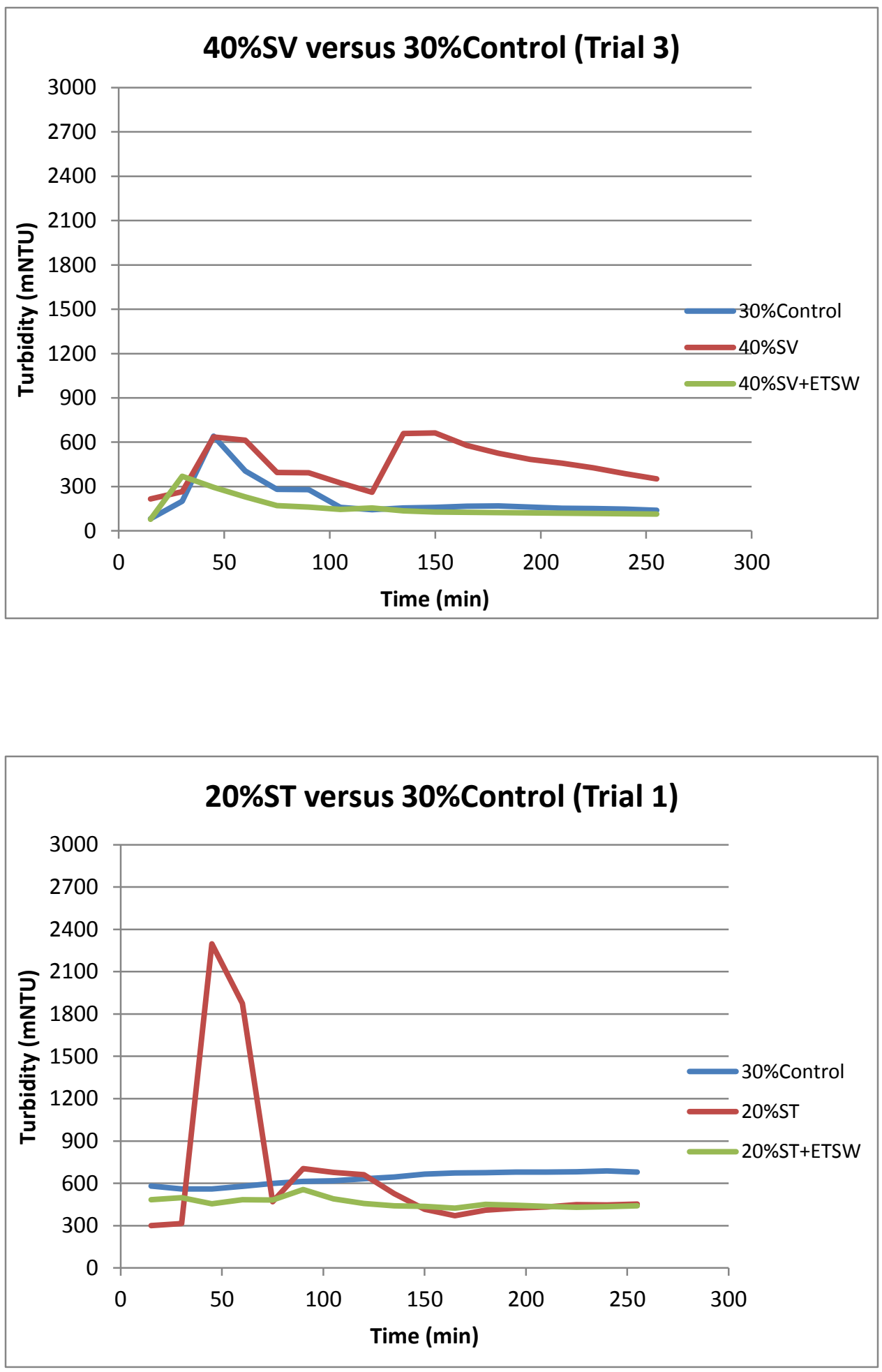

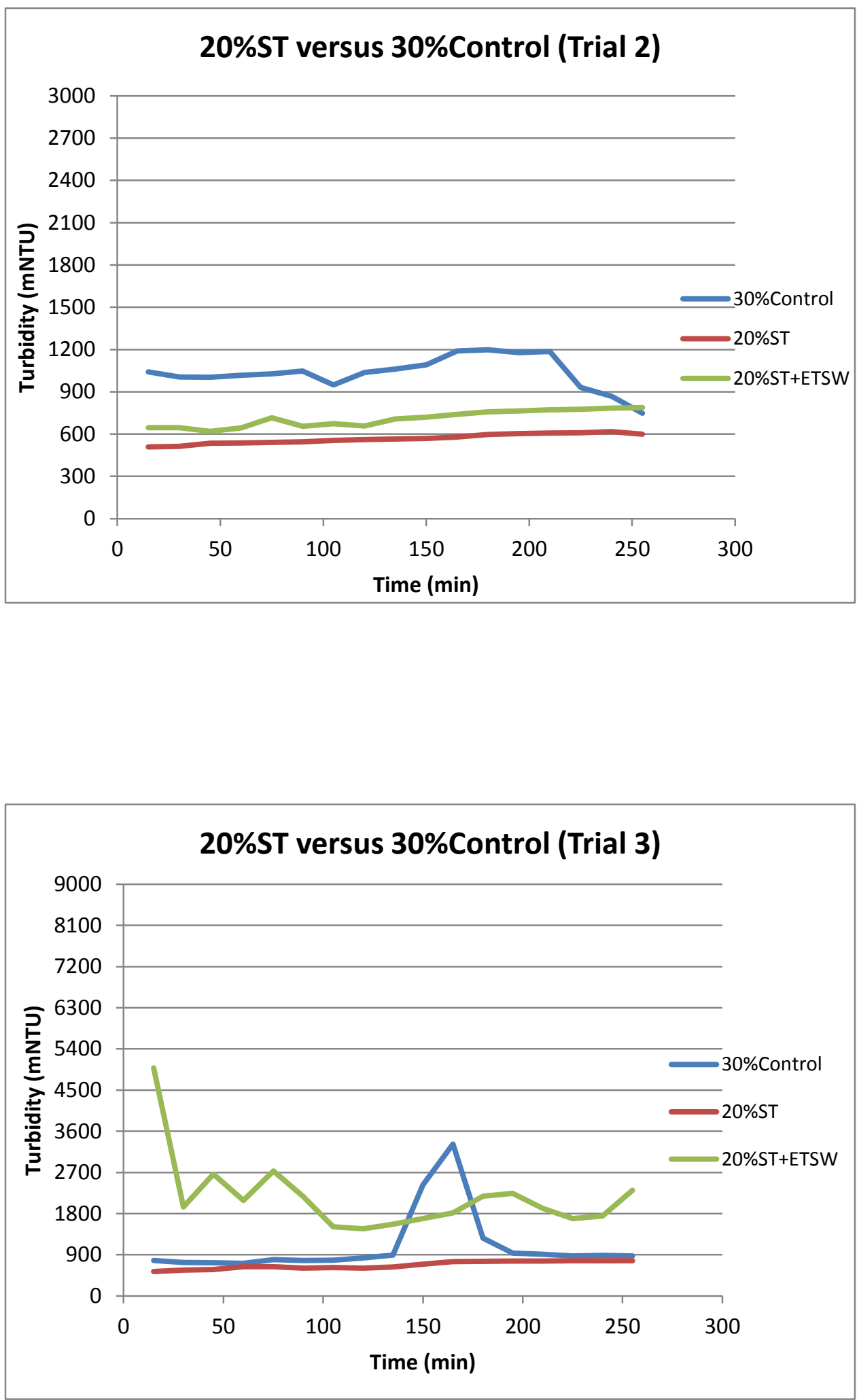


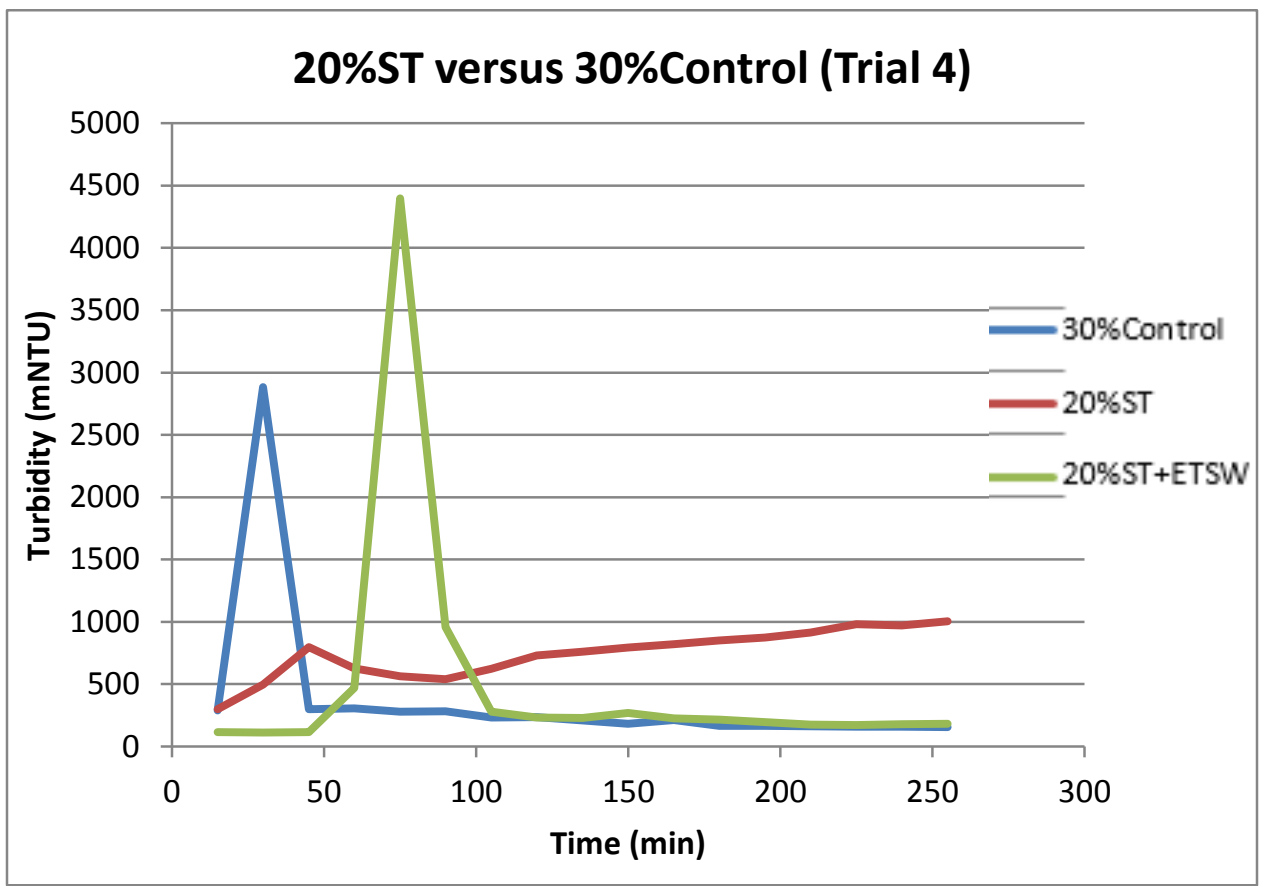


APPENDIX F- \% DOC Removal Data

\begin{tabular}{|c|c|c|c|c|c|c|c|}
\hline $\mathbf{3 0 \%}$ & $\mathbf{3 0} \%$ Control & $\mathbf{2 0 \% S V}$ & $\mathbf{3 0}$ Control & $\mathbf{2 0 \% S T}$ & $\mathbf{3 0 \% C o n t r o l}$ & $\mathbf{4 0 \% S V}$ & $\mathbf{3 0 \% C o n t r o l}$ \\
\hline 0.00 & 13.18 & 42.44 & 59.30 & 20.76 & 39.36 & 25.45 & 25.50 \\
\hline-6.31 & 8.39 & 41.70 & 31.55 & 35.84 & 37.89 & 21.64 & 30.57 \\
\hline 5.79 & 22.60 & 39.21 & 47.53 & 35.53 & 43.36 & 6.60 & 35.18 \\
\hline 31.93 & 20.07 & 37.63 & 47.04 & 42.60 & 40.28 & 16.80 & 36.85 \\
\hline 21.74 & 2.42 & 35.26 & 47.75 & 50.13 & 24.94 & 27.61 & 23.04 \\
\hline-9.73 & 22.94 & 42.53 & 36.66 & 33.78 & 45.52 & 29.06 & 25.31 \\
\hline 15.17 & 40.27 & 46.89 & 61.30 & 41.01 & 20.87 & 15.70 & 25.74 \\
\hline 13.00 & 19.85 & 66.33 & 37.68 & 45.64 & 19.60 & 48.74 & 35.91 \\
\hline 26.37 & 18.91 & 35.72 & 48.01 & 44.61 & 27.51 & 21.46 & 37.59 \\
\hline 17.70 & 28.80 & 30.61 & 16.05 & 42.34 & 27.62 & 24.42 & 30.67 \\
\hline-16.04 & 12.71 & 24.87 & 47.80 & 43.05 & 33.74 & 27.30 & 36.85 \\
\hline-5.19 & 4.03 & 28.12 & 24.29 & 49.73 & 52.05 & 30.56 & 21.79 \\
\hline 14.86 & 24.27 & 34.85 & 29.16 & 26.99 & 41.26 & 27.95 & 25.83 \\
\hline 3.01 & 35.13 & 57.34 & 28.46 & 31.97 & 39.28 & 33.17 & 28.46 \\
\hline 9.34 & 44.66 & 52.49 & 40.78 & 31.12 & 38.79 & 24.25 & 12.24 \\
\hline 17.27 & 24.45 & 29.34 & 29.55 & 40.90 & 38.56 & 22.09 & 41.50 \\
\hline 19.12 & 17.19 & 31.91 & 10.38 & 38.14 & 31.21 & 2.35 & 34.04 \\
\hline 10.98 & 23.84 & 20.17 & 35.58 & 40.04 & 24.84 & 6.15 & 25.37 \\
\hline 24.78 & 28.07 & 26.45 & 13.29 & 26.33 & 36.96 & NA & NA \\
\hline 8.01 & 30.12 & 25.39 & 18.06 & 24.43 & 46.31 & NA & NA \\
\hline 7.04 & 29.55 & 23.45 & 17.32 & 23.60 & 51.25 & NA & NA \\
\hline 20.63 & 32.67 & 25.04 & 22.87 & 14.65 & 34.29 & NA & NA \\
\hline 13.58 & 25.22 & 33.17 & 25.32 & 24.14 & 37.57 & NA & NA \\
\hline
\end{tabular}




\begin{tabular}{|c|c|c|c|c|c|c|c|}
\hline 21.96 & 36.02 & 16.78 & 31.17 & 23.18 & 20.19 & NA & $\mathrm{NA}$ \\
\hline 5.10 & 30.46 & 31.65 & 32.24 & 37.44 & NA & NA & NA \\
\hline 13.95 & 27.73 & 66.65 & 37.37 & 25.92 & NA & NA & NA \\
\hline 2.66 & 12.34 & 34.91 & 51.94 & 31.22 & NA & NA & NA \\
\hline-14.24 & 23.04 & 40.38 & 42.72 & NA & NA & NA & NA \\
\hline 26.10 & 17.46 & 38.42 & NA & NA & NA & NA & NA \\
\hline 33.79 & 18.78 & NA & NA & NA & NA & NA & NA \\
\hline 3.43 & 24.99 & NA & NA & NA & NA & NA & NA \\
\hline 17.39 & 18.37 & NA & NA & NA & NA & NA & NA \\
\hline 14.60 & 26.50 & NA & NA & NA & NA & NA & NA \\
\hline 8.15 & 18.68 & NA & NA & NA & NA & NA & NA \\
\hline 17.21 & 32.11 & NA & NA & NA & NA & NA & NA \\
\hline 41.92 & 8.75 & NA & NA & NA & NA & NA & NA \\
\hline 9.63 & 11.39 & NA & NA & NA & NA & NA & NA \\
\hline 5.82 & 14.08 & NA & NA & NA & NA & NA & NA \\
\hline 9.56 & 20.61 & NA & NA & NA & NA & NA & NA \\
\hline 11.66 & 16.77 & NA & NA & NA & NA & NA & NA \\
\hline 34.29 & 20.20 & NA & NA & NA & NA & NA & NA \\
\hline-3.88 & 19.15 & NA & NA & NA & NA & NA & NA \\
\hline 6.93 & 15.10 & NA & NA & NA & NA & NA & NA \\
\hline 3.40 & 23.38 & NA & NA & NA & NA & NA & NA \\
\hline 15.79 & 2.99 & NA & NA & NA & NA & NA & NA \\
\hline 13.93 & 55.01 & NA & NA & NA & NA & NA & NA \\
\hline 17.39 & 14.07 & NA & NA & NA & NA & NA & NA \\
\hline 17.21 & 21.52 & NA & NA & NA & NA & NA & NA \\
\hline 9.63 & 32.29 & NA & NA & NA & NA & NA & NA \\
\hline
\end{tabular}




\begin{tabular}{|c|c|c|c|c|c|c|c|}
5.82 & 30.80 & NA & NA & NA & NA & NA & NA \\
\hline 11.66 & 44.12 & NA & NA & NA & NA & NA & NA \\
\hline 34.29 & 32.90 & NA & NA & NA & NA & NA & NA \\
\hline 6.93 & 17.81 & NA & NA & NA & NA & NA & NA \\
\hline 3.40 & 19.41 & NA & NA & NA & NA & NA & NA \\
\hline 15.79 & 27.87 & NA & NA & NA & NA & NA & NA \\
\hline 16.75 & 8.01 & NA & NA & NA & NA & NA & NA \\
\hline 16.82 & 4.12 & NA & NA & NA & NA & NA & NA \\
\hline 2.36 & 16.59 & NA & NA & NA & NA & NA & NA \\
\hline 7.05 & 15.57 & NA & NA & NA & NA & NA & NA \\
\hline 18.49 & NA & NA & NA & NA & NA & NA & NA \\
\hline 33.55 & NA & NA & NA & NA & NA & NA & NA \\
\hline 13.24 & NA & NA & NA & NA & NA & NA & NA \\
\hline 4.87 & NA & NA & NA & NA & NA & NA & NA \\
\hline
\end{tabular}

\begin{tabular}{|c|c|c|c|}
\hline $\mathbf{2 0} \%$ SV+ETSW & $\mathbf{2 0} \% \mathbf{S V + E T S W}(+\mathbf{K})$ & $\mathbf{4 0 \% S V + E T S W}$ & $\mathbf{2 0} \mathbf{\text { ST+ETSW }}$ \\
\hline 35.39 & 4.80 & 21.65 & 49.21 \\
\hline 35.37 & 14.81 & 27.02 & 43.22 \\
\hline 27.90 & 12.10 & 0.48 & 37.33 \\
\hline 25.48 & 19.36 & 29.57 & 42.33 \\
\hline 33.43 & 26.21 & 29.57 & 47.38 \\
\hline 34.80 & 24.11 & 15.00 & 43.41 \\
\hline 32.97 & 25.19 & 25.32 & 43.77 \\
\hline 35.36 & 27.96 & 16.25 & 45.56 \\
\hline 30.90 & 26.03 & 8.14 & 41.25 \\
\hline 40.93 & 6.49 & 26.53 & 30.90 \\
\hline
\end{tabular}




\begin{tabular}{|c|c|c|c|}
\hline 17.59 & 22.19 & 38.60 & 47.85 \\
\hline 22.13 & 21.94 & 3.14 & 31.38 \\
\hline 24.20 & 20.58 & 19.22 & 32.28 \\
\hline 39.64 & 16.83 & 19.76 & 26.26 \\
\hline 39.61 & 19.62 & 22.93 & 25.85 \\
\hline 40.51 & 20.22 & 0.21 & 45.02 \\
\hline 37.11 & 25.42 & 29.62 & 24.13 \\
\hline 34.06 & 21.26 & 31.20 & 25.54 \\
\hline 24.18 & 8.93 & NA & 24.94 \\
\hline 30.28 & 12.27 & NA & 27.69 \\
\hline 36.31 & 1.71 & NA & 27.09 \\
\hline 41.32 & 17.69 & NA & 32.63 \\
\hline 22.08 & 23.95 & NA & 33.58 \\
\hline NA & 20.09 & NA & NA \\
\hline NA & 11.94 & NA & NA \\
\hline NA & 22.92 & NA & NA \\
\hline NA & 21.78 & NA & NA \\
\hline NA & 24.56 & NA \\
\hline & & & \\
\hline & & & \\
\hline
\end{tabular}


APPENDIX G- DO DATA

\begin{tabular}{|c|c|c|}
\hline Influent & Effluent & Change \\
\hline 10.93 & 1.7 & 9.23 \\
\hline 10.42 & 4.67 & 5.75 \\
\hline 10.62 & 3.71 & 6.91 \\
\hline 12.27 & 4.67 & 7.60 \\
\hline 11.35 & 4.38 & 6.97 \\
\hline 11.72 & 3.53 & 8.19 \\
\hline 12.70 & 4.79 & 7.91 \\
\hline 12.05 & 4.30 & 7.75 \\
\hline 11.63 & 3.16 & 8.47 \\
\hline 12.99 & 1.94 & 11.05 \\
\hline 12.17 & 1.97 & 10.20 \\
\hline 14.50 & 2.12 & 12.38 \\
\hline 12.08 & 3.76 & 8.32 \\
\hline 11.12 & 1.97 & 9.15 \\
\hline 10.46 & 1.27 & 9.19 \\
\hline 12.01 & 5.31 & 6.70 \\
\hline 11.92 & 4.21 & 7.71 \\
\hline 11.67 & 3.01 & 8.66 \\
\hline 10.87 & 3.32 & 7.55 \\
\hline 10.32 & 4.01 & 6.31 \\
\hline 11.07 & 5.03 & 6.04 \\
\hline 11.10 & 7.14 & 3.96 \\
\hline 12.07 & 7.90 & 4.17 \\
\hline
\end{tabular}




\begin{tabular}{|c|c|c|}
\hline 10.45 & 8.75 & 1.70 \\
\hline 8.94 & 6.32 & 2.62 \\
\hline 10.01 & 5.64 & 4.37 \\
\hline 9.33 & 2.89 & 6.44 \\
\hline 9.83 & 4.26 & 5.57 \\
\hline 9.66 & 5.68 & 3.98 \\
\hline 9.70 & 6.23 & 3.47 \\
\hline 9.82 & 4.81 & 5.01 \\
\hline 9.66 & 4.64 & 5.02 \\
\hline 9.76 & 5.35 & 4.41 \\
\hline 8.81 & 4.19 & 4.62 \\
\hline 7.19 & 4.38 & 2.81 \\
\hline 6.74 & 3.39 & 3.35 \\
\hline 8.49 & 3.40 & 5.09 \\
\hline 8.62 & 2.88 & 5.74 \\
\hline 8.39 & 4.23 & 4.16 \\
\hline 8.21 & 2.28 & 5.93 \\
\hline 8.31 & 2.88 & 5.43 \\
\hline 8.21 & 3.97 & 4.24 \\
\hline 8.14 & 3.18 & 4.96 \\
\hline 8.02 & 4.62 & 3.40 \\
\hline 8.17 & 3.54 & 4.63 \\
\hline 8.42 & 3.94 & 4.48 \\
\hline 7.34 & 0.27 & 7.07 \\
\hline 7.67 & 2.22 & 5.45 \\
\hline 7.23 & 0.57 & 6.66 \\
\hline
\end{tabular}




\begin{tabular}{|c|c|c|}
\hline 7.54 & 0.35 & 7.19 \\
\hline 7.05 & 0.12 & 6.93 \\
\hline 7.20 & 0.31 & 6.89 \\
\hline 7.66 & 0.90 & 6.76 \\
\hline 6.69 & 0.12 & 6.57 \\
\hline 7.17 & 0.58 & 6.59 \\
\hline 6.91 & 0.13 & 6.78 \\
\hline 7.67 & 0.07 & 7.60 \\
\hline 7.44 & 0.14 & 7.30 \\
\hline 7.53 & 0.12 & 7.41 \\
\hline 7.21 & 0.07 & 7.14 \\
\hline 7.73 & 3.08 & 4.65 \\
\hline 7.73 & 0.22 & 7.51 \\
\hline 10.49 & 6.35 & 4.14 \\
\hline 11.49 & 7.55 & 3.94 \\
\hline 12.50 & 8.56 & 3.94 \\
\hline 11.07 & 8.39 & 2.68 \\
\hline- & 8.42 & - \\
\hline 11.92 & 8.89 & 3.03 \\
\hline 11.76 & 9.37 & 2.39 \\
\hline 10.91 & 8.27 & 2.64 \\
\hline 11.87 & 8.35 & 3.52 \\
\hline 11.03 & 8.15 & 2.88 \\
\hline 12.30 & 9.71 & 2.59 \\
\hline 13.01 & 7.12 & 5.89 \\
\hline 11.93 & 7.21 & 4.72 \\
\hline
\end{tabular}




\begin{tabular}{|c|c|c|}
\hline 12.72 & 7.07 & 5.65 \\
\hline 11.95 & 7.63 & 4.32 \\
\hline 7.81 & 6.80 & 1.01 \\
\hline 9.14 & 6.09 & 3.05 \\
\hline 9.21 & 7.32 & 1.89 \\
\hline 9.02 & 6.75 & 2.27 \\
\hline 8.92 & 6.72 & 2.20 \\
\hline 10.21 & 5.88 & 4.33 \\
\hline 8.19 & 7.52 & 0.67 \\
\hline 8.72 & 7.25 & 1.48 \\
\hline 7.84 & 7.40 & 0.44 \\
\hline 6.82 & 6.29 & 0.53 \\
\hline 7.37 & 5.86 & 1.51 \\
\hline 5.93 & 5.84 & 0.09 \\
\hline 7.23 & 5.78 & 1.46 \\
\hline 6.63 & 5.79 & 0.84 \\
\hline 6.20 & 5.28 & 0.91 \\
\hline 6.20 & 5.51 & 0.68 \\
\hline 6.14 & 5.18 & 0.97 \\
\hline 6.61 & 5.36 & 1.25 \\
\hline 6.62 & 5.47 & 1.15 \\
\hline 6.70 & 5.71 & 0.98 \\
\hline 7.14 & 5.38 & 1.76 \\
\hline 7.02 & 4.26 & 2.76 \\
\hline 7.09 & 5.32 & 1.77 \\
\hline 7.09 & 3.86 & 3.23 \\
\hline
\end{tabular}




\begin{tabular}{|c|c|c|}
\hline 5.29 & 4.19 & 1.10 \\
\hline 5.68 & 3.76 & 1.92 \\
\hline 7.09 & 3.40 & 3.69 \\
\hline 10.22 & 6.00 & 4.22 \\
\hline 7.54 & 5.19 & 2.35 \\
\hline 7.58 & 5.70 & 1.88 \\
\hline 9.57 & 6.03 & 3.54 \\
\hline 8.55 & 6.39 & 2.16 \\
\hline 7.79 & 6.12 & 1.66 \\
\hline 8.61 & 6.21 & 2.40 \\
\hline 8.39 & 6.25 & 2.14 \\
\hline 10.14 & 7.80 & 2.34 \\
\hline 10.39 & 6.39 & 4.00 \\
\hline 12.34 & 9.16 & 3.18 \\
\hline 12.27 & 7.75 & 4.52 \\
\hline 12.24 & 9.57 & 2.67 \\
\hline 11.95 & 8.86 & 3.09 \\
\hline 12.09 & 7.98 & 4.12 \\
\hline 12.22 & 9.12 & 3.10 \\
\hline
\end{tabular}




\section{APPENDIX H- PHOSPHOLIPIDS AND ATP DATA}

\begin{tabular}{|c|c|}
\hline $\begin{array}{c}\text { Phospholipids Concentration Before } \\
\text { Backwash (nmol P/g media) }\end{array}$ & $\begin{array}{c}\text { Phospholipids Concentration After } \\
\text { Backwash (nmol P/g media) }\end{array}$ \\
\hline 12.28 & 35.95 \\
\hline 167.46 & 113.07 \\
\hline 36.45 & 144.66 \\
\hline 91.24 & 140.13 \\
\hline 23.14 & 23.07 \\
\hline 371.49 & 270.58 \\
\hline 157.67 & 249.52 \\
\hline 131.14 & 142.86 \\
\hline 43.22 & 90.34 \\
\hline 17.21 & 69.150 \\
\hline 22.33 & 14.77 \\
\hline 20.27 & 9.380 \\
\hline 20.27 & 9.376 \\
\hline 35.57 & 24.105 \\
\hline 8.89 & 28.660 \\
\hline 6.56 & 8.38 \\
\hline 92.61 & 77.78 \\
\hline 30.45 & 33.97 \\
\hline 167.18 & 53.25 \\
\hline 364.99 & 44.26 \\
\hline 490.40 & 219.10 \\
\hline 230.34 & 239.39 \\
\hline
\end{tabular}




\begin{tabular}{|c|c|}
\hline 149.68 & 330.78 \\
\hline 45.89 & 115.09 \\
\hline 259.90 & 16.62 \\
\hline 40.42 & 223.89 \\
\hline 10.98 & 16.02 \\
\hline 34.76 & 58.77 \\
\hline NA & 16.32 \\
\hline
\end{tabular}

\begin{tabular}{|c|c|}
\hline $\begin{array}{c}\text { Top of Media ATP Before Backwash } \\
\text { (ng ATP/g media) }\end{array}$ & $\begin{array}{c}\text { Top of Media ATP After Backwash } \\
\text { (ng ATP/g media) }\end{array}$ \\
\hline 7776.64 & 859.71 \\
\hline 688.23 & 1558.63 \\
\hline 703.93 & 1017.77 \\
\hline 40.34 & 43.94 \\
\hline 52.58 & 28.80 \\
\hline 272.55 & 486.72 \\
\hline 156.89 & 21.83 \\
\hline 374.38 & 311.96 \\
\hline 846.63 & 1497.13 \\
\hline 170.86 & 238.96 \\
\hline 386.93 & 525.09 \\
\hline 375.64 & 446.37 \\
\hline 192.98 & 206.56 \\
\hline 341.72 & 322.83 \\
\hline & \\
\hline & \\
\hline
\end{tabular}




\begin{tabular}{|c|c|}
\hline 474.43 & 213.34 \\
\hline 1492.42 & 640.54 \\
\hline 332.19 & 389.66 \\
\hline 139.17 & 124.57 \\
\hline 633.18 & 75.95 \\
\hline 5041.01 & 756.39 \\
\hline 1018.15 & 2104.29 \\
\hline 430.33 & 261.64 \\
\hline 435.93 & 361.38 \\
\hline 306.12 & 208.90 \\
\hline 11.80 & 15.91 \\
\hline 271.66 & 1485.58 \\
\hline 1148.41 & 691.50 \\
\hline 127.57 & 250.88 \\
\hline 20.66 & 136.66 \\
\hline 835.43 & 528.10 \\
\hline 207.12 & 214.64 \\
\hline 228.70 & 286.43 \\
\hline 1230.60 & 1263.82 \\
\hline 3845.15 & 2400.75 \\
\hline 495.17 & 611.97 \\
\hline 1487.63 & 327.24 \\
\hline 61.56 & 559.86 \\
\hline 7777 & 2401 \\
\hline 12 & 16 \\
\hline
\end{tabular}




\begin{tabular}{|c|c|}
\hline $\begin{array}{c}\text { Middle of Media ATP Before } \\
\text { Backwash } \\
\text { (ng ATP/g media) }\end{array}$ & $\begin{array}{c}\text { Middle of Media ATP After } \\
\text { Backwash } \\
\text { (ng ATP/g media) }\end{array}$ \\
\hline 48.84 & 33.25 \\
\hline 397.46 & 684.03 \\
\hline 477.54 & 572.25 \\
\hline 237.12 & 319.99 \\
\hline 54.63 & 94.62 \\
\hline 312.01 & 211.46 \\
\hline 78.58 & 133.64 \\
\hline 136.90 & 49.37 \\
\hline 253.18 & 536.20 \\
\hline 420.43 & 597.44 \\
\hline 70.31 & 258.62 \\
\hline 60.35 & 50.31 \\
\hline 85.69 & 26.54 \\
\hline 15.82 & 44.97 \\
\hline 567.44 & 1111.63 \\
\hline 757.98 & 956.25 \\
\hline 195.76 & 220.20 \\
\hline 55.35 & 235.91 \\
\hline 216.73 & 1971.74 \\
\hline 21.47 & 71.86 \\
\hline 134.85 & 186.58 \\
\hline 173.18 & 279.73 \\
\hline
\end{tabular}




\begin{tabular}{|c|c|}
\hline 736.08 & 1006.62 \\
\hline 150.48 & 105.66 \\
\hline 47.38 & 105.90 \\
\hline 61.56 & 92.78 \\
\hline 16 & 27 \\
\hline 758 & 1972 \\
\hline
\end{tabular}




\section{APPENDIX I- UV AND TEMPERATURE DATA}

\begin{tabular}{|c|c|c|c|}
\hline Phase2 & Phase3 & Phase 4 & Phase 5 \\
\hline 15.27 & 29.87 & 13.65 & 15.42 \\
\hline-2.82 & 25.23 & 11.24 & 38.09 \\
\hline 25.97 & 22.69 & 13.84 & 17.47 \\
\hline 14.04 & 32.27 & 16.94 & 40.86 \\
\hline 26.59 & 23.32 & 14.19 & 24.32 \\
\hline 30.87 & 18.11 & 13.15 & 24.08 \\
\hline 36.16 & 17.24 & -16.20 & 89.01 \\
\hline 27.98 & 19.11 & 0.38 & 84.83 \\
\hline 13.26 & 20.59 & -6.38 & 87.58 \\
\hline-35.41 & 25.58 & -0.22 & 85.69 \\
\hline-40.16 & -5.74 & 11.28 & 85.67 \\
\hline-24.68 & -7.09 & 1.60 & 82.23 \\
\hline 17.24 & -9.46 & 9.79 & 13.28 \\
\hline 7.88 & 0.70 & 19.65 & 12.83 \\
\hline 20.62 & 3.28 & 6.41 & 38.04 \\
\hline 21.41 & 0.63 & -5.64 & -2.69 \\
\hline 12.18 & -2.90 & -2.62 & 13.69 \\
\hline 8.12 & -4.41 & -3.61 & 29.30 \\
\hline 5.20 & 0.00 & -7.66 & 8.06 \\
\hline-31.76 & 0.64 & -7.67 & 28.77 \\
\hline-21.13 & 1.99 & -285.16 & 7.80 \\
\hline 12.35 & -0.12 & 8.92 & 26.64 \\
\hline 4.47 & -0.58 & 15.62 & -7.43 \\
\hline 20.90 & -2.77 & 13.56 & 13.41 \\
\hline-15.54 & -0.96 & 14.37 & 30.63 \\
\hline 15.25 & 11.88 & 15.77 & 31.61 \\
\hline 4.35 & 16.92 & 15.75 & 17.62 \\
\hline 13.54 & 25.28 & 7.65 & 32.42 \\
\hline 38.05 & 92.70 & -2.42 & 24.79 \\
\hline 43.66 & -83.73 & -0.20 & 37.17 \\
\hline 47.23 & -2.31 & 1.07 & 27.94 \\
\hline 25.85 & -2.90 & -12.47 & 26.19 \\
\hline 26.03 & -4.47 & 12.08 & 27.51 \\
\hline 20.55 & -3.67 & 12.92 & 28.79 \\
\hline 2.49 & 0.64 & 9.55 & 93.08 \\
\hline 24.57 & 29.87 & -5.01 & 93.32 \\
\hline 7.55 & 25.23 & -4.17 & -10.27 \\
\hline
\end{tabular}




\begin{tabular}{|c|c|c|c|}
\hline 4.02 & 22.69 & -0.24 & -16.96 \\
\hline 43.95 & $\begin{array}{l}32.27 \\
\end{array}$ & 14.29 & 7.60 \\
\hline 49.09 & 23.32 & 13.25 & -25.09 \\
\hline 45.89 & 18.11 & -143.32 & -60.04 \\
\hline 2.17 & 17.24 & 12.78 & -54.86 \\
\hline-202.93 & 19.11 & 16.37 & -9.69 \\
\hline 11.32 & 20.59 & 0.01 & 27.04 \\
\hline 16.63 & 25.58 & NA & 3.13 \\
\hline 20.86 & -5.74 & NA & 29.99 \\
\hline-2.10 & -7.09 & NA & 15.38 \\
\hline 13.02 & -9.46 & NA & 7.32 \\
\hline-1.20 & 0.70 & NA & -10.72 \\
\hline 10.90 & 3.28 & NA & -34.33 \\
\hline 18.95 & 0.63 & NA & 9.61 \\
\hline-42.17 & -2.90 & NA & -19.38 \\
\hline 30.44 & -4.41 & NA & -45.87 \\
\hline 32.42 & 0.00 & NA & 1.75 \\
\hline 36.73 & 0.64 & NA & -20.69 \\
\hline 21.08 & NA & NA & -29.16 \\
\hline-25.40 & NA & NA & -4.10 \\
\hline 20.18 & NA & NA & 9.12 \\
\hline 21.64 & NA & NA & -5.54 \\
\hline 36.43 & NA & NA & -26.88 \\
\hline 15.39 & NA & NA & 10.72 \\
\hline 92.35 & NA & NA & -0.87 \\
\hline 28.55 & NA & NA & 32.64 \\
\hline 17.35 & NA & NA & 91.40 \\
\hline 7.03 & NA & NA & 32.26 \\
\hline-1.75 & NA & NA & 30.94 \\
\hline 2.72 & NA & NA & 24.45 \\
\hline 6.02 & NA & NA & 33.76 \\
\hline-1.89 & NA & NA & 23.86 \\
\hline 13.43 & NA & NA & 32.01 \\
\hline 4.45 & NA & NA & 27.82 \\
\hline 31.17 & NA & NA & 22.87 \\
\hline 33.12 & NA & NA & 25.67 \\
\hline 37.39 & NA & NA & 31.10 \\
\hline 10.53 & NA & NA & 31.22 \\
\hline 94.35 & NA & NA & 29.22 \\
\hline 47.37 & NA & NA & 27.99 \\
\hline 45.46 & NA & NA & 36.16 \\
\hline
\end{tabular}




\begin{tabular}{|c|c|c|c|}
\hline 11.31 & NA & NA & 1.40 \\
\hline-21.89 & NA & NA & 36.55 \\
\hline-4.08 & NA & NA & 33.13 \\
\hline 4.91 & NA & NA & 29.19 \\
\hline 12.33 & NA & NA & 24.23 \\
\hline NA & NA & NA & 7.22 \\
\hline NA & NA & NA & 11.29 \\
\hline NA & NA & NA & 48.27 \\
\hline NA & NA & NA & 34.14 \\
\hline NA & NA & NA & 3.26 \\
\hline NA & NA & NA & 35.44 \\
\hline NA & NA & NA & 12.93 \\
\hline NA & NA & NA & -28.25 \\
\hline NA & NA & NA & -27.78 \\
\hline NA & NA & NA & 6.90 \\
\hline NA & NA & NA & 31.94 \\
\hline NA & NA & NA & 13.51 \\
\hline NA & NA & NA & -31.07 \\
\hline NA & NA & NA & -16.74 \\
\hline NA & NA & NA & -32.53 \\
\hline NA & NA & NA & 26.31 \\
\hline NA & NA & NA & 26.17 \\
\hline NA & NA & NA & 27.00 \\
\hline NA & NA & NA & 29.51 \\
\hline NA & NA & NA & 25.68 \\
\hline NA & NA & NA & -36.55 \\
\hline NA & NA & NA & 36.60 \\
\hline NA & NA & NA & 38.99 \\
\hline NA & NA & NA & 23.15 \\
\hline NA & NA & NA & -2.69 \\
\hline NA & NA & NA & -27.80 \\
\hline NA & NA & NA & 3.39 \\
\hline NA & NA & NA & 24.10 \\
\hline NA & NA & NA & 42.51 \\
\hline NA & NA & NA & 31.98 \\
\hline NA & NA & NA & 16.30 \\
\hline NA & NA & NA & -31.71 \\
\hline NA & NA & NA & -10.06 \\
\hline NA & NA & NA & -9.13 \\
\hline NA & NA & NA & 4.60 \\
\hline NA & NA & NA & 1.85 \\
\hline
\end{tabular}




\begin{tabular}{|l|l|l|l|} 
NA & NA & NA & 11.79 \\
\hline NA & NA & NA & 21.25 \\
\hline NA & NA & NA & 33.22 \\
\hline
\end{tabular}

TEMPERATURE DATA $\left({ }^{\circ} \mathrm{C}\right)$

\begin{tabular}{|c|c|c|c|}
\hline $\begin{array}{c}\text { Phase 1 } \\
\text { (August 15, } 2014 \text { to } \\
\text { October 15, 2014, } \\
60 \text { days) }\end{array}$ & $\begin{array}{c}\text { Phase2 } \\
\text { (October 20, } 2014 \text { to } \\
\text { December 20, 2014, } \\
60 \text { days) }\end{array}$ & $\begin{array}{c}\text { Phase } 3 \\
\text { (July } 15,2015 \\
\text { to August } 15, \\
2015,30 \text { days) }\end{array}$ & $\begin{array}{c}\text { Phase } 4 \\
\text { (May 1, } 2015 \text { to } \\
\text { June 30, 2015, } 60 \\
\text { days) }\end{array}$ \\
\hline 20.3 & 20.30 & 20.00 & 19.30 \\
\hline 21.3 & 19.40 & 20.40 & 19.90 \\
\hline 22.5 & 19.30 & 21.00 & 20.50 \\
\hline 21.4 & 19.00 & 21.00 & 20.40 \\
\hline 20.5 & 18.40 & 21.40 & 20.50 \\
\hline 20.7 & 18.70 & 22.50 & 21.00 \\
\hline 21.7 & 18.00 & 22.80 & 21.00 \\
\hline 21.00 & 17.50 & 21.90 & 20.90 \\
\hline 20.1 & 18.30 & 22.00 & NA \\
\hline 21.10 & 17.30 & 22.90 & NA \\
\hline 19.90 & 17.50 & NA & NA \\
\hline 20.40 & 15.60 & NA & NA \\
\hline 20.10 & 16.10 & NA & NA \\
\hline 19.80 & 15.30 & NA & NA \\
\hline 19.90 & 14.90 & NA & NA \\
\hline NA & 14.50 & NA & NA \\
\hline NA & 14.30 & NA & NA \\
\hline NA & 13.70 & NA & NA \\
\hline NA & 13.40 & NA & NA \\
\hline NA & 13.10 & NA & NA \\
\hline NA & 12.90 & NA & NA \\
\hline
\end{tabular}

